\title{
Tides and their seminal impact on the geology, geography, history, and socio-economics of the Bay of Fundy, eastern Canada
}

\author{
Con Desplanque ${ }^{1}$ and David J. Mossman ${ }^{2^{*}}$ \\ 1. 27 Harding Avenue, Amherst, NS B4H 2A8 \\ 2. Department of Geography, Mount Allison University, 144 Main St., Sackville, NB E4L 1A7 \\ * Corresponding author \\ Date received:April 16, 2003 g Date accepted:June 6, 2004 \\ "Into this Universe, and why not knowing, \\ Nor whence, like water willy-nilly flowing; \\ And out of it, as wind along the Waste; \\ I know not whither, willy nilly blowing." \\ RubÁIYÁT OF OMAR KHAYYÁM \\ Quatrain XXIX
}

Dedicated to two dear, patient and lovable ladies, Elly and Marie 
Preface 3

Abstract/Résumé 5

1. Wave And Tide Fundamentals 7

1.1. Prologue 7

1.2. Waves and water particles 7

1.2.1. Water waves: vibrations subject to gravity 7

1.2.2. Wave forms and wave types 8

1.3. Tides and tide generation 11

1.3.1. Introduction 11

1.3.2. Tide prediction 11

1.3.3. The tide-producing forces 13

1.3.4. Variations in strength of the tides 15

1.3.4.1. Gravitational influences and accelerations 15

1.3.4.2. The distance factor 15

1.3.4.3. Springs and neaps 15

1.3.4.4. Diurnal inequality 15

1.4. The Coriolis effect 18

1.4.1. Overview 18

1.4.2. Fundamental relationships 81

1.4.3. Applications to tides and water currents 19

2. Regional tides 22

2.1. Terms of reference 22

2.2. Overview of regional tides along the eastern Canadian seaboard 22

2.3. Graphical synthesis of regional tides 23

2.4. Additional considerations 26

2.5. A succession of standing and progressive waves 27

3. Tides of the North Atlantic 28

3.1. Water particle movements 28

3.2. Tidal constituents and harmonic analysis 29

3.3. Equinoctial tides: east vs west 32

\section{Tides of the Gulf of Maine 36}

4.1. A degenerate amphidromic system 36

4.2. Sills, banks, and channels 36

4.3. Tides pre and post-Pleistocene 37

5. Tides of the Bay of Fundy 41

5.1. Introduction 41

5.2. Geologic origin of the Bay and its tides 41

5.3. Characteristics of Bay of Fundy Tides 42

5.3.1. Resonance and range of modern Fundy tides 42

5.3.2. Exponential increase in tidal range and amplitude 42

5.3.3. Significance of diurnal inequalities in the Bay 45

5.3.4. Tidal cycling at Herring Cove (Fundy National Park) 47

5.4. Impacts of Fundy tides 49

5.4.1. Erosion 49

5.4.2. Sedimentation and related processes 52

6. Tidal bores in Estuaries 57

6.1. Tidal volume, tidal prisms 57

6.2. Waves of translation - tidal bores 57

6.3. Limiting condition for bore development 58

6.4. Tidal bores in the Bay of Fundy 60

6.5. Quiantang River bore, China 61
7. Ebb and flow in estuaries 63

7.1. Introduction 63

7.2. Reshaping the tidal wave through time 63

7.2.1. The Shubenacadie River estuary 63

7.2.2. The Cornwallis River estuary 64

7.3. The Reversing Falls - a unique estuarine feature 66

7.4. Tidal power 69

7.5. Prospects for Fundy tidal power 71

8. Ice phenomena in a Bay of Fundy estuary 74

8.1. Winter conditions: a short case history 74

8.2. The phenomenon of ice walls 76

8.3. Astronomical cycles and ice build-up 77

8.4. Hazards versus benefits of ice walls 78

8.5. Ice-related problems in Bay of Fundy estuaries 80

9. Sea-level changes and tidal marshes 82

9.1. Postglacial sea-level rise 82

9.2. Memories of the marshes 84

9.3. Coastal erosion 85

9.4. Coastal defence 86

9.5. Overview of marsh types 86

9.6. Tidal flooding and marsh growth 88

9.7. Historical development of the tidal marshes 91

9.8. Rehabilitation and reclamation 94

10. Storm tides in the Bay of Fundy 97

10.1. Introduction 97

10.2. Atmospheric pressure changes and wind set-up 97

10.3. The Saxby Tide, 1869: a prediction fulfilled 99

10.4. Height of the Saxby Tide 100

10.5. The storm tide of 1759100

10.6. The Groundhog Day storm, 1976101

11. Periodicity of the tides 103

11.1. Introduction: The Saros cycle 103

11.2. Astronomy and the variations of tides 103

11.3. The largest astronomical tides 104

11.4. Coincidence of storm tides with Saros 106

11.5. Probability of a repeat of the Saxby Tide 108

12. Tidal boundary problems in the coastal zone 110

12.1. Introduction: caveat emptor! 110

12.2. Measurement of tidal levels 110

12.3. Tide prediction: mean sea level and mean high water 111

12.4. The water's edge: confusion in legislature and literature 111

12.5. De jure maris 114

12.6. Boundary issues 114

12.7. Determination of MHW, Bay of Fundy 115

12.8. The bottom line 115

13. Conclusions 118

Acknowledgments 119

References 120

Appendix: Glossary of Terms 127 


\title{
Preface
}

\author{
BY Gordon FAdER
}

From the earliest European exploration of the New World in the $17^{\text {th }}$ Century, mariners have been acutely aware of the extreme high tides and associated strong currents of the Bay of Fundy. Indeed the region is known internationally for tides that can reach $15 \mathrm{~m}$ or more in height and expose vast expanses of seabed during low water. Local tourism actually invites potential visitors to come and walk on the ocean floor. For those who go down to the shoreline, knowledge of the rising tides is an essential survival tool, as in places these tides can literally outrun those who venture too far offshore.

Recent interest and debate in both the Canadian and global press has focused on whether the tides of Fundy are indeed the highest in the world as claimed by many in Atlantic Canada. The title is also claimed by communities in Ungava Bay, northern Quebec. However, recent research by the Canadian Hydrographic Service indicates that the Fundy tides likely outrange those of Ungava Bay by just a few centimetres. But to be fair, the margin of error is greater than the difference, and appropriate data for a meaningful comparison do not exist. Of course, the ultimate question is: why does the Bay of Fundy have such high tides? Surely it can't be just the narrowing shape and shoaling of the bay. And how long have these tides existed: are they a relatively new phenomenon of postglacial emergence? And perhaps more importantly, will the tides change in the future with rising water levels? The development of coastal areas through continued urban sprawl and the maintenance of large areas of dykeland depend on such an understanding.

But there is more to the tides than just an elevational shift of water. These tides drive much of the richness of the Fundy and Gulf of Maine ecosystem through movement of over 100 cubic kilometres of water into the Bay each tidal cycle. Such a massive exchange thoroughly mixes the waters and greatly increases productivity, a process that extends well out into the Gulf of Maine. These nutrient-enhanced fast-moving waters nourish rich fisheries in the Bay and Gulf, particularly with regard to sea scallops, and provide for a substantial sustainable economic return for the region. Recent seabed mapping has discovered large areas of the floor of Fundy covered in unique linear mussel bioherms never before seen on the adjacent Scotian Shelf. Even migrating shorebirds, such as the semipalmated sandpiper, depend on Fundy tides and associated vast mudflats for the provision of essential food to support their long migration from the Canadian North to South America. On the other hand, the Fundy tides result in a cooler climate for the region. For those who live in Nova Scotia's Annapolis Valley, a trip to the Fundy shoreline is a welcomed relief from oppressive summer heat. In contrast, in winter strong westerly winds that blow across the Bay often pick up moisture and produce large local snowfalls ("Fundy flurries") in the Annapolis Valley.

The fast moving waters clocked at over $16 \mathrm{~km}$ per hour at Cape Split in the inner Bay of Fundy have also produced dramatic effects on the seabed. Extensive desert-like sand dunes cover many areas, and in Chignecto Bay and Minas Channel constricted areas are scoured down to bedrock in depressions as deep as $60 \mathrm{~m}$. I have always said that if you want to experience the wrath of God, take a hike to Cape Split, a new provincial park at the eastern end of North Mountain, Nova Scotia, and stand at the edge of the $100 \mathrm{~m}$ cliff at the time of maximum tidal flood. There you will observe impressive roiling and boiling of the sea, with the generation of large vortices, as the ocean becomes river-like in its inward surge.

Having led many scientific expeditions to study the marine geology of the Bay of Fundy, I am always amazed by the unique and rapidly changing environmental conditions there, and their imprint on the seabed. Once, while we were attempting to run a seismic traverse through Minas Channel at slack water, the CCGS Hudson, although traveling at 5 knots, was actually moving backwards. With expensive gear towed behind the vessel I was very worried and not sure what to do in this circumstance so forged ahead at gear-shattering high speed. As we began to escape the clutches of the high current of the channel just off Cape Split, a large oceanographic gyre located in Scots Bay literally shoved the entire ship to the north in an instant. To top it all off a violent thunderstorm raged while all this was going on.

This synthesis report presents a comprehensive anatomy of the Bay of Fundy and its world-class tides. The work is the result of a long collaboration between Con Desplanque and David Mossman. From the beginnings of postglacial high tide development, perhaps 8000 years ago, the authors describe in detail the many physical factors that play a role in the formation and characteristics of the tides, including the dominant near-resonance length of the Bay of Fundy. The influence of geography, morphology, and gravitational forces of the Sun and Moon, as well as a summary of the geological origin of the Bay and a history of its tides, are all expertly presented. Unique characteristics arising from the high tides, such as tidal bores and reversing falls, are part of the synthesis, as are the age-old dream of electricity generation from Fundy tidal power and the unique conditions of severe winter ice. The ever-present hazard potential from combined high tides and storm surges is evaluated with evidence from the great Saxby tide of 1869 and the Groundhog Day storm of 1976. 
This publication is a must for oceanographers and oceanographic students who want to understand how geography, geology, and oceanography can combine in unique ways to produce such high tides and energy rich events. Those interested in the history and environment of the region will find the paper of particular interest as the tides play a critical role in defining the characteristics of the coastal zone. Engineers who must develop structures in such a coastal zone will see how humankind has attempted to mitigate the effects of such a dynamic system and what some of the predicted and unpredicted results can be. The tides of Fundy truly play a dominant role in the physical, chemical, and biological processes of the region.

The production of synthesis reports like this is becoming more of a rare event, as the modern applied science approach limits opportunities for such a thorough and integrated study. This publication will indeed serve as a definitive benchmark study of the region with the "World's Highest Tides". 


\section{Abstract}

Tides are an ever-present reality in many coastal regions of the world, and their causes and influence have long been matters of intrigue. In few places do tides play a greater role in the economics and character of a region and its people than around the shores of the Bay of Fundy in eastern Canada. Indeed, the Bay of Fundy presents a wonderful natural laboratory for the study of tides and their effects. However, to understand these phenomena more fully, some large perspectives are called for on the general physics of the tides and their operation on an oceanic scale. The geologic history of the region too provides key insights into how and why the most dramatic tides in the world have come to be in the Bay of Fundy.

Tidal characteristics along the eastern Canadian seaboard result from a combination of diurnal (daily) and semidiurnal (twice daily) tides, the latter mostly dominant. Tidal ranges in the upper Bay of Fundy commonly exceed $15 \mathrm{~m}$, in large part a consequence of tectonic forces that initiated the Bay during the Triassic. The existence and position of the Bay is principally determined by a half-graben, the Fundy Basin, which was established at the onset of the opening of the Atlantic Ocean. Due to the proportions of the Bay of Fundy, differences in tidal range through the Gulf of Maine-Bay of Fundy-Georges Bank system are governed by near resonance with the forcing North Atlantic tides. Although Fundy tide curves are sinusoidal, tide prediction calls for consideration of distinct diurnal inequalities. Overlapping of the cycles of spring and perigean tides every 206 days results in an annual progression of 1.5 months in the periods of especially high tides. Depending on the year, these strong tides can occur at all seasons. The strongest Fundy tides occur when the three elements - anomalistic, synodical, and tropical monthly cycles - peak simultaneously. The closest match occurs at intervals of 18.03 years, a cycle known as the Saros. Tidal movements at Herring Cove, in Fundy National Park, illustrate the annual expected tidal variations.

Vigorous quasi-equilibrium conditions characterize interactions between land and sea in macrotidal regions like the Bay of Fundy. Ephemeral on the scale of geologic time, estuaries progressively infill with sediments as relative sea level rises, forcing fringing salt marshes to grow to successively higher levels. Although closely linked to a regime of tides with large amplitude and strong tidal currents, Fundy salt marshes rarely experience overflow. Established about $1.2 \mathrm{~m}$ lower than the highest astronomical tide, only very large tides are able to cover the marshes with a significant depth of water. Peak tides arrive in sets at periods of 7 months, 4.53 years, and 18.03 years. For months on end no tidal flooding of the high marshes occurs. Most salt marshes are raised to the level of the average tide of the 18-year cycle. The exact locations of coastal zone water levels such as mean high water and mean low water is a recurring problem and the subject of much litigation.

Marigrams constructed for selected river estuaries illustrate how the estuarine tidal wave is reshaped over its course, to form bores, and varies in its sediment-carrying and erosional capacity as a result of changing water surface gradients. Changing seasons bring about dramatic changes in the character of the estuaries, especially so as ice conditions develop during the second half of the 206-day cycle when the difference in height between Neap tide and Spring tide is increasing, the optimal time for overflow in any season. Maximum ice hazard, including build-up of "ice walls" in Fundy estuaries, occurs one or two months before perigean and spring tides combine to form the largest tide of the cycle. Although "ice walls" and associated phenomena pose hazards for man-made constructions, important natural purposes are served which need to be considered in coastal development and management schemes. Tides play a major role in erosion and in complex interactions among Fundy physical, biological, and chemical processes. Recent observations on mud flat grain size alterations, over deepening areas of the sea bed, and changes in the benthic community indicate changing environmental conditions in the Bay, caused possibly by increased hydrodynamic energy in the system. 


\section{Résumé}

Les marées constituent une réalité omniprésente dans de nombreuses régions côtières du monde, et leurs causes et leur influence intriguent depuis longtemps. Il existe peu d'endroits où les marées jouent un rôle plus marquant au sein de l'économie et du caractère d'une région et de ses habitats que dans le secteur du rivage de la baie de Fundy, dans l'Est du Canada. La baie de Fundy représente effectivement un merveilleux laboratoire naturel pour l'étude des marées et de leurs effets. Il faut toutefois, pour mieux comprendre ces phénomènes, des perspectives élargies des caractéristiques physiques générales des marées et de leur fonctionnement à l'échelle océanique. Le passé géologique de la région fournit lui aussi des indices précieux sur la façon dont les marées les plus spectaculaires du globe sont apparues dans la baie de Fundy et sur les raisons de leur présence.

Les caractéristiques des marées le long du littoral de l'Est du Canada découlent d'une combinaison de marées diurnes (quotidiennes) et semi-diurnes (biquotidiennes), parmi laquelle ces dernières prédominent principalement. Les amplitudes des marées dans la partie supérieure de la baie de Fundy dépassent communément 15 mètres, en grande partie en raison des forces tectoniques qui ont sculpté la baie au cours du Trias. L'existence et l'emplacement de la baie sont principalement déterminés par un semi-graben, le bassin de Fundy, dont l'établissement remonte au début de l'ouverture de l'océan Atlantique. Vu les proportions de la baie de Fundy, les différences d'amplitude des marées à l'intérieur du système du golfe du Maine, de la baie de Fundy et du Banc Georges sont régies par une quasi-résonance avec les marées de contrainte de l'Atlantique Nord. Même si les courbes des marées de Fundy sont sinusoïdales, les prévisions des marées nécessitent la considération d'inégalités diurnes distinctes. Le chevauchement des cycles des marées de vives-eaux et des marées de périgée tous les 206 jours entraîne une progression annuelle de 1,5 mois des périodes de marées particulièrement élevées. Selon l'année, ces marées de grande envergure peuvent survenir toutes les saisons. Les marées les plus fortes de Fundy apparaissent lorsque les trois éléments - les cycles mensuels anomalistique, synodique et tropique - culminent simultanément. Le jumelage le plus proche survient à des intervalles de 18,3 ans en vertu d'un cycle appelé le cycle Saros. Les mouvements des marées de l'anse Herring dans le parc national Fundy illustrent les variations annuelles des marées anticipées.

Les interactions entre la terre et la mer dans les régions macrotidales comme la baie de Fundy sont caractérisées par des conditions de quasi-équilibre intenses. Des estuaires, éphémères à l'échelle des temps géologiques, se remplissent progressivement de sédiments au fur et à mesure que s'élève le niveau relatif de la mer, ce qui force les marais salés en bordure à passer à des niveaux successivement supérieurs. Même si les marais salés de Fundy sont étroitement liés à un régime de marées de grande amplitude et de courants périodiques puissants, ils débordent rarement. Comme ces marais sont établis à environ 1,2 mètre de moins que les marées astronomiques les plus élevées, seules les très grandes marées peuvent les recouvrir d'une couche d'eau d'une profondeur substantielle. Les marées les plus importantes se présentent en série à des périodes de sept mois, 4,53 ans et 18,03 ans. Aucune inondation des marais élevés due aux marées ne survient pendant des mois et des mois. La majorité des marais salés s'élèvent au niveau moyen du cycle de 18 ans. Les emplacements exacts des niveaux d'eau des zones côtières, comme le niveau moyen des hautes-eaux et le niveau moyen des basses-eaux, ne cessent de poser des problèmes et font l'objet de beaucoup de litiges.

Les courbes de marées établies dans le cas de certains estuaires de rivières illustrent de quelle façon les vagues des marées estuariennes se transforment le long de leur trajet pour former des mascarets et dans quelle mesure varient leur capacité de transport de sédiments et capacité d'érosion par suite des variations des pentes de la ligne d'eau. Les saisons qui se succèdent entraînent des changements spectaculaires du caractère des estuaires, en particulier lorsque des glaces apparaissent au cours de la seconde moitié du cycle de 206 jours, quand la différence de hauteur entre la marée de mortes-eaux et la marée de vives-eaux s'accroît, moment optimal de débordement au cours de n'importe quelle saison. Le danger maximal de glaces, notamment l'apparition de «murs de glace» dans les estuaires de Fundy, survient un ou deux mois avant que les marées de périgée et de vives-eaux se combinent pour former la marée la plus importante du cycle. Même si les «murs de glace » et les phénomènes connexes posent des dangers aux constructions érigées, ils servent des fins naturelles importantes qu'il faut considérer dans les programmes d'aménagement et de mise en valeur des côtes. Les marées jouent un rôle marquant dans l'érosion et dans les interactions complexes au sein des processus physiques, biologiques et chimiques de Fundy. Les observations récentes des modifications des grosseurs des grains des vasières, les secteurs d'approfondissement marqué du plancher océanique et les changements survenus dans la communauté benthique révèlent que les conditions du milieu de la baie changent, possiblement en raison de l'énergie hydrodynamique accrue à l'intérieur du système.

[Traduit par la rédaction] 


\section{Wave and Tide Fundamentals}

\subsection{PROLOGUE}

Oceans cover nearly three quarters of planet Earth. Our lives are intimately linked to them and to their tides in diverse ways, most of which we poorly appreciate. Subject to fanciful theories and speculations for thousands of years, tides have long piqued our curiosity. Sir Isaac Newton (1642-1727) first identified gravitational forces as the prime movers in tide generation. He laid the basis of tidal theory, conceiving an "equilibrium tide" that would apply to ideal conditions of a global ocean. Pierre Simon de Laplace (1749-1827) shares honours with Newton because he formulated equations of motion for tides on a rotating Earth, and was first to distinguish tidal phenomena according to different types (species) of tides. Laplace perceived the harmonic method of analyzing tides, later elaborated by Lord Kelvin (1824-1907), inventor of the earliest tide-predicting machine in 1872.

Yet despite the ease with which tide tables are now constructed, no one to this day really comprehends how gravitational forces work. Neither has anyone been able to conceive a purely dynamic theory to directly relate tide-generating forces to actual tides (Clancy 1969; LeBlond and Mysak 1978). Laplace recognized that there could be no perfect theory, the chief difficulty being Earth's rotation. He preferred to write in terms of tidal waves, with the same periods as those induced by rhythmical components of gravitational forces. The problem of tides is that of a fluid motion modified by the geometry (including depth) of ocean basins, by friction, and by such forces as the Coriolis effect due to Earth's rotation.

The ebb and flow of tides provide fascinating measures of an ocean's pulse (Defant 1958). Nowhere does this beat more impressively than in the Bay of Fundy on the western shore of the North Atlantic Ocean. Here the tide attains world record levels, with tidal range approaching $16 \mathrm{~m}$ at times of particular astronomical conditions. Storm surges, tidal bores that gain height in an estuary, and great waves that batter the shore: all stir the blood and instil respect for the raw power of nature.

Other processes related to tides, among them currents, shifting sediments, erosion, development of tidal estuaries, and salt marsh growth and decay, work more subtly, creating changes over decades, centuries and millennia, rather than in a matter of hours or days. These processes, in turn, evolve in response to postglacial sea-level recovery. The unmistakable hand of Homo sapiens too, is now everywhere evident along the shore, for it is in the world's coastal zones that humankind has by choice become most concentrated.

The main purpose of this review is to provide a general survey of tides and an overview of their relationship to, and effect on, the Bay of Fundy (henceforth sometimes referred to as "the Bay"), home to the world's highest tides. Worldwide there is now an increased focus on understanding tidal processes and documenting changes on short-, medium-, and long-term time scales by various historical and scientific means. The Bay of Fundy and its tidal processes form a dynamic entity, and serve as a model for comparison with similar tidal regimes elsewhere.

\subsection{WAVES AND WATER PARTICLES}

\subsubsection{Water waves: vibrations subject to gravity}

Long before Aristotle (384-322 B.C.E.) wrote about the relationship between wind and waves, mankind had been engaged in the study of waves. Yet despite the writings of Aristotle, Newton, Kelvin, Stokes, Helmholtz, and others, details of the physics of wave oscillations are still being worked out. Here we no more than touch on this vast subject. Splendid comprehensive elementary treatment of waves - tidal and otherwise - is provided by Pethick (1984), Pugh (1987) and Sverdrup et al. (2003).

Waves in general play an important role in meteorological and oceanographic processes such as mixing in the upper ocean layer and production of oscillatory currents, as well as a number of processes involving air-water interactions. Ocean waters do not conform precisely to the dynamics of idealized fluids upon which mathematical models of wave behaviour are based. Even so, a water wave is essentially a vibration subject to gravity. With this in mind we briefly examine the birth of waves in water and the characteristic oscillatory behaviour required to produce ordinary tide waves (or "tidal waves", not to be confused with the improper popular synonym for tsunami).

In any material at rest, except of course for vibrations on an atomic scale, none of the particles of the material are moving in relation to each other. However when an external force moves some of the particles out of their rest positions without breaking a bond, tension is built up within the material. If the external force is relaxed, the displaced particles will return toward their former positions: to do so they have to move with a certain velocity thus giving them momentum. However, this momentum will not immediately disappear when the particles reach their rest positions. They will overshoot, building up a new tension in reversed direction. The particles will continue to oscillate about their rest positions, their displacement dependent upon the strength of the initial force. Because the moving particles come into contact with other particles that do not move in the same direction or at the same rate, the energy that started the oscillation will eventually be dissipated over more and more smaller, sub-atomic particles, increasing the temperature of the material.

At Earth's surface, gravity compels all particles making up a body of water to be collectively drawn as close to the centre of 
the Earth as the container will allow. Hence, the surface area of a small body of water is virtually a flat plane, with all points on it being the same distance from the centre of the Earth. Disturbances from external sources of energy cause some of these particles to move horizontally. The result is that some particles are raised to an elevation higher than the rest plane, leaving a void where they have been removed. When external energy sources are removed, higher particles will tend to move back towards the void, creating an oscillating motion. Another factor that needs to be considered is surface tension. Water particles have an affinity for each other, and when this linkage is disturbed, surface tension will tend to restore the displaced particles to their original positions. However surface tension is a much smaller force than that of gravity, especially if large masses are involved, and it is only important when the displacements are small.

When displacement occurs, more water particles per unit area are above a certain datum plane in a given area than there are at nearby unit areas. (Since water is about as compressible as high strength steel, this means that the water level in the area where the particles are moved is higher than the original rest plane.) In this highly simplified wave, the place where the water is at the highest level is called the crest and that of the lowest level is called the trough.

To illustrate some further basic concepts, imagine a stone thrown into water: the stone's impact causes a set of concentric ripples to move outward. The distance between the crests of two subsequent ripples is called the wave length, $\mathrm{L}$. The time it takes for a wave to move over the distance of one wave length is called a period or cycle, T. The vertical distance between the crest (High Water) and the trough (Low Water) is the height, or range of the wave. Half the range is called the amplitude A, and represents the maximum displacement of the wave from the rest plane. The frequency, $\mathrm{f}$, is the number of cycles that pass a given location during a unit of time. The most common period of a tidal wave is 12.42 hours; thus its frequency (the reciprocal of the period) is 0.08051 cycles per hour. The wave speed or celerity, $\mathrm{c}$, is the horizontal rate of advance of the wave as a whole, where $\mathrm{c}=\mathrm{L} / \mathrm{t}=\mathrm{f} \cdot \mathrm{L}$ (see Fig. 1.).

\subsubsection{Wave forms and wave types}

The form of a water wave is most commonly like a sine or cosine curve. As the crest of a wave is its most visible feature, it is customary to express the shape of a wave as a function of time $\mathrm{t}$ :

$$
H_{t}=A \cdot \cos (360 \cdot f \cdot t) \text { or, } A \cdot \cos (2 \pi \cdot f \cdot t)=A \cdot \cos (n \cdot t)
$$

where $t$ is the time from the original High Water occurrence, at the location where High Water occurs at $t=0$. It can also be expressed as a function of the location at the distance $\mathrm{x}$ :

$$
H_{x}=A \cdot \cos (360 \cdot x / L)=A \cdot \cos (2 \pi \cdot x / L)=A \cdot \cos (k \cdot x)
$$

where $\mathrm{k}$ is the wave number, and $\mathrm{x}$ is the distance from the location where High Water occurs at that point in time. The angular speed, $\mathrm{n}$, of a wave is equal to $360 \cdot \mathrm{f}$ when the angle is measured in degrees, and equal to $2 \pi \cdot \mathrm{f}$ when measured in radians, as is used in (1). The wave number, $\mathrm{k}$, is equal to either $360 / \mathrm{L}$ or $2 \pi / \mathrm{L}$, depending on whether degrees or radians are used, as in (2). Although (1) and (2) are the most convenient ways to express the shape of a wave, it is not always possible to use them. A more general equation is required if one wishes to use time in a particular time zone, or the time that the actual or alleged cause of the wave occurs, or when one wants to compare or combine one wave with another (Eagleson and Dean 1966). This equation can be written as follows:

$$
\begin{gathered}
\mathrm{H}_{\mathrm{u}}(\mathrm{x}, \mathrm{t})=\mathrm{A} \cdot \cos (2 \pi(\mathrm{t} / \mathrm{T}-\mathrm{x} / \mathrm{L})) \text {, or } \\
\mathrm{H}_{\mathrm{u}}(\mathrm{x}, \mathrm{t})=\mathrm{A} \cdot \cos (\mathrm{n} \cdot \mathrm{t}-\mathrm{k} \cdot \mathrm{x})
\end{gathered}
$$

These equations describe a progressive wave moving in a positive $\mathrm{x}$-direction at the distance $\mathrm{x}$ in time $\mathrm{t}$. When the argument $(n \cdot t-k \cdot x)$ is equal to zero, High Water will occur. This means that High Water will occur when $\mathrm{t}=\mathrm{T} \cdot \mathrm{x} / \mathrm{L}=\mathrm{k} \cdot \mathrm{x} / \mathrm{n}$.

When the wave moves in the opposite (negative) $\mathrm{x}$-direction, the appropriate equation becomes:

$$
\mathrm{H}_{\mathrm{d}}(\mathrm{x}, \mathrm{t})=\mathrm{A} \cdot \cos (\mathrm{n} \cdot \mathrm{t}+\mathrm{k} \cdot \mathrm{x})
$$

When two waves with the same amplitude A, and the same frequency for period $\mathrm{T}$, are moving in opposite directions, the resultant wave will be a standing wave which can be described by the following equation:

$$
\begin{gathered}
H_{s}(x, t)=H_{u}+H_{d}=A[\cos (n \cdot t-k \cdot x)-\cos (n \cdot t+k \cdot x)]= \\
2 A \cdot \cos (2 \pi \cdot t / T) \cdot \cos (2 \pi \cdot x / L)
\end{gathered}
$$

Figure 2 illustrates the consequences of such an event. $\mathrm{H}_{s}$ is maximum when $\mathrm{t}=0$, or $\mathrm{t}=\mathrm{T}$ and $\mathrm{x}=0$, or $\mathrm{x}=\mathrm{L}$ or when $\mathrm{t}=0.5 \mathrm{~T}$ and $\mathrm{x}=0.5 \mathrm{~L} \cdot \mathrm{H}_{\mathrm{s}}$ is minimum when $\mathrm{t}=0.5 \mathrm{~T}$ and $\mathrm{x}=0$ or $\mathrm{x}=\mathrm{L}$ (or when $\mathrm{t}=0, \mathrm{~T}$ and $\mathrm{x}=0.5 \mathrm{~L}) \cdot \mathrm{H}_{\mathrm{s}}$ is 0 at all places when $\mathrm{t}=0.25 \mathrm{~T}$ or $\mathrm{t}=0.75 \mathrm{~T}$ or at all times when $\mathrm{x}=0.25 \mathrm{~L}$ or $\mathrm{x}=0.75 \mathrm{~L}$ (node). Note that at any value of $t$ the shape of the wave will be that of a cosine curve. At the closed end of a channel, should a progressive wave be reflected, a standing wave may form. Thereby the energy of the wave is temporarily transformed into potential energy. In theory wave height can double as indicated by the factor $2 \mathrm{~A}$ in (6). The maximum vertical fluctuations occur at the end of the channel and at locations that are distant from the end by multiples of half the wave length. These locations are called "anti-nodes", whereas at the "nodes" halfway between there will be no surface fluctuations. However, strong currents will be in evidence because the water flows to and fro between the anti-nodes. Consequently, when the water surface is high at the "even" anti-nodes, it will be low at the "odd" anti-nodes.

In the foregoing discussion, it is assumed that the wave height is small relative to wavelength and water depth. Although the range of the wave will always be small relative to wave length, it need not be so with respect to the depth. 


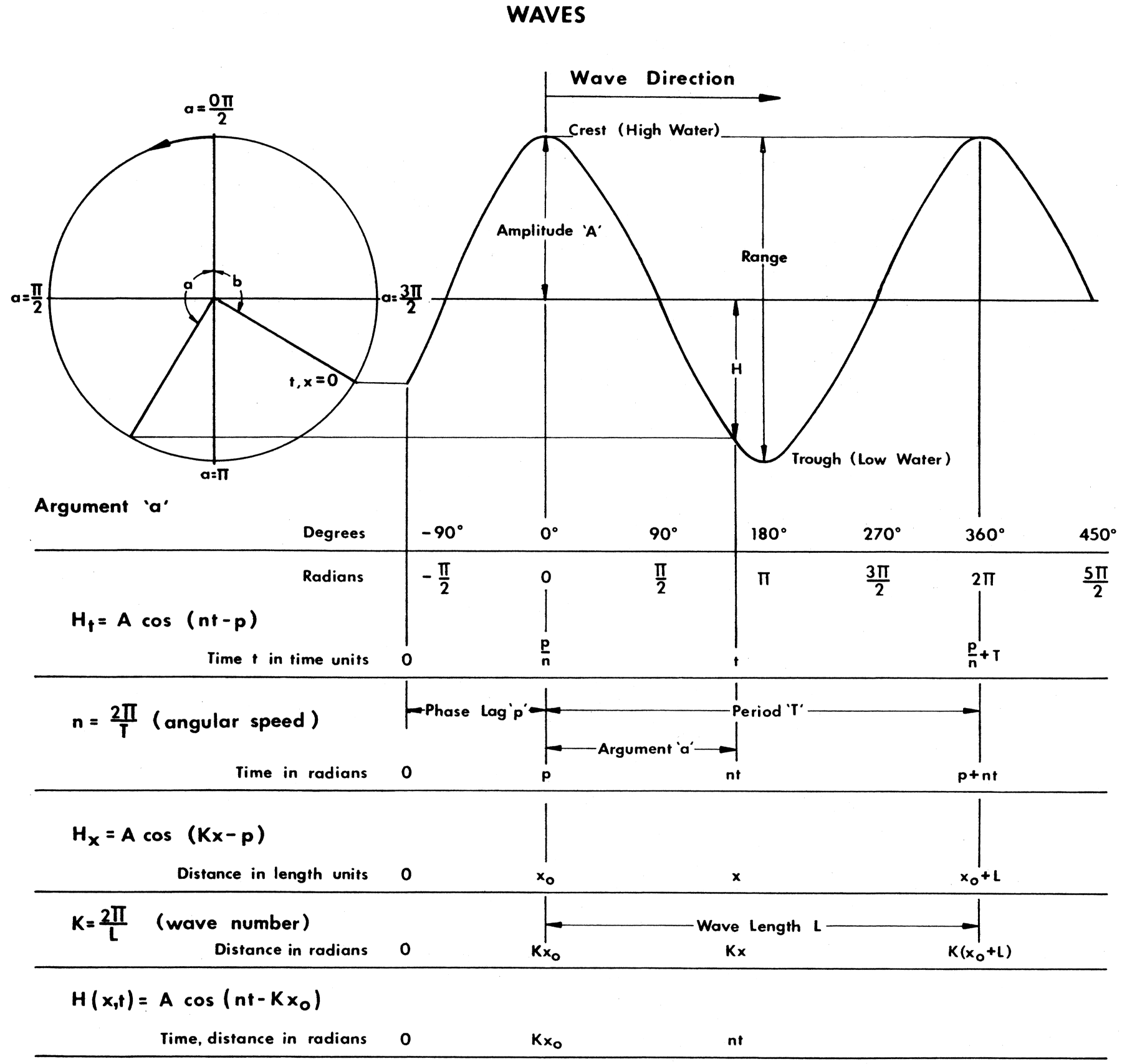

Fig. 1 Characteristics of wave generation, shape, and propagation given for degrees and radians, where $\mathrm{H}_{t}$ is the shape of the wave as a function of time $t, H_{x}$ is the shape of the wave as a function of distance $x, n$ is the angular speed of the wave in radians, and $\mathrm{K}$ is the wave number.

As derived from the dispersion relation, the wave speed of a sinusoidal wave in a body of water can be expressed as:

$$
\mathrm{c}=[(\mathrm{g} / \mathrm{K}) \tanh (\mathrm{K} \cdot \mathrm{D})]^{0.5}
$$

where $\mathrm{D}$ is water depth, $\mathrm{g}$ is acceleration due to gravity, and $\mathrm{K}$ is wave number $2 \pi / L$. If the relationship between depth $\mathrm{D}$ and wave length $L$ is expressed as $L=m \cdot D$, one can calculate the wave speed for different values of the ratio $m$. When $m$ is small, wave speed, $\mathrm{c}$, tends towards the value of $(\mathrm{g} / \mathrm{K})^{0.5}$; when large, it will approach $(\mathrm{g} \cdot \mathrm{D})^{0.5}$. In the first situation, the waves are termed deep water waves, and in the latter case shallow water waves (see Table 1 ).

In the Atlantic ocean, where water depths are in the order of 5000 metres and both the distance across and the tidal wave length, $\mathrm{L}$, are about $5000 \mathrm{~km}$, the value of $m$ is approximately 1000. Thus, even oceanic tidal waves are shallow water waves, affected by ocean depth. Particle motions in shallow waves are uniform with depth. Since water depth affects celerity or wave speed, waves moving into shallower water will decelerate. If, 


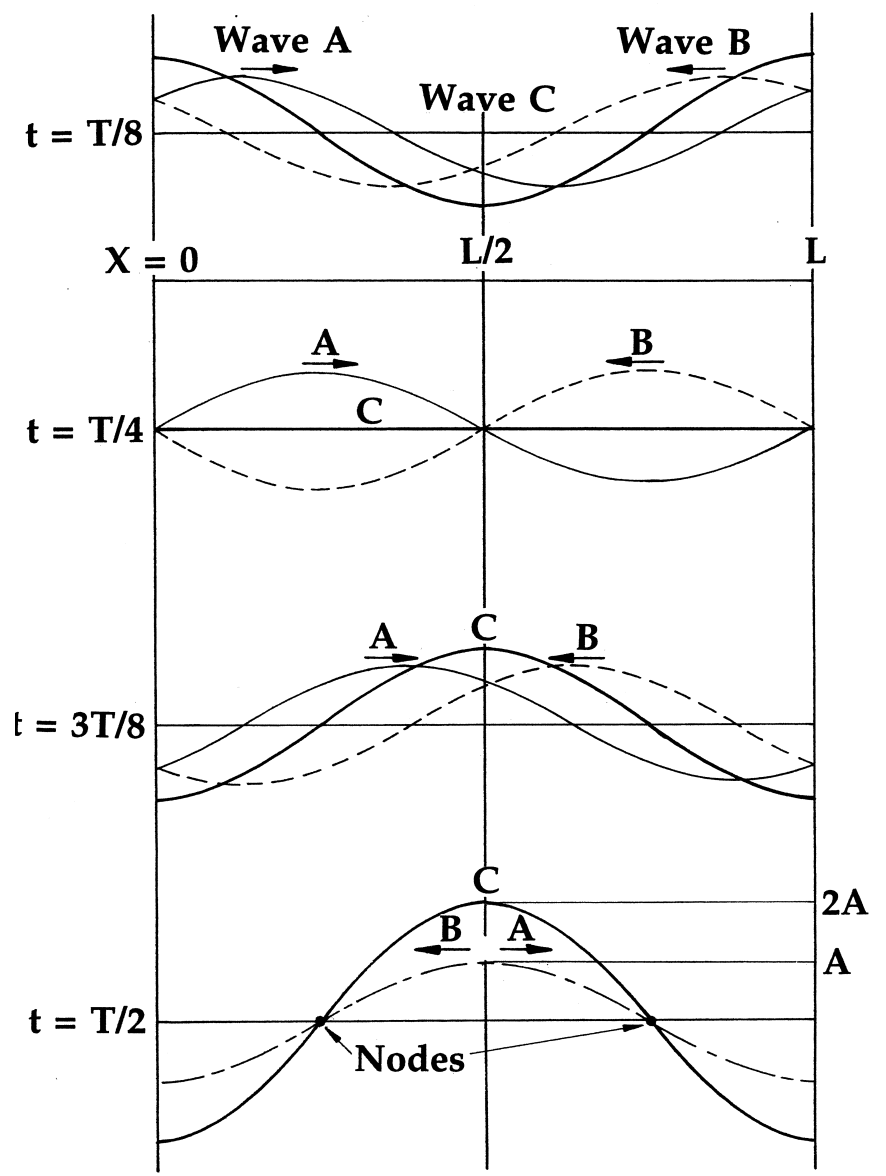

Fig. 2 Standing wave $C$ formed by waves A and B moving in opposite directions. Note the absence of vertical fluctuation at the nodes compared with maximum fluctuation at antinodes.

at the right flank of the wave, water is shallower than on the left flank, the wave on the right side will fall behind the wave crest on the left side. In effect, wave crests tend to conform to the depth contours over which they are moving. Thus, a wave approaching an island that rises very steeply from the ocean bottom, will pass the island unchanged, whereas a wave approaching an island surrounded with a gradually shallowing shelf tends to move toward the shore line in nearly concentric circles. This bending of the wave crest because of changing depths is called refraction.

There is a relationship between the wave speed, $c$, and the speed of the particles in the oscillating body of water. The particle displacement amplitude, $\mathrm{u}^{\prime}$, can be expressed as follows:

$$
\mathrm{u}^{\prime}=(\mathrm{A} / \mathrm{D}) \cdot \mathrm{c}
$$

where $\mathrm{A}$ is the amplitude of the tidal wave. For shallow water waves, this equation becomes:

$$
\mathrm{u}^{\prime}=\mathrm{A}(\mathrm{g} / \mathrm{D})^{0.5}
$$

Table 1. Wave speeds calculated at different wave length/depth ratios.

\begin{tabular}{cccc}
\hline $\mathrm{m}=\mathrm{L} / \mathrm{D}$ & $\mathrm{c}$ & $\mathrm{c} /(\mathrm{g} \cdot \mathrm{D})^{0.5}$ & $\mathrm{c} /(\mathrm{g} \cdot \mathrm{K})^{0.5}$ \\
\hline 0.1 & $0.395 \cdot \mathrm{D}^{0.5}$ & 0.13 & 1.00 short waves \\
0.5 & $0.883 \cdot \mathrm{D}^{0.5}$ & 0.28 & 1.00 (deep water) \\
1 & $1.249 \cdot \mathrm{D}^{0.5}$ & 0.40 & 1.00 \\
2 & $1.763 \cdot \mathrm{D}^{0.5}$ & 0.56 & 1.00 \\
5 & $2.576 \cdot \mathrm{D}^{0.5}$ & 0.82 & 0.92 \\
6.25 & $2.730 \cdot \mathrm{D}^{0.5}$ & 0.87 & 0.87 \\
10 & $2.948 \cdot \mathrm{D}^{0.5}$ & 0.94 & 0.75 \\
100 & $3.129 \cdot \mathrm{D}^{0.5}$ & 0.99 & 0.25 long waves \\
1000 & $3.131 \cdot \mathrm{D}^{0.5}$ & 1.00 & 0.07 (shallow water) \\
\hline
\end{tabular}

Table 2. Characteristics of a tide wave with a 12.4 hour period and an amplitude of $0.45 \mathrm{~m}$

\begin{tabular}{cccccc}
\hline Depth & $\begin{array}{c}\text { Wave } \\
\text { length }\end{array}$ & $\begin{array}{c}\text { Wave } \\
\text { speed }\end{array}$ & \multicolumn{2}{c}{$\begin{array}{c}\text { Particle speed } \\
\text { amplitude }\end{array}$} & $\begin{array}{c}\text { Particle } \\
\text { displacement } \\
\text { amplitude }\end{array}$ \\
$\begin{array}{cccccc}\mathrm{D} \\
(\mathrm{m})\end{array}$ & $\begin{array}{c}\mathrm{L} \\
(\mathrm{km})\end{array}$ & $\begin{array}{c}\mathrm{c} \\
(\mathrm{m} / \mathrm{s})\end{array}$ & $\begin{array}{c}\mathrm{u}^{\prime} \\
(\mathrm{m} / \mathrm{s})\end{array}$ & $\begin{array}{c}\mathrm{u}^{\prime} \\
(\mathrm{km} / \mathrm{hr})\end{array}$ & $\begin{array}{c}\mathrm{u} \\
(\mathrm{m})\end{array}$ \\
\hline 5000 & 9916 & 221.4 & 0.02 & 0.072 & 142 \\
1000 & 4434 & 99 & 0.04 & 0.160 & 318 \\
200 & 1983 & 44.3 & 0.10 & 0.369 & 710 \\
50 & 992 & 22.1 & 0.20 & 0.717 & 1420 \\
10 & 443 & 9.9 & 0.45 & 1.604 & 3176 \\
\hline
\end{tabular}

This means that the amplitude of the particle movement becomes:

$$
\mathrm{u}=\mathrm{T} \cdot \mathrm{u}^{\prime} /(2 \pi)
$$

The relationship between period and wave length in this situation is expressed as:

$$
\mathrm{L}=\mathrm{c} \cdot \mathrm{T}
$$

where $\mathrm{T}$ is the period of the wave. The period of the most common tidal movement is 12.42 hours or 44714 seconds. In the Atlantic, the tides have an amplitude of approximately $0.45 \mathrm{~m}$. Table 2 provides the characteristics of a tidal wave of these dimensions in waters of various depths.

Note that in waters $5000 \mathrm{~m}$ deep, particle displacement from its rest position needs to be only $142 \mathrm{~m}$ during a tidal period in order to make a tidal wave possible. For shallower water on the continental shelf, the required displacement becomes thousands of metres. The gravitational influences of the Moon 
and the Sun countering those of the Earth cause these particles to move. In contrast to wind movements, which only create a shear force at the surface of the water body, these gravitational influences act on particles at all depths of the ocean.

We turn next to the generation of shallow-water waves in the oceans.

\subsection{TIDES AND TIDE GENERATION}

\subsubsection{Introduction}

Tides, the longest of oceanic waves, involve alternating rise and fall of sea level due to gravitational effects exerted on the Earth by the Moon and Sun. People have long recognized that there is a connection between tides and the positions of the Moon and Sun relative to Earth. However, the nature of this connection is by no means obvious, and the influence of these celestial bodies on tidal events results in complex flow patterns. Nevertheless, the magnitude of the effects that generate tides can be precisely calculated from the astronomy alone, the chief caveat being that the ocean's response to these effects will be constrained by continental landmasses, the Earth's rotation, the geometry of ocean basins, and the transience of weather. According to Newton's equilibrium tidal theory, an ideal wave forms instantaneously upon an Earth uniformly covered by a deep layer of water, under the influence of the gravitational effects of the Moon and Sun. This theory is not meant to provide a realistic picture of what actually occurs in nature, but it does give accurately the tidal periods, the relative forcing magnitudes, and the astronomical phases of the tides. It is this idealized calculation that forms the cornerstone upon which tidal analysis and predictions are based.

The dynamic tidal theory employed by oceanographers shows that there is no wave crest formed instantaneously in the ocean directly under the Moon (or Sun), or at its antipodal point. The vertical tide movements at most locations can be represented by a time-space graph in the form of a modified sinusoidal curve like that of a simple harmonic motion. In harmonic motion, an object is accelerated by a variable force, the strength of which can be represented by a sine curve. Half the time this force will have a positive direction. When this force becomes zero at the moment it changes to a negative direction, the resulting velocity will reach its maximum strength. The velocity graph throughout the cycle will also be sinusoidal, but $90^{\circ}$ out of phase with acceleration. The object moved by the force will reach its farthest displacement in the positive direction when velocity becomes zero. This means that instead of a "tidal bulge" as customarily shown to be formed beneath the Moon, there will be a depression. Thus, generally only horizontal or "tractive" forces are responsible for generating tidal movements in the ocean.

It is important to note here the three main astronomical reasons for variations in the strength of these gravitational forces:
1. Variable distance between Moon and Earth. This variation causes the greatest deviations from the average (mean) tide in the Bay of Fundy. Because the Moon's orbit is elliptical, once a month at perigee the Moon is closest to the Earth, and thus its gravitational pull is then at its greatest, resulting in stronger than average tides. These so-called perigean tides recur every anomalistic month of 27.555 days.

2. Variable celestial positions of the Moon, Sun, and Earth relative to each other. The cycle of the Moon's phases in which there are two sets each of spring and neap tides, is the synodical month of 29.531 days. In the first set, spring tides are stronger than average because the Earth is either between the Sun and Moon (full moon), or the Moon is between Earth and Sun (new moon). A week later, during the first or last quarter of the moon, its gravitational influence is diminished by that of the Sun, which is then acting at right angles. The resulting tides, weaker than usual, are called neap tides.

3. Declination of the Moon and Sun relative to the Earth's equator. Declination is the angular distance in degrees between a heavenly body and the celestial equator (the plane in which the Earth's equator is situated) when it passes through the local meridian. A complete cycle, in which the Moon crosses the Equator twice, lasts 27.322 days and is called a tropical month. However, it takes 18.6 years for the Moon to complete its cycle of maximum declination, ranging between $28.5^{\circ} \mathrm{N}$ and $28.5^{\circ} \mathrm{S}$ with reference to Earth's equatorial plane.

One can expect stronger than usual tides a few days later than full and new moon, and weaker tides near the quarter phases of the moon. There is a certain inertia in the development of the tides, analogous to the fact that the months of July and August are on average warmer in the Northern Hemisphere than June, when the days are longer and the Sun is higher. For this reason the highest tides occur a few days after the astronomical configurations which induce them.

\subsubsection{Tidal prediction}

Tidal predictions are based on harmonic analysis of local tides. In the Bay of Fundy (Fig. 3) the principal hydrographic station is located at Saint John, New Brunswick. [Henceforth, New Brunswick will be abbreviated to N.B. and Nova Scotia to N.S.] Predictions are made and published annually for this reference port. Upon analysis, the observed tides are broken down into a large number of cosine curves, so-called tidal constituents, each representing the influence of a particular tidal influence or characteristic of the local tide. The first seven harmonic constituents listed in Table 3 account for $>90 \%$ of the total variability of the tides. As many as 62 tidal constituents are routinely used for tide prediction. The $\mathrm{M}_{2}$ constituent represents the influence that the Moon has on the local tides, 


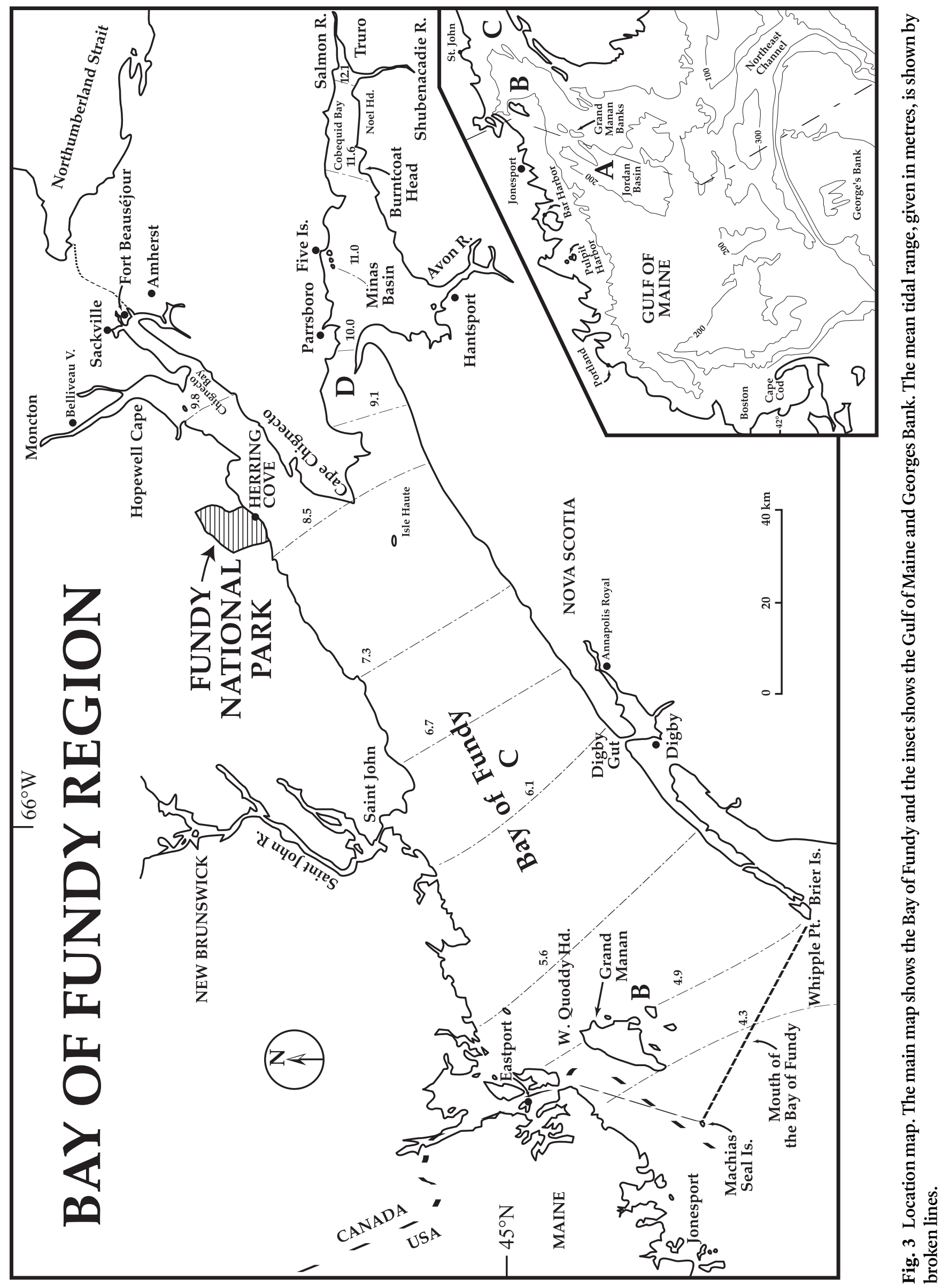


supposing for simplicity that it makes a circular orbit around the Earth in the plane of its equator at a distance resulting in (most cases) average tides. The $\mathrm{S}_{2}$ constituent represents the Sun's gravitational influence, assuming that Earth moves in a circular orbit around the Sun at a distance producing the average effect, and assuming that the Earth's equator is located in the ecliptic. Other constituents make corrections to these basic assumptions, because of variations in actual and sometimes apparent movements of these heavenly bodies. Constituents with the subscript " 2 " repeat themselves twice a day, causing two daily (semidiurnal) tides. Those with subscript " 1 " occur once a day, and those with subscript " 4 ", four times a day. The $\mathrm{K}_{4}$ constituent is the main overtide in the Bay of Fundy. It appears where the usual sinusoidal shape of the tidal wave is distorted upon entering shallow, narrowing inlets. This process results in loss of symmetry of the tidal wave, causing the water to rise faster than it will drop in the following ebb (Forester 1983; Canadian Hydrographic Service 1981).

Nowhere does the pulsating ebb and flow of the tide beat more impressively than in the Bay of Fundy (Defant 1958). Here the tidal range exceeds $16 \mathrm{~m}$ at times of particular astronomical conditions. Fundy tides are an integral part of the semidiurnal tidal system prevailing in the North Atlantic area (Davis and Browne 1996).

\subsubsection{The tide-producing forces}

In Atlantic Canada there are usually two unequal tides each day. They are due to the combined gravitational effects of the
Moon and Sun, and the centrifugal forces resulting from the revolution of the Earth-Moon and Earth-Sun systems around their common centres of gravity. For instance, the Earth and the Moon revolve in essentially circular orbits round their combined centre of mass (barycentre) every 27.3 days (sidereal month). Thus every point on Earth has an angular velocity of $2 \pi$ per 27.3 days, and each will experience an equal acceleration as a centrifugal force away from the Moon. The total of all these forces on the mass of the Earth is balanced by the total gravitational effects of the Moon's mass on Earth's mass, keeping the Earth on its orbit, just as the gravitational effects of the Earth keep the Moon on its orbit (Doodson and Warburg 1941; OPEN 1993). The magnitude of the force $\left(F_{g}\right)$ keeping these bodies on their respective orbits can be expressed with the following equation:

$$
F_{g}=G \cdot M_{e} \cdot M_{m} / R^{2}
$$

where $M_{e}$ and $M_{m}$ are the masses of the Earth and Moon, $G$ the universal gravitational constant, and $\mathrm{R}$ the distance between the centres of $M_{e}$ and $M_{m}$. Further, the Moon's gravitational attraction on all particles making up the Earth is directed towards the centre of the Moon and hence, except for the line joining the centres of the masses of the Earth and Moon, will not be exactly parallel to the direction of the centrifugal force. The composite magnitude of the centrifugal and gravitational effects, known as the tide-producing force $\left(\mathrm{F}_{\mathrm{TP}}\right)$ will depend on the distance of each particle of Earth from the centre of the Moon. This distance can be more or less than the value of $\mathrm{R}$.

Table 3. Constituents in the Gulf of Maine - Bay of Fundy - Georges Bank system (in metres)

\begin{tabular}{lcccccccccc}
\hline & $\mathrm{M}_{2}$ & $\mathrm{~S}_{2}$ & $\mathrm{~N}_{2}$ & $\mathrm{~K}_{2}$ & $(\mathrm{SD})$ & $\mathrm{K}_{1}$ & $\mathrm{P}_{1}$ & $\mathrm{O}_{1}$ & $(\mathrm{DL})$ & $\mathrm{K}_{4}$ \\
\hline Atlantic Ocean & & & & & & & & & & \\
Station 22B & 0.441 & 0.090 & 0.112 & & 0.45 & 0.075 & & 0.209 & & \\
Gulf of Maine & & & & & & & & & & \\
Portland & 1.353 & 0.213 & 0.289 & 0.057 & 1.38 & 0.146 & 0.044 & 0.155 & & 0.063 \\
Pulpit Harbor & 1.492 & 0.237 & 0.320 & 0.065 & 1.49 & 0.139 & 0.047 & 0.111 & & 0.007 \\
Bar Harbor & 1.546 & 0.253 & 0.356 & & 1.58 & 0.140 & & 0.110 & & \\
Eastport & 2.613 & 0.426 & 0.526 & 0.116 & 2.67 & 0.146 & 0.044 & 0.115 & & 0.063 \\
Bay of Fundy & & & & & & & & & & \\
Saint John & 3.076 & 0.503 & 0.659 & 0.143 & 3.14 & 0.153 & 0.049 & 0.119 & 0.18 & 0.057 \\
Partridge Island & 3.085 & 0.509 & 0.597 & 0.137 & 3.14 & 0.162 & 0.055 & 0.107 & 0.18 & 0.040 \\
Cape Blomidon & 5.029 & 0.732 & 1.006 & 0.198 & 5.11 & 0.162 & 0.055 & 0.116 & 0.18 & 0.046 \\
Parrsboro & 5.051 & 0.753 & 0.847 & 0.204 & 5.12 & 0.192 & 0.073 & 0.128 & 0.21 & 0.091 \\
Five Islands & 5.400 & 0.831 & 1.129 & 0.226 & 5.51 & 0.181 & 0.058 & 0.129 & 0.20 & 0.023 \\
Hantsport & 5.665 & 0.847 & 0.722 & 0.236 & 5.73 & 0.209 & 0.065 & 0.152 & 0.24 & 0.192 \\
Burntcoat Head & 5.642 & 0.832 & 1.097 & 0.226 & 5.73 & 0.143 & 0.049 & 0.122 & 0.18 & 0.101 \\
\hline
\end{tabular}

Notes. $\mathrm{SD}=$ average amplitude of semidiurnal tides; $\mathrm{DL}=$ average amplitude of diurnal tides; $\mathrm{M}_{2}=$ principal lunar; $\mathrm{S}_{2}=$ principal solar; $\mathrm{N}_{2}=$ longer lunar elliptic; $\mathrm{K}_{2}=$ lunisolar semidiurnal; $\mathrm{K}_{1}=$ lunisolar diurnal declination; $\mathrm{O}_{1}=$ principal lunar diurnal; $\mathrm{P}_{1}=$ principal solar diurnal; $\mathrm{K}_{4}=$ lunar quarter-diurnal 
The magnitude of $\mathrm{F}_{\mathrm{TP}}$ (Fig. 4) on a particle with the mass $\mathrm{m}$ at point $\mathrm{Q}$, in relation to a similar particle at the centre of the Earth, for example (given the Earth's radius $=\mathrm{a}$ ), is:

$$
\mathrm{F}_{\mathrm{TP}}=\mathrm{G} \cdot \mathrm{M}_{\mathrm{m}} \cdot \mathrm{m} /(\mathrm{R}-\mathrm{a})^{2}-\mathrm{G} \cdot \mathrm{M}_{\mathrm{m}} \cdot \mathrm{m} / \mathrm{R}^{2}
$$

In this equation the last part represents the equivalent centrifugal effect. The equation is simplified by means of a calculus derivative to:

$$
\mathrm{F}_{\mathrm{TP}}=2 \cdot \mathrm{G} \cdot \mathrm{M}_{\mathrm{m}} \cdot \mathrm{m} \cdot \mathrm{a} / \mathrm{R}^{3}
$$

At point $\mathrm{Q}$ (Fig. 4) the $\mathrm{F}_{\mathrm{TP}}$ acts toward the Moon (a is positive), but at point $\mathrm{P}$, away from it (a is negative). At these points the effect is perpendicular to the Earth's surface and, although at its maximum value in relation to the Earth's gravity, it is insignificant and has negligible effect on raising the water surface. The $\mathrm{F}_{\mathrm{TP}}$ will be zero in the plane through the centre of the Earth perpendicular to the line connecting it with the centre of the Moon. However, at points on the Earth's surface halfway between this plane and points Q and P (W, X, Y and $\mathrm{Z}$ ), the horizontal components (tractive forces) of the $\mathrm{F}_{\mathrm{TP}}$ will be greatest, causing maximum effects and moving particles towards points Q and P (Clancy 1969).
These forces will cause particles in the oceans to move along looping paths of limited distances, but enough to cause the tidal movements. The looping patterns are thus variable for each latitude, season, and phase of the Moon - see Desplanque and Mossman (1998a) for charts of particle movements. For example, during its new- and full-moon phases, the Moon makes its transit through the local meridian at 12:00 and 24:00 hours, and during its first and last quarter phases at 06:00 and 18:00 hours. Individual water particles reach their most westerly displacement position during the evening in the summer, and during the morning in the winter and, whereas the tides in the ocean are chiefly semidiurnal, the looping tracks of the individual particles are mainly diurnal. The ocean water would thus receive an impulse with every second oscillation, in contrast to the pendulum of a grandfather clock that, through its escapement wheel, receives an impulse every oscillation. The dimensions of the loops indicate that the movement of the water particles can maintain the tidal movement in deeper waters, but not in shallow ones. The movements, in sum constituting a progressive tidal wave, measure in mid-ocean a few hundred metres at most. However, like water spilled from the edge of a shallow dish, tidal effects become more evident in shallowing coastal waters where rotary tidal currents of amphidromic systems are impeded.

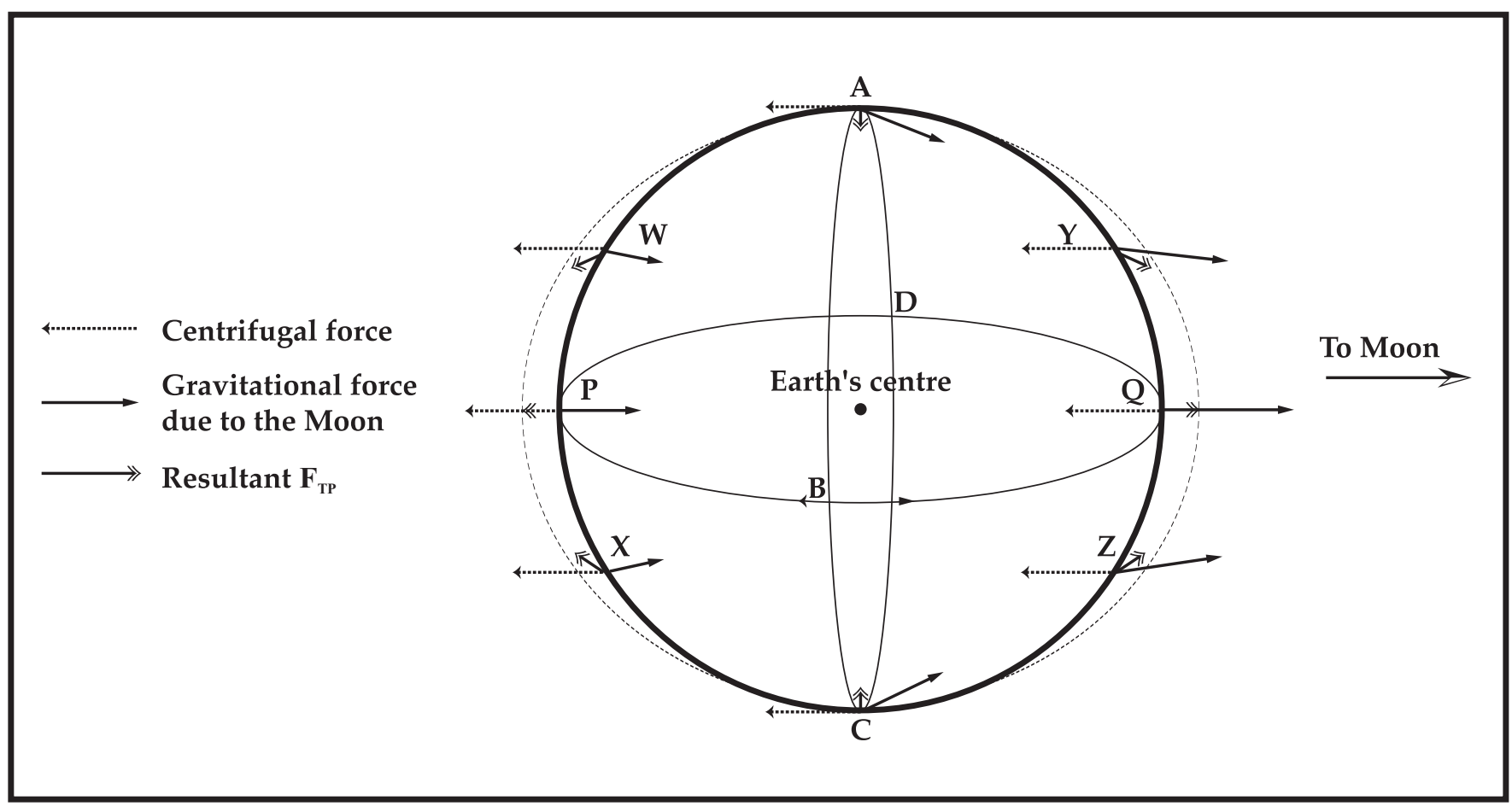

Fig. 4 The centrifugal force has the same magnitude and direction at all points. Gravitational force exerted by the Moon on the Earth varies in magnitude inversely with the square of the distance to the Moon and direction (towards the centre of the Moon). The tide-producing force $\left(\mathrm{F}_{\mathrm{TP}}\right)$ at any location $(\mathrm{P})$ is the resultant of centrifugal and gravitational forces at that point and varies inversely with the cube of the distance from the Moon. The theoretical ocean's response to $\mathrm{F}_{\mathrm{TP}}$, according to the tidal equilibrium theory, is shown by broken lines. 


\subsubsection{Variations in strength of the tides}

\subsubsection{Gravitational influences and accelerations.}

On average, the Earth requires 24 hours to revolve with respect to the Sun. Similarly the Moon seems to travel around the Earth in 24 lunar hours, equivalent to 24.84 solar hours. To illustrate the different possible situations, the Sun is used in the following discussion; the Moon could also be used, but the periods would then be measured in lunar hours.

First, consider the Sun's gravitational influences on a particle of water subject to semidiurnal oscillations near the Equator. At sunrise, around 06:00 hours, the particle is on (terminator) circle T. It is not accelerated horizontally (Fig. 5). However, shortly afterwards it will be drawn toward the east, to be accelerated strongest in that direction at 09:00 hours. The acceleration ceases at noon, to be replaced shortly afterwards by a westerly acceleration, which will be at its maximum at 15:00 hours. At 18:00 hours this acceleration will be reversed to an easterly acceleration. The process is repeated over and over again in cycles of 12 solar hours. When the acceleration in an easterly direction stops at 12:00 hours and at 24:00 hours, the particle affected by it will reach its maximum velocity in this direction. The maximum velocity in a westerly direction will occur at 06:00 and 18:00 hours (Fig. 5). The particle will not move at 03:00, 09:00, 15:00 and 21:00 hours. Note that when the particle is accelerated the fastest to the east, it is at its most westerly position in its semidiurnal oscillation.

If the vertical accelerations caused by the Sun and Moon were of any consequence, the same reasoning could be used. In the case of the Sun these accelerations would be strongest upward at noon and midnight, and strongest downward at 06:00 and 18:00 hours. This means that the displacement of the water surface (Fig. 5) would be downward at noon and midnight.

Because the horizontal or tractive accelerations need not compete with much stronger terrestrial gravitation, they can set water particles in motion in the almost frictionless ocean because neighbouring particles are subject to almost identical influences. A constant acceleration of $8.4 \cdot 10^{8} \cdot \mathrm{g}(8.237$ $\cdot 10^{-7} \mathrm{~ms}^{-2}$, applied for one hour to a particle originally at rest, will impart to that particle a speed of $0.003 \mathrm{~ms}^{-1}$, or $10.8 \mathrm{~m} / \mathrm{hr}$. The distance travelled in that interval is $5.4 \mathrm{~m}$. In a three hour period, the velocity will have been $24.4 \mathrm{~m} / \mathrm{hr}$ and the distance travelled $48.6 \mathrm{~m}$.

\subsubsection{The distance factor.}

Once in the anomalistic month of 27.555 days, the Moon's distance from Earth is $92.7 \%$ of the mean distance between the two bodies. Since the effect of the Moon's gravitation on the particles in the ocean is inversely proportional to the cube of the distance, the effect is 1.255 times stronger than the average effect. Approximately 14 days later, with the Moon in apogee, the distance is 1.058 times the average distance and the Moon's effect is reduced to $84.4 \%$ of its average value. The Earth is closest to the Sun shortly after New Year, making its influence 5.2\% stronger than average, while in the first days of July its effect is reduced by $4.9 \%$. Thus, in theory, the Moon's effect varies between 0.844 and 1.255 times its average effect because of varying distance, while for the same reason the Sun's effect varies between 0.438 and 0.484 times the Moon's average effect.

\subsubsection{Springs and neaps.}

The relationship between synodical month and the mean semidiurnal reappearance of the tide " $\mathrm{M}_{2}$ " is given by $\mathrm{M}_{2}=12$ $(1-1 / \mathrm{M})=12.42$ hours ( 12 hours and 25 minutes). Twice during the synodical month, the Earth, Moon, and Sun are almost aligned. The gravitational effects of Sun and Moon are additive and the so-called spring tides are stronger than usual. Due to inertia in the development of tides, the highest tides occur a few days after the appropriate astronomical configurations. Such tides are called spring tides because they spring or reach higher than normal. When the tides along the European coastlines are analyzed it turns out that the actual effect of the Sun is between 0.3 and 0.4 times that of the Moon's effect, a little less than the theoretical value of 0.46 . Thus, the bimonthly variation in this region is between 0.6 and 1.4 times the mean tide, more than caused by the variation in the distance between Earth and Moon. Small wonder, therefore, that western Europeans have regarded the cycle associated with changing Moon phases as the most important one. When the Moon is in either the first or last quarter, the actions of the Moon and Sun are perpendicular to each other and tend to counteract each other. Because the Moon's effect is the strongest, it will prevail, but in a reduced fashion. When this condition exists, the tides are called neap tides, a Saxon term related to the Germanic word "knippen", to pinch, meaning that they are reduced in size. In waters bordering most of North America, the influence of the Sun on the tides is itself rather "nipped". Consequently, the tidal variations caused by once-monthly so-called perigean tides are much more prominent.

\subsubsection{Diurnal inequality.}

Tides are generally semidiurnal, i.e., there are two High Waters and two Low Waters during a day, be it a solar or a lunar day. The strength of tides is modified by changing distances between Earth and Moon, and between Earth and Sun, and also because the Moon and the Sun act from varying directions. Changing declinations of the Sun and the Moon with respect to the plane of the ecliptic cause diurnal variations in the strength of the tides, a phenomenon called diurnal inequality. Usually, both the two High Waters and the two Low Waters during a day are affected, their respective levels being unequal. Elsewhere, High Waters during a day reach almost equal levels, in contrast to the levels of the Low Waters, which may be different.

The declination of the Sun is due to the fact that the plane of 


\section{ACCELERATIONS}

$W^{\prime \prime}=\left[-A \sin \left(\frac{t}{v}\right)+B \sin \left(\frac{2 t}{v}\right)\right] c . u$

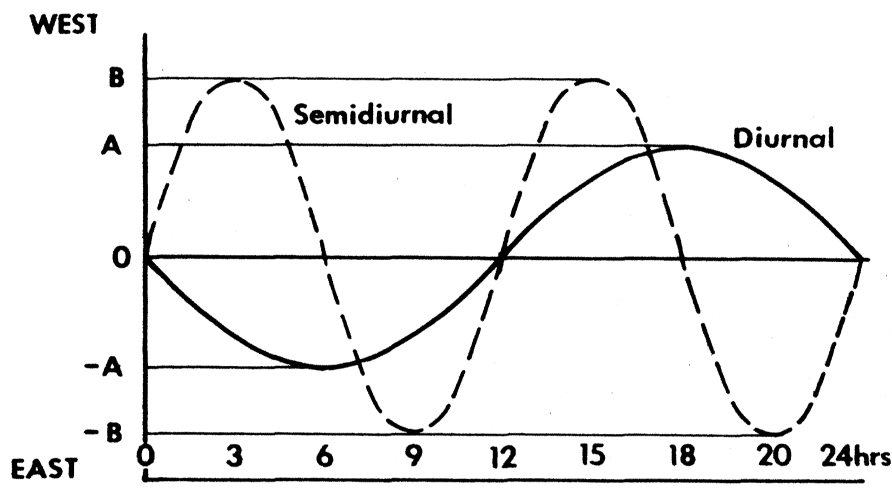

TRANSIT

VELOCITIES

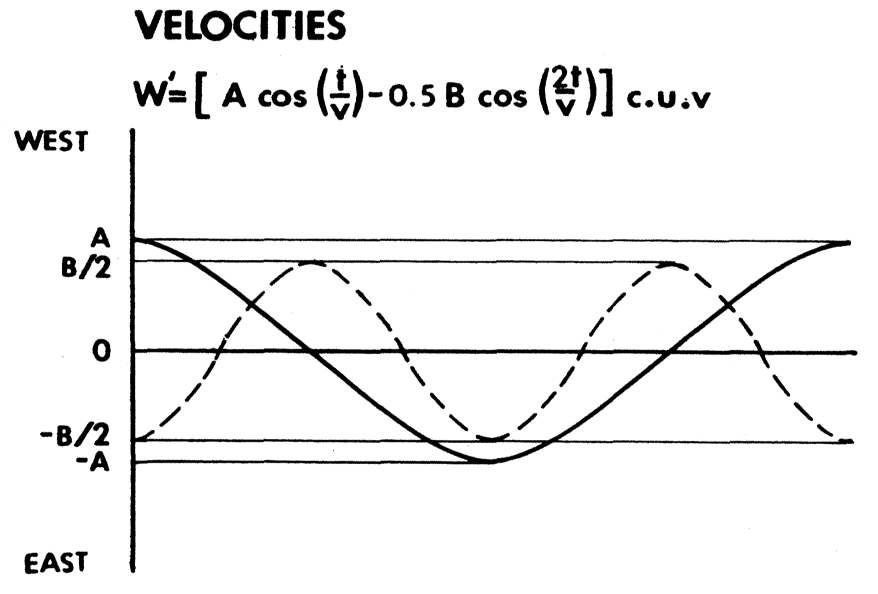

$N^{\prime \prime}=\left[-H \cos \left(\frac{t}{v}\right)-I \cos \left(\frac{2 t}{v}\right)\right] c \cdot u$

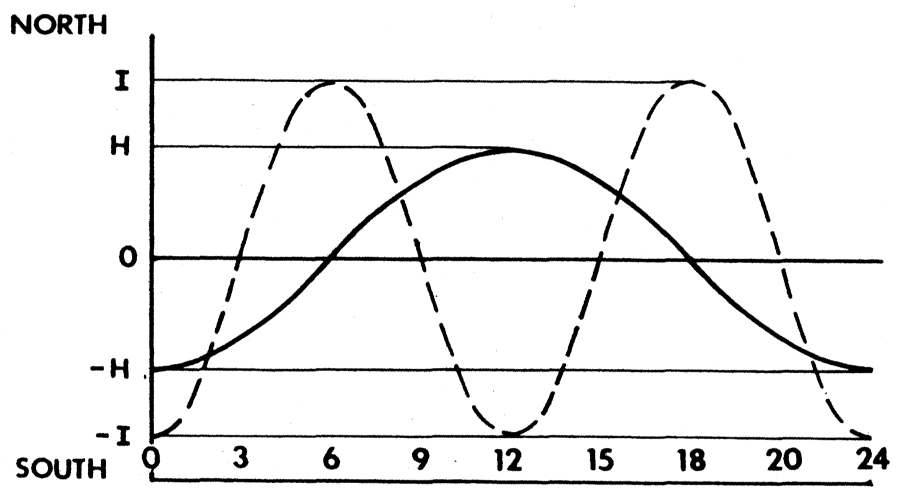

TRANSIT

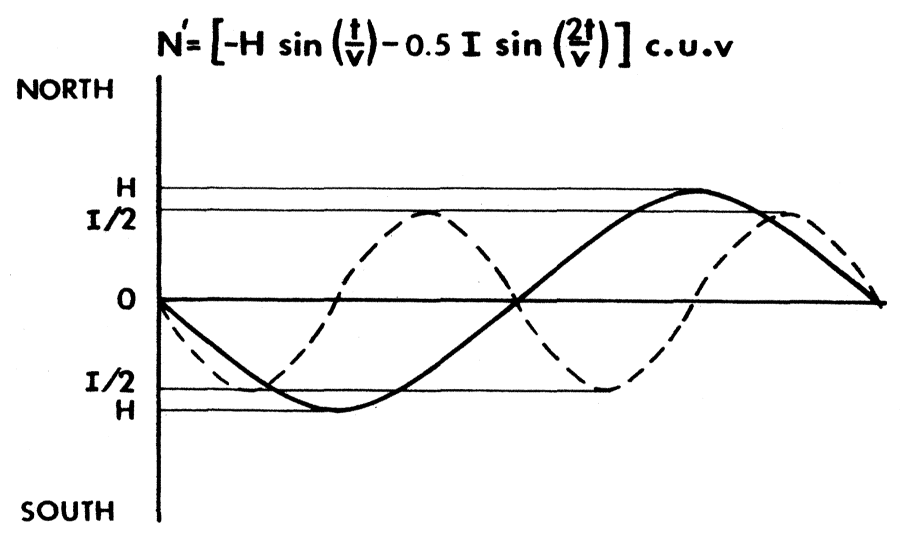

DISPLACEMENTS

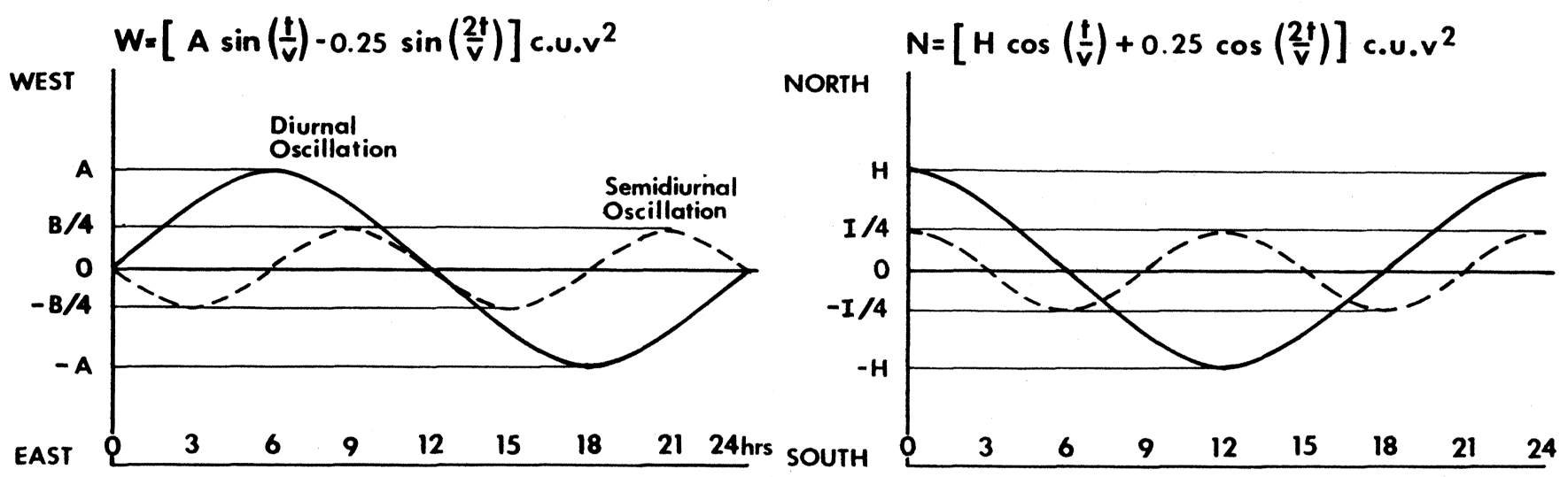

Fig. 5 Development of the semidiurnal oscillation is shown by the relationship between acceleration, velocity, and displacements of water particles (in E-W direction in left column, N-S direction in right column) resulting from gravitational influences of the Sun and Moon on Earth. (The Coriolis effect is not taken into consideration here.) 


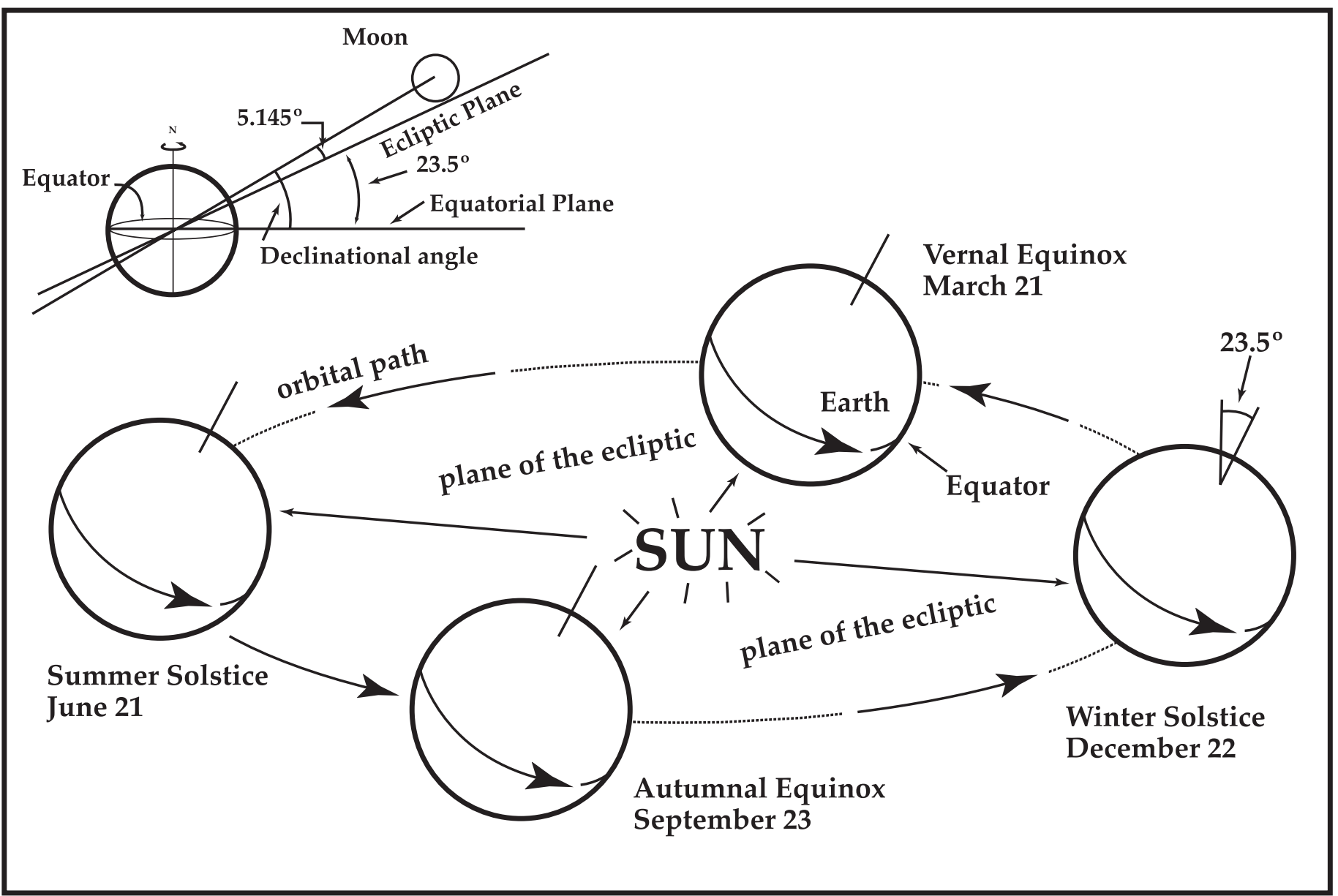

Fig. 6 Earth's equator makes an angle of about $23.5^{\circ}$ (actually $23.452^{\circ}$ ) to the plane (ecliptic) in which it moves around the Sun. The noonday Sun at the summer solstice stands over $23.5^{\circ} \mathrm{N}$ latitude, and at the winter solstice over $23.5^{\circ} \mathrm{S}$ latitude. Adding to Earth's tilt, the Moon is at an angle of about $5^{\circ}$ to the ecliptic. The monthly swing was $57.2^{\circ}$ during November 1987 but decreased to $36.6^{\circ}$ in February 1997 , only to increase again to $57.2^{\circ}$ over the following 9.3 year period. Thus, the amount of (maximum) declination of the Moon's orbit is constantly varying.

the Earth's equator makes an angle of $23.452^{\circ}$ with the plane in which the Earth orbits the Sun (Fig. 6). Hence the Sun appears higher in the sky during summer in the Northern Hemisphere, reaching its highest point at noon on 21 June. Conversely, at noon on 21 December the Sun appears $46.9^{\circ}$ lower above the horizon. Thus, summer days are longer than summer nights, and winter days are shorter than winter nights. At an equinox, the Sun is overhead at the Equator on about 21 March and 23 September, the day length is the same as night length everywhere on Earth. The Sun is said to have a north declination between the spring and fall equinoxes, and a south declination during the remainder of the year.

The Moon goes through a similar but much shorter declinational cycle, lasting 27.322 days. As the Moon's plane makes an angle of $5.145^{\circ}$ with the ecliptic, the declination of the Moon is more variable than that of the Sun. Thus, there are years when the declination of the Moon ranges from $28.597^{\circ}$ North to $28.597^{\circ}$ South, 14 days later. This condition existed in 1987 and will occur again in 2005, 18.6 years later. But in 1996 the maximum variation in declination of the Moon ranged between $18.307^{\circ}$ North and South.

The declinations of the Moon and Sun have a great influence on the directions of the accelerations affecting particles in the oceans. During an equinox, not only days and nights are of equal duration, but the two tides caused by the Sun will also have the same strength. Nor is the Moon able to produce diurnal inequality when it crosses the plane of the Earth's equator. Because the Moon's orbit is never more than $5^{\circ}$ from the ecliptic, the Moon's declination is close to the Sun's declination when there is a new moon. At full moon, it has an opposite declination to that of the Sun. Consequently, the only periods during which both Sun and Moon can cause little or no diurnal inequality are when there is a full or new moon near an equinox. These two periods fall annually between 8 March and 3 April, and between 10 September and 6 October. For the remainder of the year either the Moon or the Sun, or both, will 
be in declination. The role of diurnal inequalities in the Bay of Fundy is explored in greater detail in a later section (5.3.3).

\subsection{THE CORIOLIS EFFECT}

\subsubsection{Overview}

As a result of Earth's rotation, any object freely moving near or in contact with its surface will veer to the right in the Northern Hemisphere and to the left in the Southern Hemisphere. This is called the Coriolis effect. It affects winds everywhere, and in the oceans it results in the circular motion of water. The French mathematician Gaspard Gustave de Coriolis explained the phenomenon, applicable to frictionless motion, early in the 1800s. The effect is caused by Earth's eastward rotation. At the Equator the eastward movement of the planet's surface is about $1670 \mathrm{~km} / \mathrm{hr}$ (actually, $6378.16 \mathrm{~km} \cdot \pi \cdot 2 / 24=$ $1669.8 \mathrm{~km} / \mathrm{hr}$ ), but falls off at higher latitudes as the circumference of the Earth, in the axial plane normal to Earth's axis, gradually decreases (OPEN 1993). Thus at $45^{\circ}$ latitude the velocity is about $1200 \mathrm{~km} / \mathrm{hr}(1179 \mathrm{~km} / \mathrm{hr})$, falling off to zero at the poles. Any object freely moving away from the Equator, north or south, is moved to the east at higher latitudes because of higher eastward inertia. Conversely, an object approaching the Equator from north or south is effectively retarded due to smaller eastward inertia; it is moved to the west as it approaches the Equator from either north or south. Consequently, essentially frictionless objects such as wind and ocean currents, and tidal waters entering and leaving coastal embayments, are deflected to the right in the Northern Hemisphere and to the left in the Southern Hemisphere.

In the case of the atmosphere, air moves from high pressure areas to depressions. The depressions are filled from all sides, and air currents are deflected to the right by the Coriolis effect. However, the result is that the winds approaching and converging near the depression, in the Northern Hemisphere, form a cyclonic anticlockwise circulation. Water surfaces beneath a developing atmospheric depression, rise in elevation, drawing water from areas under high pressure systems. Famous whirlpools, such as the Maelstrom off Norway, and the Old Sow near Deer Island in Passamaquoddy Bay in the Bay of Fundy, are also subject to the Coriolis effect.

Flat rotating objects such as a record player or merry-goround can be used to illustrate the Coriolis effect. In terms of vector algebra, the fundamental relations are briefly set out below; they apply to the apparent centrifugal force working on a particle in a circular orbit and its counterpart, the centripetal force, which keeps it on this orbit.

\subsubsection{Fundamental relationships}

In relation to the stars, the Earth rotates once in a so-called sidereal day, which lasts 86186 seconds. Thus each particle in or on Earth has an angular velocity of $w=2 \pi / 86186=7.29 \cdot 10^{-5}$ radians per second. Its linear velocity depends on its distance from the Earth's axis, which runs from pole to pole (Doodson and Warburg 1941).

Now consider an object of mass $\mathrm{m}$, moving along the circular path (Fig. $7 \mathrm{a}$ ) with a velocity V. If it takes $t$ seconds to go around the circle at a constant speed, the object's velocity will be $\mathrm{V}=2 \pi \cdot \mathrm{R} / \mathrm{t}$, in which case the angular speed is $\mathrm{w}$ radians per second $(w=2 \pi / t)$. Thus, the linear velocity $V=w \cdot R$. If this mass moves from point $A$ to point $B$ on its circular path, it is deflected the distance $\mathrm{DB}(=\mathrm{x})$ from the straight path it would have taken had it not been constrained by some force. If the distance $A B$ was covered in $t$ seconds, the force $f$ must have been $2 \mathrm{x} / \mathrm{t}^{2} \mathrm{~ms}^{-2}$, because

$$
x=0.5 f \cdot t^{2} .
$$

When the angle $w$ is very small, $\mathrm{AD}$ is approximately the same as $A B$ and is equal to $V \cdot t$ and $w \cdot R \cdot t($ Fig. $7 b)$, whence:

and

$$
\mathrm{x}=\mathrm{R}-\mathrm{R} \cos \mathrm{w} \cdot \mathrm{t}=\mathrm{R}(1-\cos (\mathrm{w} \cdot \mathrm{t})),
$$

$$
1-\mathrm{x} / \mathrm{R}=\cos (\mathrm{w} \cdot \mathrm{t})=\left(1-\sin ^{2}(\mathrm{w} \cdot \mathrm{t})\right)^{0.5},
$$$$
(1-\mathrm{x} / \mathrm{R})^{2}=1-\sin ^{2}(\mathrm{w} \cdot \mathrm{t}) \text {, }
$$

whence

$$
1-2 x / R+(x / R)^{2}=1-\sin ^{2}(w \cdot t) .
$$

Now, $(\mathrm{x} / \mathrm{R})^{2}$ is insignificantly small, and when $\mathrm{w} \cdot \mathrm{t}$ is small, $\sin ^{2}$ $(\mathrm{w} \cdot \mathrm{t})=(\mathrm{w} \cdot \mathrm{t})^{2}$, because $\mathrm{w}$ is measured in radians. Thus, $2 \mathrm{x} / \mathrm{R}$ $\approx(\mathrm{w} \cdot \mathrm{t})^{2}$, and $\mathrm{x} \approx \mathrm{R}(\mathrm{w} \cdot \mathrm{t})^{2} / 2$. Since $\mathrm{x}$ is the distance a mass is moved by force $\mathrm{f}$, in $\mathrm{t}$ seconds, $0.5 \mathrm{R} \cdot(\mathrm{w} \cdot \mathrm{t})^{2} \approx 0.5 \mathrm{f} \cdot \mathrm{t}^{2}$, and,

$$
\mathrm{f} \approx \mathrm{R} \cdot \mathrm{w}^{2} \approx \mathrm{V}^{2} / \mathrm{r},(\text { since } \mathrm{V}=\mathrm{w} \cdot \mathrm{R})
$$

Thus the apparent centrifugal force acting on mass $\mathrm{m}$ is $\mathrm{m} \cdot \mathrm{V}^{2} / \mathrm{R}$. Taking $\mathrm{w}$ as the angular velocity, then $\mathrm{V}=\mathrm{R} \cdot \mathrm{w}$, and the centrifugal force, may be expressed as $\mathrm{m} \cdot \mathrm{R} \cdot \mathrm{w}^{2}$ (Fig. $7 \mathrm{c}$ ).

Suppose now that a particle with mass $\mathrm{m}$, is moving along a circle with radius $\mathrm{R}$, at latitude $l$. Its velocity is $\mathrm{R} \cdot \mathrm{w}$, and the centrifugal force acting upon it will be $\mathrm{m} \cdot \mathrm{R} \cdot \mathrm{w}^{2}$. Relative to the Earth, it seems to be at rest. However, if it is given a velocity V in the direction of rotation, its real velocity in space will be $\mathrm{R} \cdot \mathrm{W}$ $+\mathrm{V}$, or $\mathrm{R}(\mathrm{w}+\mathrm{V} / \mathrm{R})$, its angular velocity having been changed from $w$ to $(w+V / R)$, and the apparent centrifugal force acting upon it $\mathrm{m} \cdot \mathrm{R}(\mathrm{w}+\mathrm{V} / \mathrm{R})^{2}$, which is equivalent to:

$$
\mathrm{m} \cdot \mathrm{R} \cdot \mathrm{w}^{2}+2 \mathrm{~m} \cdot \mathrm{w} \cdot \mathrm{V}+\mathrm{m} \cdot \mathrm{V}^{2} / \mathrm{R}
$$

The first term in (16) is the normal centrifugal force resulting in the equatorial bulge, and is balanced by the slope from Equator to the poles of the Earth. The third term is very small because of the divisor $\mathrm{R}$, and can be ignored. The remaining middle term can be split into vertical and horizontal components (Fig. 7d). The vertical one will affect the local apparent gravity force, but the horizontal component will cause a tractive force acting along the Earth's surface, effectively moving the mass to the right (in this case toward the Equator, the initial motion having been west to east in the Northern Hemisphere). 
The magnitude of this Coriolis effect is $2 \mathrm{~m} \cdot \mathrm{V} \cdot \mathrm{w} \cdot \sin l$. In general, the coefficient of this force, acting on a mass $\mathrm{m}$, moving relative to the Earth's surface with a velocity V, is expressed as:

$$
\mathrm{f}=2 \mathrm{~V} \cdot \mathrm{w} \cdot \sin l
$$

Centrifugal force, unlike gravity, is affected by the relative speed of the object. Thus even an object traveling due east (Northern Hemisphere) undergoes an apparent deflection. This is because it has an angular rotational velocity (measured in degrees or radians/unit time) exceeding that of Earth's surface. The result of this imbalance causes the object to deviate to the right, towards the Equator, away from Earth's axis of rotation. The principle applies to any freely moving object provided it is not on the Equator no matter what its direction with respect to our rotating frame of reference.

The Coriolis acceleration thus expressed is proportional to the speed of the moving object and its latitudinal position. The magnitude of this "force" increases with increasing latitude, and the speed of the moving object, and is dependent upon the rotational velocity of Earth on its axis (Tolmazin 1985). Only at the Equator, where $\sin l=0$, is there no Coriolis effect. Nevertheless it is important to appreciate that Coriolis deflections are not real. They are apparent deflections resulting from observations made at a fixed location to track freely moving objects.

\subsubsection{Applications to tides and water currents}

Frictional coupling between moving water and Earth is weak except for a thin layer directly adjacent to the solid Earth. Consequently lateral water movements induced by tide generating forces respond readily to the Coriolis effect to an extent that is directly proportional to the mass and the speed of the object in question. Thus, one litre of water, having a mass of $1 \mathrm{~kg}$, and moving at a speed of $1 \mathrm{~ms}^{-1}(1.944 \mathrm{knot})$ in relation to the Earth at $45^{\circ} \mathrm{N}$ latitude, will be moved to the right of its original direction. It will have been deflected by the Coriolis effect with an acceleration of:

$$
4 \cdot \pi / 86186 \cdot \sin 45^{\circ}=1.031 \cdot 10^{-4} \mathrm{~ms}^{-2}
$$

(as the angular velocity $=2 \pi / 86186$ radians/s). This is about 95112 times smaller than the Earth's gravitational force. To compensate for this deflective force, a rising slope to the right of 1:95 112 would be caused by the Coriolis effect in the Northern Hemisphere. The slope of this gradient is given by the ratio $1: \mathrm{g} /$ $(2 \cdot \mathrm{V} \cdot \mathrm{w} \cdot \sin l)$. For example, if a channel has a surface width of $\mathrm{W}$ metres, and is carrying a current of $\mathrm{C} \mathrm{ms}^{-1}$ or of $\mathrm{K}$ knots, the water flowing at the right bank will be $\mathrm{H} \mathrm{m}$ higher than on the left bank. The amount $\mathrm{H}$ can be established by

$$
\mathrm{H}=\mathrm{W} \cdot \mathrm{C} / 67254 \cdot \sin l
$$

$\left(\right.$ where $\left.67245=9.80 / 4 \pi \cdot 86186 \mathrm{~ms}^{-1}\right)$ or,

$$
\mathrm{H}=\mathrm{W} \cdot \mathrm{K} / 130733 \cdot \sin l
$$

a)

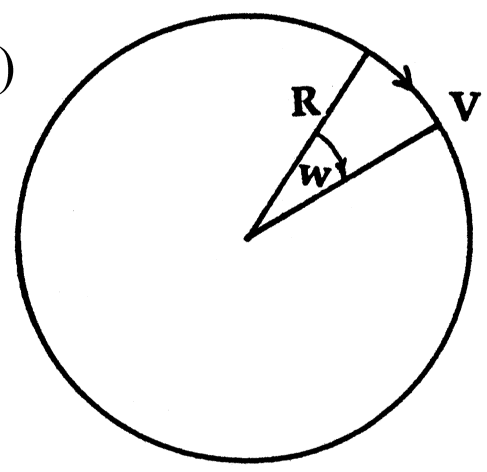

b)

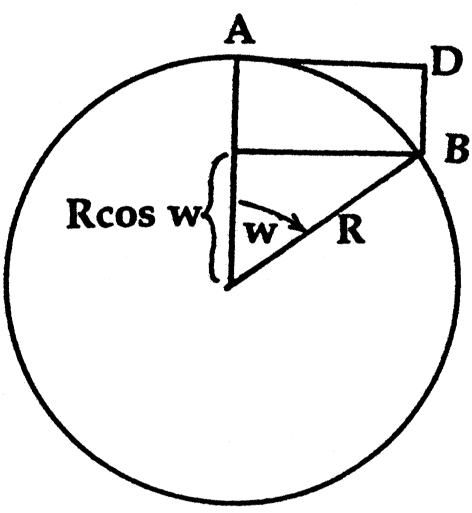

c)

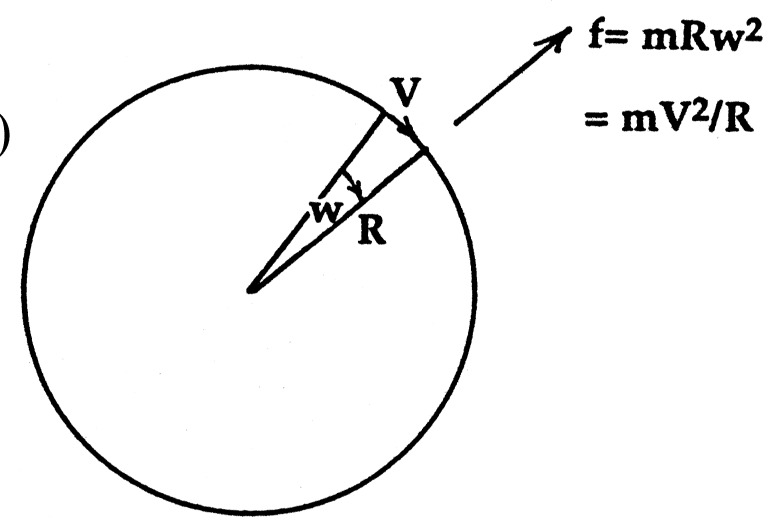

d)

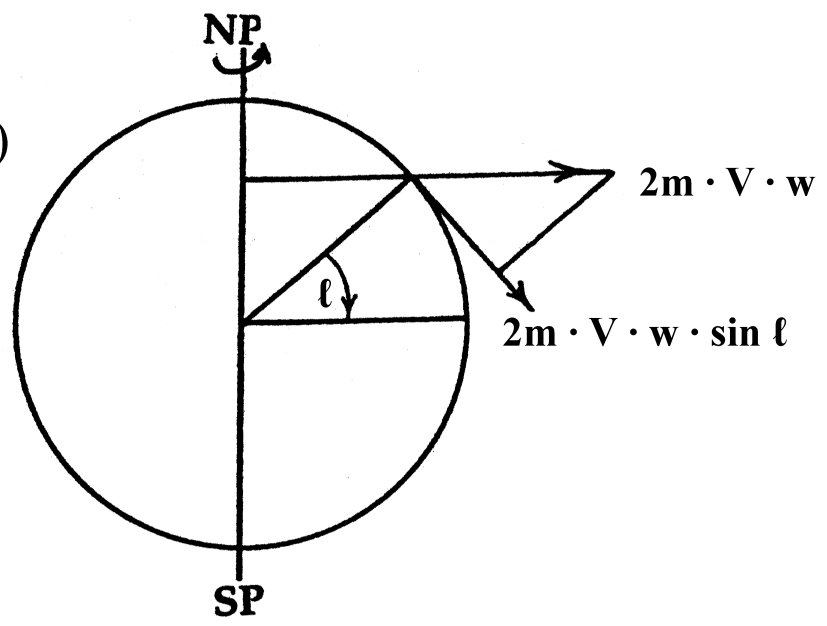

Fig. 7 Calculation of centrifugal force and Coriolis effect acting at Earth's surface. 
(where $130732=9.80 / 4 \pi \cdot 67254 \cdot 1.944 \mathrm{~ms}^{-1}$, for conversion from knots). In the above two cases, the dimensions are given respectively as follows:

Dimensions: $\mathrm{W} \mathrm{m}, \mathrm{C} \mathrm{ms}^{-1}$, whence $\mathrm{H}=\mathrm{m}^{2} \mathrm{~s} / \mathrm{m} / \mathrm{s}=\mathrm{m}$ Dimensions: $\mathrm{W} \mathrm{m}, \mathrm{k}=1852 \mathrm{~m} / \mathrm{hr}=0.5144 \mathrm{~ms}^{-1}=1 \mathrm{knot}$

In the Bay of Fundy and elsewhere, tidal ranges in wide stretches of water with strong tidal currents will be higher on the side of the channel that is to the right of the flood tide. When the tide reaches its peak level at any segment of the tidal estuary or channel, except for the uppermost reach of the tide, the water continues flowing landward because waters in the upper reaches will still not have reached their maximum level. Some time is required before the tidal current in the upper reaches comes to a standstill and then reverses. When the highest level is reached, the incoming tide will be higher at the right bank than at the left bank. Thereafter the water will be at a lower level and falling. In some instances the ebb current may be faster than the inward flow, causing a steeper lateral slope, but at a lower level. However the incoming tide will be more concentrated at the right bank. In the Bay of Fundy this will be at the southern or Nova Scotia side of the Bay, while the outgoing tide will be higher at the northern or New Brunswick side, resulting in an anticlockwise movement of the bulk of the tidal water.

Charts of the Bay of Fundy indicate that near Saint John, N.B., the Bay is $57 \mathrm{~km}$ wide. Tidal currents in that region have an average incoming velocity of $1.7 \mathrm{knots}$ or $0.875 \mathrm{~ms}^{-1}$. Under these conditions the lateral water surface gradient due to the Coriolis effect can be calculated from equation (18) as:

$$
\begin{gathered}
\mathrm{H}=57000 \cdot 0.875 . \sin 45^{\circ} / 67254=0.52 \mathrm{~m} \\
\left(\text { or } \mathrm{H}=57000 \cdot 1.7 \cdot \sin 45^{\circ} / 130732=0.52 \mathrm{~m}\right) .
\end{gathered}
$$

That is to say the water level on the Nova Scotia side is 0.52 $m$ higher than on the New Brunswick side. This will be higher during the periods of maximum velocity, and lower when the velocities are lower than average.

At High Water in Saint John, the water continues to move towards the head of the Bay, where High Water occurs some time later. Assuming the current has a speed of 0.8 knots $(0.4$ $\mathrm{ms})$, the outcome again can be calculated from (18) as:

$$
\begin{gathered}
\mathrm{H}=57000 \cdot 0.4 \cdot \sin 45^{\circ} / 67254=0.24 \mathrm{~m} \\
\left(\text { or, } \mathrm{H}=57000 \cdot 0.8 \cdot \sin 45^{\circ} / 130732=0.24 \mathrm{~m}\right) \text {. }
\end{gathered}
$$

Current speeds decrease after the water starts rising above Mean Water Level, and the movement correspondingly accelerates less. When acceleration to the right has ceased, the velocity to the right has to be counteracted by an opposite acceleration, either by the water moving in the opposite direction, or by the slope caused by the Coriolis effect. Eventually the water accumulated on the right side will start to move to the left. This movement causes a residual anticlockwise movement of the water in the Bay of Fundy and the Gulf of Maine as recorded by the movements of drift bottles. The phenomenon has been attributed to freshwater discharge of tributary rivers. However, compared with the tidal exchange, freshwater discharge is minuscule and of little account in the generation of residual currents.

The distance between Cape Cod and Cape Sable along the great circle is $414 \mathrm{~km}$. The current speed in the Northeast Channel and over the Georges Bank may reach 2 knots or $1 \mathrm{~ms}^{-1}$. Theoretically, water levels at the Nova Scotia side could be more than $4 \mathrm{~m}$ higher $\left(\mathrm{H}=414000 \cdot 2 \sin 42.5^{\circ} / 130732=\right.$ $4.28 \mathrm{~m}$ ) than at Cape Cod when the water surface is near mean water level. Near High Water the currents are not as strong and the Coriolis gradient correspondingly less. However it seems likely that the Coriolis effect contributes to much stronger tides along the Gulf of Maine coastline of Nova Scotia than near Cape Cod and the Great South Channel (between Nantucket Shoals and Georges Bank). The range of the tides on the Nova Scotia side varies between $2 \mathrm{~m}$ on the Atlantic Ocean side to $4.5 \mathrm{~m}$ near the entrance to the Bay of Fundy, while on the Cape Cod side it varies between 0.5 and $1.0 \mathrm{~m}$. Even at the head of the Bay of Fundy there is a substantial Coriolis effect on water levels. For example, hydrographic charts show that in the 5300 $\mathrm{m}$ wide Minas Channel, currents of 8 knots can occur. This means that on one side of the Channel the water levels could be about $0.23 \mathrm{~m}$ higher $\left(\mathrm{H}=53000 \cdot 8 \cdot \sin 45^{\circ} / 130732=0.23\right.$ $\mathrm{m})$ than at the other side, because of Coriolis gradients.

The swing of the Coriolis effect with incoming tides might therefore be expected to exert a relatively stronger erosive power on southern or southeastern shores of channels and estuaries in the Bay of Fundy than ebb tides do on the opposite sides. In estuaries, of course, this swing is in the opposite sense to that of stream flow. Therefore, in Bay of Fundy estuaries at such times as stream discharge is relatively high, lateral mixing of fresh water and saline water will be promoted by the Coriolis effect.

The Coriolis effect is joined by the constraining effect of landmasses in imposing amphidromic systems on the tides (Fig. 8). Amphidromic systems occur in individual basins, seas, and lakes, for example the Gulf of St. Lawrence, or Lake Geneva on the border of Switzerland and France. In the elongated Lake Geneva, a gravitational forces cause a seiche, with alternately higher levels at one side than the other. In the Gulf of St. Lawrence, which is a more rounded body of water, the tidal movement is generated and kept going mainly by the ocean tides that enter through the Cabot Strait, with higher levels being at the right-hand side of the inflow. This results in the surface of the entire Gulf resembling a wobbling plate on a flat surface, with the highest (or lowest) rim of the plate rotating anticlockwise. In both cases the dimensions of the bodies of water must be such that a harmonic oscillation can take place. In the Gulf, the Coriolis effect causes a tidal wave to move anticlockwise, being high in the Cabot Strait when the ocean tide peaks. Dynamic tidal analysis thus treats tides as standing waves. The tides themselves are generally classified in terms of the ratio of the total amplitudes of the two principal diurnal components to the total amplitudes of the two principal semidiurnal components (for details see Fig. 4-3 in Desplanque and Mossman 1998a). 


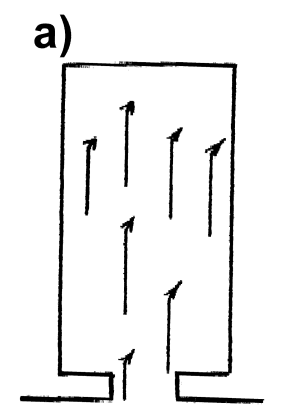

b)

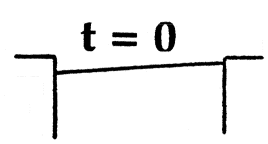

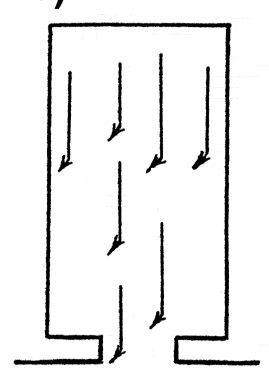

c)

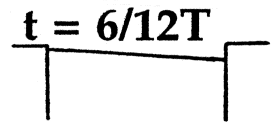

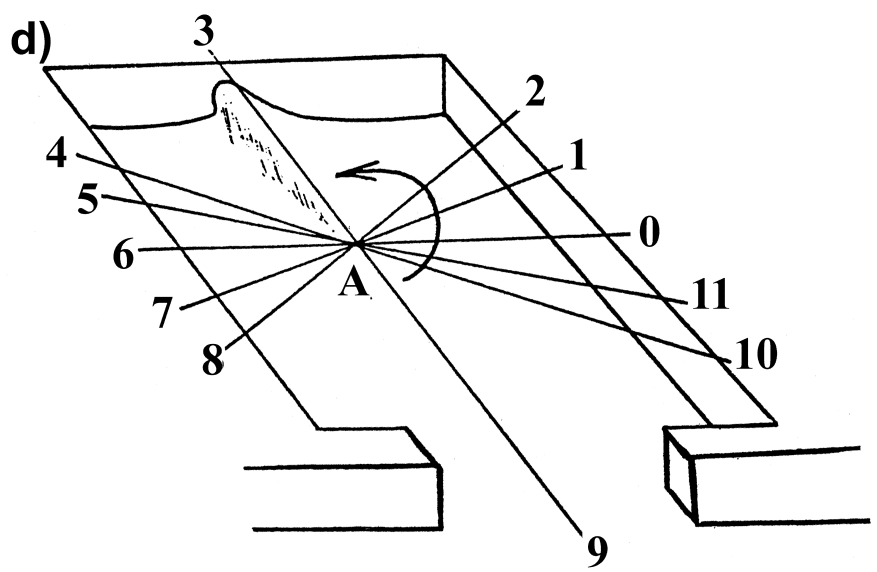

Fig. 8 In an amphidromic system developed in a bay in the northern hemisphere the flood tide (a) is deflected to the right, and the ebb tide (b) to the left by the Coriolis effect; (c) shows the result in cross-section. In (d) the tidal crest is shown at co-tidal lines for hour 3; motion of tidal crest is shown by arrow upon the water surface. "A" marks the (no tide) amphidromic point. Modified after OPEN(1993).

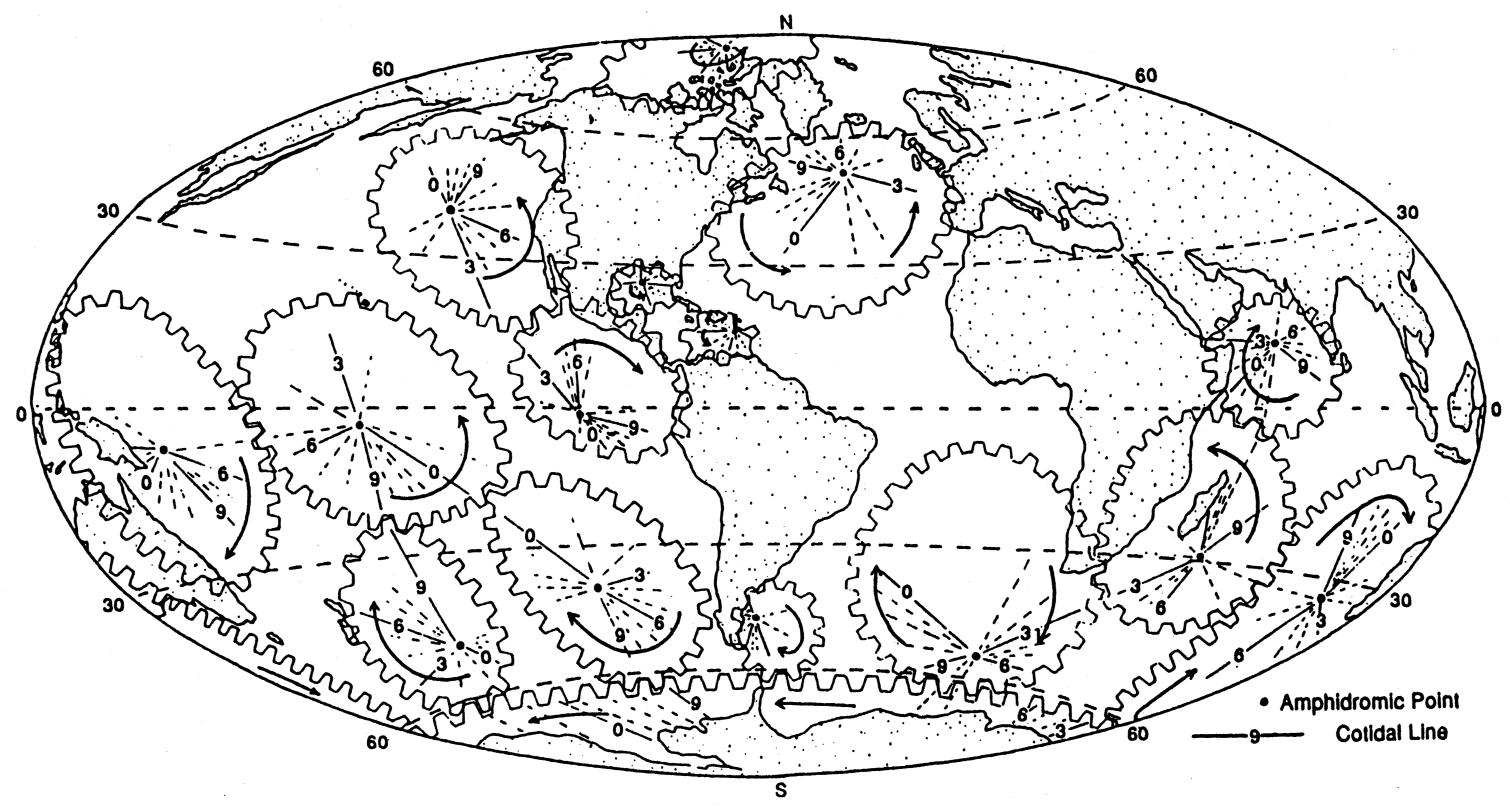

Fig. 9 In this illustration of amphidromic systems as gears, all amphidromic points are linked by co-tidal lines. All independent systems (e.g. south of $30^{\circ} \mathrm{S}$ ) rotate clockwise as predicted by the dynamical theory of tides and the Coriolis effect. After Railsback (1991), with permission.

When the declination of the Moon is at its maximum value of $28.96^{\circ}$, the Moon at its average distance from Earth will cause a maximum clockwise displacement of water particles around the poles of $438.5 \mathrm{~m}$. If there were no Coriolis effect (i.e. if Earth were not rotating) the radius of the circular movement would be $146.1 \mathrm{~m}$. The Coriolis effect thus tends to increase substantially the clockwise movements in the Northern Hemisphere, especially at points closer the North Pole. It has a much lesser effect on the anticlockwise movements that occur just north of the Equator. It is nil at the Equator, and maximum at the poles.
Note that although in the ocean basins anticlockwise motion of tide waves about amphidromic points occurs in the Northern Hemisphere, and vice versa in the Southern Hemisphere, several exceptions exist. The reason for these exceptions lies in the behaviour of the cotidal lines linking two amphidromic points. An example occurs in the southeastern Atlantic-western Indian Ocean system; here, as eloquently illustrated by Railsback (1991), amphidromic points linked by cotidal lines are likened to intermeshed gears (Fig. 9), and as such must necessarily rotate in opposite directions. This concept is particularly useful in explaining the anomalous sweep of the tides in low latitude systems. 


\section{Regional Tides}

\subsection{TERMS OF REFERENCE}

Defant (1958) described tides, colourfully, as "... the heartbeat of the ocean, a pulse that can be felt all over the world." More technically, "tide" is the periodic rise and fall of the ocean surface in response to gravitational forces of the Moon and Sun. The periodicity of the tides is imposed by astronomical cycles determined by the relative motions of the Earth, Moon, and Sun. The regularity of tidal movements makes accurate prediction possible, and sets tides apart from other changes in sea level and from irregular phenomena like earthquakes, storms, and volcanic eruptions. In practice, tides are a mixture of diurnal (daily) variations, with one low and one high tide each day, and semidiurnal (twice daily) variation with two low and two high tides each day. In relatively shallow coastal waters these motions are of course greatly magnified. The "range" of the tides generally refers to the vertical movement of the water surface between the Low Water and the High Water levels of the tide. This factor, and the regime or mixture of the two types of tides varies from one area to another and also over time at any given location.

In Canada, the tidal levels in use (Canadian Tide and Current Tables 2004) are:

MWL - Mean Water Level - average of all hourly water levels observed over the available period of record; in comparison, Mean Sea Level (MSL) is a statistically established entity.

HHWLT - Higher High Water, large tide - average of the highest high waters, one from each of 19 years of predictions.

HHWMT - Higher High Water, mean tide - average of all the higher high waters from 19 years of predictions.

LLWMT - Low Low Water, mean tide - average of all the lower low waters from 19 years of predictions.

LLWLT - Lower Low Water, large tide - average of lowest low waters, one from each of 19 years of predictions.

LNT - Lowest Normal Tide - in present usage it is synonymous with LLWLT, but on older charts it may refer to a variety of low water chart datums - it is also called Chart Datum(CD), a most important term of reference.

All tidal measurements are made from the local Chart Datum (CD), an elevation so low that the tide at that place will seldom if ever fall below it. Thus, soundings on hydrographic charts show mariners the minimum depth of water. The tidal range gives them an extra margin of safety. Generally the tidal range is small and so is the margin of safety. However, for the Bay of Fundy, on charts showing a number of tidal stations, the difference between Chart Datum and Mean Water Level in one section of the charted area may be quite different than it is in other sections. The soundings on such charts do not allow one to construct a proper three-dimensional picture of the shape of the Bay. On land, the datum used by geodesists, surveyors, and engineers is the Geodetic Survey of Canada Datum (GSCD, or GD). This datum is based on the value of mean sea level prior to 1910 as determined from a period of observations at tide stations at Halifax and Yarmouth, N.S., and Pointe au-Père, Quebec, on the east coast, and Prince Rupert, Vancouver, and Victoria, British Columbia, on the west coast. In 1922 the datum was adjusted in the Canadian levelling network. Because in most areas of the Maritime Provinces the landmass is submerging relative to mean sea level, geodetic datum drops gradually below mean sea level. However, there is a dearth of data, and no one is certain exactly what the difference is between GSCD and MWL at different stations. This situation is troublesome for engineers and biologists who need to know the proper relation between the two datums at particular places.

\subsection{OVERVIEW OF REGIONAL TIDES ALONG THE EASTERN CANADIAN SEABOARD}

Between the Atlantic Ocean and the eastern seaboard of the North American continent lies the continental shelf. In large measure a result of planation during the ongoing PleistoceneHolocene Ice Age, the continental shelf has depths of less than $250 \mathrm{~m}$. Near Cape Breton Island, it extends more than $200 \mathrm{~km}$ from the coast, although near the southern tip of Nova Scotia it narrows to $130 \mathrm{~km}$ (Fader et al. 1977). Farther south, along the coast of the United States, the shelf varies between 25 and $200 \mathrm{~km}$. Off the continental shelf the seabed drops to depths of $5000 \mathrm{~m}$ over a distance of about $200 \mathrm{~km}$. This $200 \mathrm{~km}$-wide margin is known as the continental slope. Along the outer edge of the shelf the average tide ranges between 80 and $100 \mathrm{~cm}$. After crossing the continental shelf, the tidal range along the shore of Nova Scotia is increased to between 120 and $140 \mathrm{~cm}$.

When the relative positions of the Earth, Moon, and Sun generate exceptionally large tides, the tidal range along the shoreline of Nova Scotia may reach as high as $200 \mathrm{~cm}$. This increase is $40-50 \%$ above average. Conversely, when the relative positions of the Earth, Moon, and Sun are such that tides are weakened, ranges drop by about $40 \%$ below the average. Variations in tidal strength of $60 \%$ to $140 \%$ are observed in the Gulf of Maine and the Bay of Fundy (Fairbridge 1966).

Between the Gulf of Maine and the Bay of Fundy, along the edge of the continental shelf off southwestern Nova Scotia and Cape Cod, Massachusetts, a series of shoals and banks acts as a sill obstructing tidal flow (see Fig. 3); in places the water is barely $4 \mathrm{~m}$ deep. Three channels cross this sill, of which the Northeast Channel is by far the largest between ocean and Gulf. Located between Georges Bank and Browns Bank, it is $230 \mathrm{~m}$ deep, $40 \mathrm{~km}$ wide, and $70 \mathrm{~km}$ long.

Tides on the ocean side of the Northeast Channel have an 
average range of $90 \mathrm{~cm}$, but $320 \mathrm{~km}$ eastward at Bar Harbor, Maine, they have a mean range of $310 \mathrm{~cm}$. High Water on this part of the coast is 3 hours later than along the edge of the continental shelf. The strength of tides in the southern bight of the Gulf of Maine, up to Race Point off Cape Cod, is rather uniform, varying between 210 and $310 \mathrm{~cm}$ for average tides; however between Bar Harbor and Jonesport $50 \mathrm{~km}$ to the east, their strength steadily increases toward the upper reaches of the Bay of Fundy. The average tidal range at the entrances to Minas Basin, Cumberland Basin, and Shepody Bay, each about 320 $\mathrm{km}$ from Bar Harbor, is $960 \mathrm{~cm}$. However, in the Minas Basin the tides are 100 minutes later than at Bar Harbor. Tidal ranges are greatest in the estuaries of the Salmon and Shubenacadie rivers in the Minas Basin, $400 \mathrm{~km}$ from Bar Harbor. Depending upon astronomical conditions, this average range increases to $1360 \mathrm{~cm}$. To the dismay of many inhabitants along this coast, even this enormous tidal range may be greatly extended by storm conditions.

\subsection{GRAPHICAL SYNTHESIS OF REGIONAL TIDES}

Figure 10 (see separate pull-out) shows the tidal ranges along the eastern Canadian seaboard during mean and large tides. At most places the tide reaches a maximum level on an average interval of 12.4 hours. Usually one of the two daily High Waters is higher than the other and is called the Higher High Water. Similarly, a Lower High Water and a Lower Low Water occur during a day-long tidal cycle. The distance that the tide moves up or down from the Mean Water Level is called the amplitude of the tide, and the total vertical distance between High Water and Low Water is the tidal range. The range given in the Canadian tide tables for a given locality is specifically for the distance between Higher High Water and Lower Low Water. This gives a somewhat larger value than ranges listed in American tide tables, which are calculated from the mean of the semidiurnal tides.

The center line of the band representing the tidal ranges (Fig. 10) depicts the local Mean Water Level; the pair of lines closest to this center line delineates the range during average tidal fluctuations in the area, and the outer pair delineates the fluctuation during large tides. Large tides occur when the main tide-producing astronomical forces are at maximum strength and working more or less in unison. The rise in feet of the Higher High Water above Mean Water Level during large and mean tides, and the fall of the Lower Low Waters below that datum, are shown on the chart beside the inserts which indicate the tidal characteristics near the principal tidal stations in the region.

Along the eastern Canadian seaboard the tidal ranges are rather uniform at 4 to 5 feet $(1.22-1.52 \mathrm{~m})$. The smallest tidal ranges in the charted area are recorded on the west coast of the Magdalen Islands and in the western Northumberland Strait, with mean ranges of 1.5 and 2.0 feet $(0.45 \mathrm{~m}$ and $0.61 \mathrm{~m})$. However in embayments such as the Bay of Fundy, the Bay of Chaleur, the channel leading to the St Lawrence River estuary, and the eastern and central parts of the Northumberland Strait, tidal ranges gradually increase at points more distant from ocean tides (White and Johns 1977).

Tidal characteristics near the principal, or reference, ports (e.g., Halifax, North Sydney) are included as marigrams in Fig. 10. The examples show the predicted tidal movements for March, 1966, a date chosen arbitrarily, the particular astronomical conditions for which are given with the sample set in the legend (inset at lower left of Fig. 10). The marigrams for this month are typical of any monthly period except that the sinusoidal diurnal and semidiurnal variations are offset according to astronomical conditions. In order to accentuate these characteristics, different vertical scales are employed. For this reason the local tidal amplitudes of Higher High and Lower Low Water during large and average tides are printed to the left of the inserts (see "Typical Tidal Variations over one Month"). Note that ranges are largest shortly after full moon and new moon during spring tides. When the Moon shows its quarter phases, the amplitudes are small and the tides are neap. The influence of the distance of the Moon from the Earth is such that when the Moon is in perigee (closest to Earth), spring tides are higher than when the Moon is in apogee (farthest from Earth). The diurnal inequality between high waters and low waters is nil when the Moon moves through the plane of Earth's equator, and as seen from Earth, reaches its peak when the Moon is in its most northerly or southerly position in the sky.

Local tidal characteristics along the eastern Canadian seaboard result from a combination of diurnal tides and semidiurnal tides. The diurnal tide repeats itself every 24.8 hours, and the semidiurnal tide every 12.4 hours (see insert, lower left hand side of Fig. 10). At most locations the semidiurnal tide is dominant. An exception is in the southern Gulf of St. Lawrence where, under certain astronomical conditions, only one High Water and one Low Water occur daily; here semidiurnal tides may have less than half the range of the diurnal component. Diurnal tides dominate along the north coast of Prince Edward Island, the west coast of the Magdalen Islands, and in the western portion of the Northumberland Strait.

Tidal characteristics also depend on the phase relationship between the diurnal and semidiurnal components. This manifests itself prominently in the Gulf of St. Lawrence where the strengths of both components are similar. Here there is less variation than in the Fundy tides, and there is no annual progression of 1.5 months in the highest tides. Tides in the Gulf of St. Lawrence tended to be higher in 1969 and 1973 (Fig.11), years of relatively low tides in the Bay of Fundy (Canadian Hydrographic Service 1964, 1969a, 1969b, 1973, 1979, 1981).

Several other interesting contrasts exist among regional tides. In the Gulf of St Lawrence, when the High Water of a diurnal tide coincides with one of the two High Waters of the semidiurnal tide, the Higher High Water of the day is higher than the Lower High Water, assuming that the semidiurnal tide dominates at the location. This situation is because the other semidiurnal peak will coincide with the diurnal Low Water. 


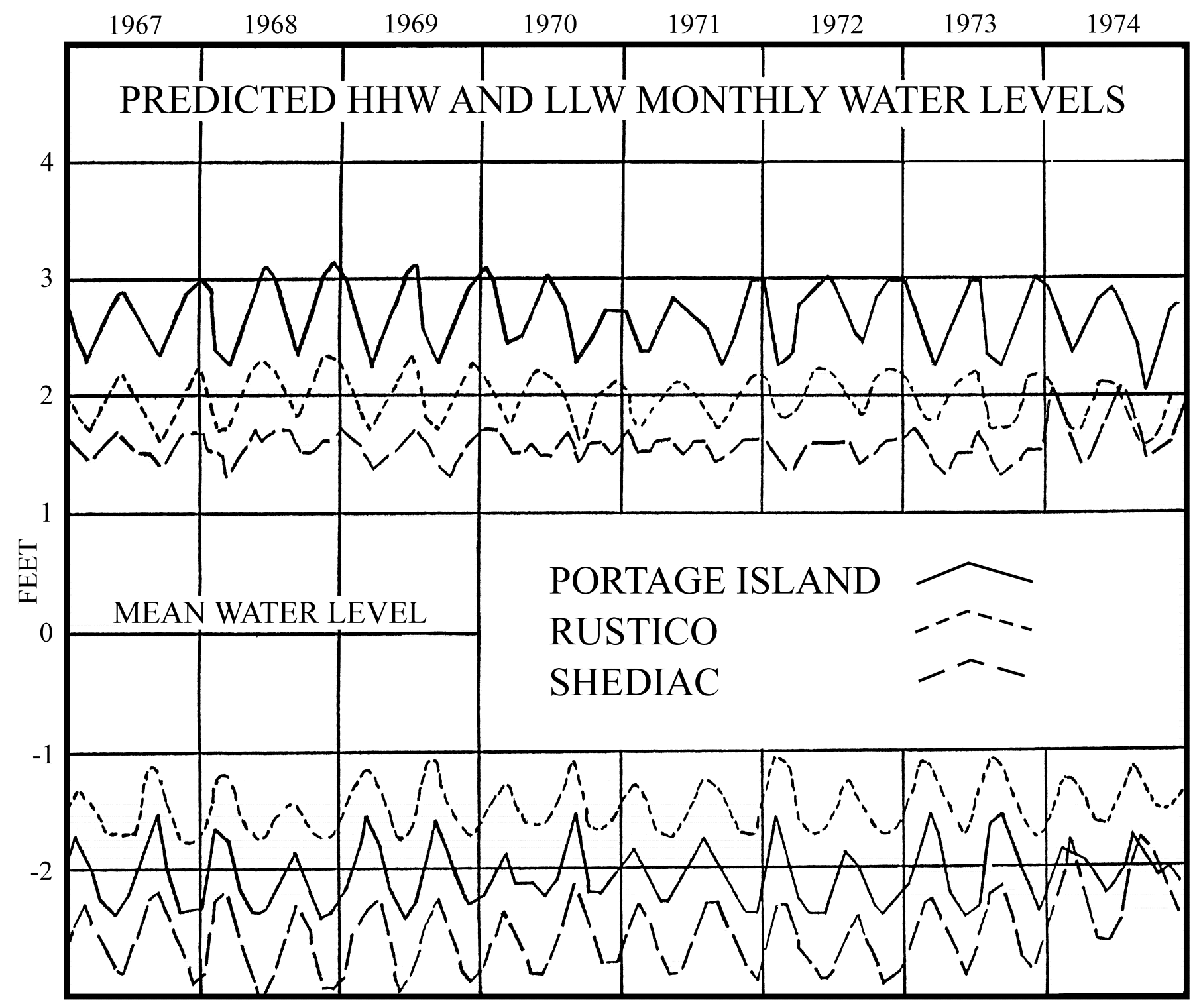

Fig. 11 Predicted maximum (Highest High Water) and minimum (Lowest Low Water) monthly water levels for The Gulf of St. Lawrence ports of Portage Island, Shediac Bay, New Brunswick, and Rustico, Prince Edward Island, over an arbitrarily chosen 8 year interval. Note that the HHW and the LLW occurred near the winter and summer solstices.

Under these conditions the semidiurnal Low Waters will occur when the diurnal tide is near Mean Water Level and both will drop to almost the same level. This combination occurs in the western section of the Gulf of St. Lawrence (Fig. 10) where the High Waters at Rustico, P.E.I., Portage Island, N.B., and Pointe St. Pierre, Quebec, are usually unequal, in contrast to the almost equal Low Waters. (In Fig. 10 this is shown on the inserts indicating tidal characteristics near certain ports.) Note too, in Fig. 11, that the highest tides in the Gulf of St. Lawrence occur at mid-year and at year end, contradicting the age-old notion that equinoctial tides (March and September) will be the larger tides. Conditions similar to those of the Gulf of St. Lawrence prevail along the east coast of Newfoundland near St. John's and Argentia. The opposite conditions prevail in the Northumberland Strait where one of the semidiurnal Low
Waters nearly coincides with the diurnal Low Water resulting in generally unequal Low Waters and almost equal High Waters (e.g., at Charlottetown, P.E.I., Pictou, N.S., and Shediac, N.B.). As shown in Fig. 12, for Halifax, North Sydney, and Charlottetown, the winter tides are predicted to be higher than summer tides. Note, too, that the Low Waters of Charlottetown extend much further below MSL than the High Waters reach above this level. This is because of the diurnal inequality of the tides, which causes High Water to be nearly the same each day and Low Water level to vary.

As a result of the Coriolis effect, in large bodies of water such as the North Atlantic Ocean and the Gulf of St. Lawrence, the tides and especially the semidiurnal tides circulate along the surrounding coastlines in an anti-clockwise progression forming an amphidromic system. At and near the system's central 


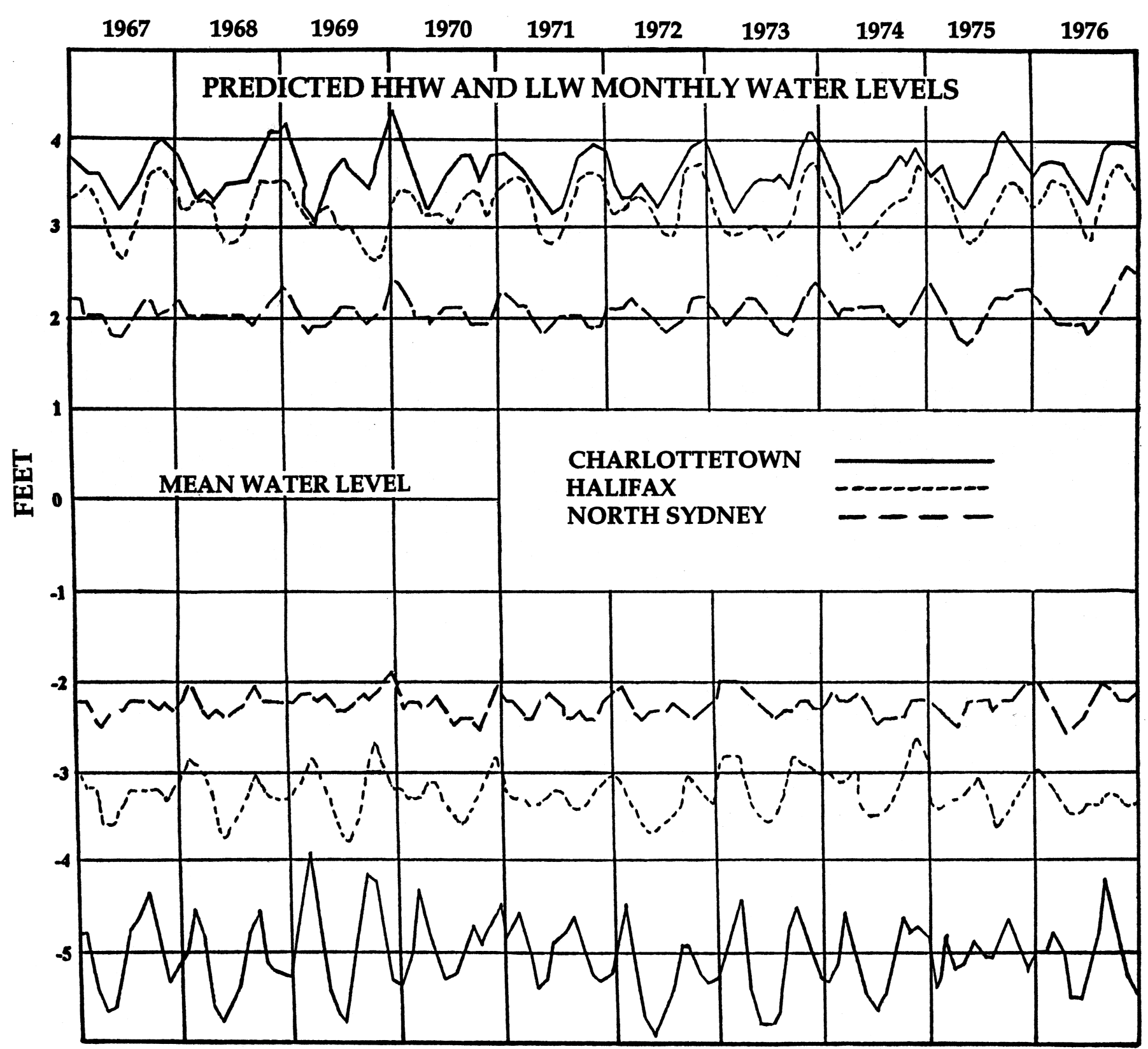

Fig. 12 Predicted maximum (HHW) and minimum (LLW) monthly water levels for the Atlantic Ocean ports of Halifax and North Sydney, N.S., and Charlottetown, Prince Edward Island, over an arbitrarily chosen 10 year interval. Note that in all years the HHW occur near the winter solstice, and the LLW near the summer solstice.

point the tidal range is nil. The location of the amphidromic system in the Gulf of St. Lawrence is shown in Fig. 10. Farther removed from the central point the tidal range gradually increases. Illustrating this progression the chart shows (in lunar hours, 1 to 12) the approximate positions of High Water of the semidiurnal component of the tide in this system. This semidiurnal system splits at the western side of the Northumberland Strait, one wave going directly into the Strait and the other traveling around Prince Edward Island and moving partly into the eastern entrance of the Strait; as it moves westward to Shediac Bay (see Fig. 10), it meets the wave trough of the one entering the west entrance. The result is that the semidiurnal tide is scarcely noticeable in this area, and so the diurnal tide becomes dominant. Only when the Moon is near the Equator will semidiurnal tides be observed.

Tides in the Gulf of St. Lawrence are generated and maintained by tidal movements in the Atlantic Ocean. The two systems appear to be synchronized, with simultaneous High Waters and simultaneous Low Waters at their meeting place in the Cabot Strait. Thus, the diurnal tide in the Gulf maintains a see-saw relationship with that of the Atlantic Ocean, being high in the Gulf when it is low in the ocean. The Coriolis ef- 
fect causes the diurnal tides to peak in the northeastern part of the Gulf before they reach their maximum level along the southwestern coastline.

\subsection{ADDITIONAL CONSIDERATIONS}

During spring and summer in the Bay of Fundy and in the Northumberland Strait, the Lower Low Water occurs during the daytime (and HLW at night!) so that the tidal flats absorb considerable heat from the Sun. As the tide rises over the warm tidal flats, the water temperature rises, especially in the Northumberland Strait where the water cover is comparatively thin.

During the same seasons, in the western section of the Gulf of St. Lawrence the Lower High Water occurs during the daytime, covering to a limited depth the Sun-heated beaches and shoals with almost the same temperature-raising effects as occur along the Northumberland Strait. This has ecological implications. For example, both sections of the Gulf have a mollusc fauna similar to that found near Virginia along the eastern U.S. seaboard. The species involved need a water temperature above $68^{\circ} \mathrm{F}\left(20^{\circ} \mathrm{C}\right)$ to spawn. Yet, even during the warmest months of the year the mean air temperature in the Gulf is less than this value. Tidal characteristics of the area are therefore probably important factors in the propagation of these species in this part of the Gulf.

Conditions are reversed during fall and winter, exposing tidal flats to heat loss at Lower Low Water during the night. This results in the following Lower High Water being cooled well below normal sea water temperature as it flows over these frigid flats, circumstances that probably aggravate ice conditions.

A tidal wave with a period of about 12.4 hours appears in the Atlantic Ocean in front of the Gulf of Maine, causing a wave to enter through the Northeast Channel. The wave propagates over the Gulf, reaching the shore about three hours later. As this progressive wave moves along the mouth of the Bay of Fundy, a standing wave is formed, and energy becomes concentrated toward the head of the Bay as its cross-sectional area is gradually reduced.

A standing wave can form in a basin in which the water moves periodically from one side to the other, high water at one side corresponding to low water on the other. The strength of the tide is strongest at the ends of the basin. Although in the center of the basin the water surface does not move up and down, strong currents are present because a large volume of water must move to and fro in order to create the High Water alternately at both ends.

The funnel-shaped Bay of Fundy branches at its northeast end into the Minas Basin and Chignecto Bay. The dimensions of the Bay of Fundy are such that its natural period of oscillation closely approximates that of the semidiurnal tidal component, thus greatly increasing resonance. There are fascinating variations on this theme. For example, as detailed in section 1.4.3 (on applications to tides and water currents), due to the Coriolis effect the entering tidal stream is deflected toward the southern shore of the Bay and the retreating stream to the north.

On average, the up and down sweep of the tide solely due to the Coriolis effect is larger on the Nova Scotia side for the incoming tide than for the outgoing tide on the corresponding opposite New Brunswick shore (see Fig. 13). Thus, when the water reaches its highest level (A), the tide is still coming in, filling the upper reaches of the Bay, and the water maintains a lateral slope $A B$ (Fig. 13a). At the turn of the tide, it is level (BC), although the level on the Nova Scotia side will have already dropped (A to C). Note that, like the sweep of the tidal level due to the Coriolis effect, the range of the incoming tide in any Fundy cross-section is higher perpendicular to the axis of the Bay on the Nova Scotia side. Likewise, tidal flow entering the Gulf of Maine, results in a higher tidal range on the Nova Scotia side. The same argument applies to any cross-section as the tide ebbs (Fig. 13b). Approaching the turn of the tide, the water continues flowing seaward for some time, just as it still has kinetic energy which allows it to flow upward to higher level (D) on the New Brunswick side than on the Nova Scotia side (F). At the turn of the tide, it is level (DE).

Thus, the south shore experiences a greater tidal range than does the north shore, as well as a counter-clockwise system of residual tidal currents (see Fig. 13). Turbulent current in the narrow strait between Minas Channel and the Minas Basin can exceed 11 knots.

In the upper reaches of the Bay of Fundy, the standing wave fills the estuaries. However, the rate of rise of tide is so rapid that large flows of water into the mouths of the estuaries would be required if the water surface in the estuaries were to rise at the same rate as in the Bay. Because the estuarine cross-sections are relatively small, particularly at low tide, such large flows of water are not able to enter. Therefore, filling of the estuaries is delayed. Physical restrictions on flow velocities are much more severe in shallow water than in deep water. The result is that water flowing in the more shallow parts is overtaken in time by water which, although entering the estuary later, moves faster in the deeper water. Thus, on the gently sloping bottom of the estuary a tidal bore commonly develops, most impressively so when the tide has its largest amplitude.

Theoretically, in basins where a standing wave occurs, hardly any currents are at the end where the tides are strongest. However, if there are shallow estuaries to be filled, strong tidal currents will develop in a relatively short time. These currents are the main agents of transportation and deposition of sedimentary materials in the Bay.

High Water occurs progressively later further up the estuaries. This High Water can happen quite a distance up the estuary, and considerably later than the time of High Water at the mouth. The time differential depends in turn on the gradient of the estuary bottom within the tidal range. As we shall see (section 9.5), these two factors are intimately linked to the evolution of the tidal marshes within estuaries in the Bay of Fundy. 


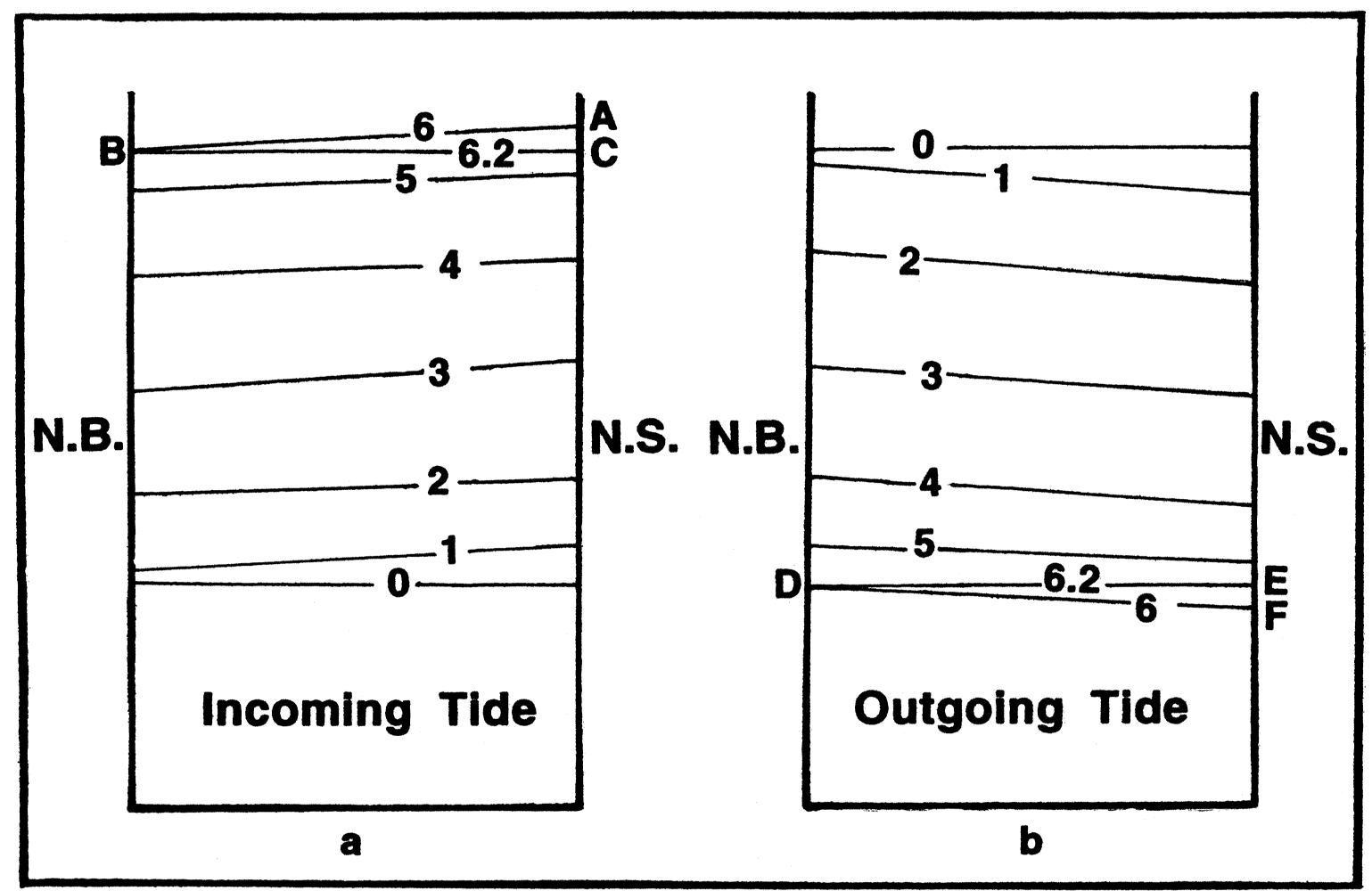

Fig. 13 Diagrams show, respectively for ebb and flow, the tidal levels across the Bay of Fundy from Nova Scotia to New Brunswick. The greatest slope in each instance occurs at mid-tide. Tidal range on the Nova Scotia shore is greater than on the New Brunswick shore in any cross-section perpendicular to the axis of the bay. Given is a 24.8 hour lunar day, with each semidiurnal tide being 6.2 hours long. See text for details.

\subsection{A SUCCESSION OF STANDING AND PROGRESSIVE WAVES}

A profound difference exists between the tidal regime of the Gulf of St. Lawrence and that of the Bay of Fundy. This much is evident in the frequencies and occurrence of monthly maximum and minimum tidal water levels. Predicted tide water levels over typical 8-and 10-year intervals are shown for three ports in, respectively, the Gulf of St. Lawrence (Fig. 11) and the Atlantic coast (Fig. 12). Note that in all years the highest High Waters for Charlottetown, Halifax, and North Sydney (i.e., the Atlantic coast) were predicted around the winter solstice (Fig. 12), whereas the lowest Low Waters occurred near the summer solstice. However, for the three ports in the Gulf of St. Lawrence (Fig. 11), the highest High Waters and the lowest Low Waters occurred near the solstices, but with no noticeable difference between those near the winter solstice and those near the summer one. The smallest ranges of the tides were predicted to occur near the equinoxes.

The above relationships clearly demonstrate that the tidal regime along the Atlantic coast is different from that in the
Gulf of St. Lawrence. Both are unlike the one in the Bay of Fundy. While in most waters, the largest tides occur in the same part of the year, in the Bay of Fundy they are more influenced by the shifting coincidence of spring and perigean tides with the result that each year they occur about 47 days later than in the previous year. Overall, regional tides along the eastern Canadian seaboard are best described as a succession of standing and progressive waves. The standing waves occur in the Atlantic Ocean, the Gulf of St. Lawrence, and the main body of the Bay of Fundy, whereas the progressive waves occur in the Gulf of Maine, the upper reaches of the Bay of Fundy, and in the estuaries leading into the Gulf and Bay. Progressive waves, unless supplied by external sources of energy such as air currents, do not grow in strength, for they lose energy when moving through confining channels. Likewise, progressive waves entering a restricted harbour mouth lose strength when they expand over the wider harbour surface. However, as we shall see, the wave entering the Gulf of Maine through the Northeast Channel seems to gain in strength while spreading over the Gulf. In fact it becomes 3.5 times stronger on reaching the shoreline. 


\section{Tides of the North Atlantic}

\subsection{WATER PARTICLE MOVEMENTS}

According to Pliny the Elder, writing in his Historia naturalis: “... tides swell more during the equinoxes, more during the autumn than in the spring, but... were empty at midwinter and even more so at midsummer". Unknown to Pliny, the tides are much complicated by the shape of the oceanic basins. The example of conditions prevailing in the North Atlantic on 5 September, 1975, with the new moon in perigee (and rather small declinations of the Sun, $6.5^{\circ}$, and Moon, $5.8^{\circ}$ ) serves very well to illustrate (Clancy 1969). With the Moon closest to Earth on its monthly orbit, higher than normal tides can be expected. The theoretical movements of individual particles in the ocean on this date (for details see Desplanque and Mossman 1998a) are rather small, clockwise, and predominantly diurnal. Nevertheless, the tides on that day were large. Table 4 provides the times and heights of the tides as they were predicted to be at sixteen ports along the eastern seaboard of the North American continent.

Do movements of the North Atlantic ocean follow water particle movements generated locally, or are they a result of an oscillating motion of the ocean with a period of 12.4 hours? First let us compare the times of High Water with the location of water particles in their cycle near $45^{\circ} \mathrm{N}$ latitude.
Table 4 shows that the highest tides on the western side of the Atlantic reach the highest levels of the day between 18:45 and 20:49 AST (moving from north to south, as indicated by the theoretical particle movements calculated for that day). The smaller high tides for that day occurred between 6:30 and 8:30 AST.

Semidiurnal tides are predominant in the Atlantic Ocean, the diurnal component being small (Fairbridge 1966). On the eastern side of the Atlantic (Table 5), the diurnal inequality of the tide is small. The High Waters from Morocco to France (about $15^{\circ} \mathrm{N}$ and $45^{\circ} \mathrm{N}$ latitude respectively) occur between 9:40 and 11:35 AST (13:40-15:35 GMT) and 22:00 and 24:50 AST (2:00-4:00 GMT), the tidal wave moving from south to north (Schwiderski 1980). These times coincide closely with those for the easternmost locations of water particles (Desplanque and Mossman 1998a).

Given the Atlantic Ocean's $5000 \mathrm{~km}$ width and $5000 \mathrm{~m}$ depth, a scale model of this ocean as an oscillating basin would be approximately $1 \mathrm{~m}$ square and $1 \mathrm{~mm}$ deep. As it turns out, such a model is unrealistic (see Kwong et al. 1997) although it clearly illustrates the shallowness of the ocean. For example, if the ocean is oscillating, then when the water is high at one side of the ocean it should be low at the other side. So, if it is high between 9:40 and 11:40 AST (Table 5) at the eastern side

Table 4. Tides predicted for 5 September, 1975, along the eastern seaboard of North America

\begin{tabular}{|c|c|c|c|c|c|c|c|c|}
\hline & \multicolumn{2}{|c|}{ Low Water } & \multicolumn{2}{|c|}{ High Water } & \multicolumn{2}{|c|}{ Low Water } & \multicolumn{2}{|c|}{ High Water } \\
\hline & AST & $\mathrm{m}+\mathrm{CD}$ & AST & $\mathrm{m}+\mathrm{CD}$ & AST & $\mathrm{m}+\mathrm{CD}$ & AST & $\mathrm{m}+\mathrm{CD}$ \\
\hline St. John's, NF & 0020 & 0.24 & 0630 & 1.07 & 1225 & 0.15 & 1845 & 1.37 \\
\hline Argentia, NF & 0045 & 0.36 & 0700 & 2.29 & 1255 & 0.27 & 1920 & 2.56 \\
\hline Point Tupper, NS & 0100 & 0.43 & 0650 & 2.26 & 1335 & 0.46 & 1915 & 2.19 \\
\hline Halifax, NS & 0110 & 0.21 & 0705 & 2.10 & 1330 & 0.34 & 1920 & 2.16 \\
\hline Yarmouth, NS & 0315 & 0.09 & 0935 & 4.51 & 1540 & 0.18 & 2205 & 4.79 \\
\hline Saint John, NB & 0430 & 0.18 & 1040 & 8.14 & 1700 & 0.24 & 2300 & 8.50 \\
\hline Eastport, Ma. & 0447 & -0.73 & 1053 & 6.22 & 1711 & -0.76 & 2315 & 6.49 \\
\hline Portland, Ma. & 0450 & -0.40 & 1102 & 3.08 & 1711 & -0.37 & 2325 & 3.29 \\
\hline Boston, Mass. & 0507 & -0.46 & 1117 & 2.87 & 1726 & -0.43 & 2339 & 3.51 \\
\hline Newport, R.I. & 0112 & -0.21 & 0746 & 1.40 & 1336 & -0.24 & 2011 & 1.43 \\
\hline New York, N.Y. & 0226 & -0.18 & 0830 & 1.68 & 1448 & -0.18 & 2049 & 1.80 \\
\hline Sandy Hook, N.J. & 0152 & -0.21 & 0758 & 1.74 & 1409 & -0.21 & 2016 & 1.83 \\
\hline Charleston, S.C. & 0156 & -0.15 & 0808 & 1.89 & 1417 & -0.24 & 2018 & 2.01 \\
\hline Savannah Harb., Ga. & 0205 & -0.21 & 0812 & 2.53 & 1429 & -0.30 & 2033 & 2.71 \\
\hline Mayport, Fla. & 0204 & -0.06 & 0825 & 1.88 & 1425 & -0.18 & 2051 & 1.77 \\
\hline Miami Harb., Fla. & 0203 & -0.09 & 0815 & 1.01 & 1429 & -0.09 & 2041 & 1.01 \\
\hline
\end{tabular}

Notes. Times are given in Atlantic Standard Time (AST) $(z+4)$. All heights are measured in metres above the Chart Datum at each port. Tides in the Gulf of Maine, e.g., Yarmouth to Boston, are secondary movements caused by the Atlantic tide, and they occur about three hours later than the Atlantic tide. Data from U.S. Department of Commerce $(1953,1975)$ 
one should expect it to be low at the same time on the western side. However, according to Table 4, low tide occurs in the west between 12:25 and 14:29. It appears, therefore, that ocean tides are more in tune with water particle movements than with an oscillating system.

\subsection{TIDAL CONSTITUENTS AND HARMONIC ANALYSIS}

Except for the Gulf of Maine and the Bay of Fundy, the ranges of tides on the eastern side of the Atlantic Ocean are substantially greater than those along the North American coast (Apel 1987). Harmonic analysis, the principle first applied to tidal problems by Lord Kelvin(1824-1907), is the most satisfactory method of comparing characteristics of tides observed at various locations (Schureman 1941, 1949; Fairbridge 1966). This method relies on the fact that the observed tide is the result of several astronomically driven partial tides. Just as complicated sea waves can be reconstructed by combining several wave trains, so also can tides be calculated by combining partial tides, or tidal constituents. For most ports bordering the North Atlantic Ocean (Desplanque and Mossman 1998a), the $\mathrm{M}_{2}$ constituent is dominant (see Table 3; Fig. 14).

Since 1977, tidal records have been collected along the edge of the continental shelf off North America, and more recently at several stations in the mid-Atlantic between Newfoundland and Portugal. Tables 6 and 7 show the results of analyses of these data together with data from shore stations. The ranges of the major constituents at these stations are given and the strength of other constituents is compared with $\mathrm{M}_{2}$. This can be used to determine if the local $\mathrm{S}_{2}$ tide is close to its theoretical strength of $46 \%$ of the $\mathrm{M}_{2}$ strength.

The value of the initial phase $\mathrm{p}$ (known as the phase lag and representing the phase of the constituent at the time of origin) is given as the epoch (Table 6), based on the local meridian of the observation station, and the $65^{\circ} 30^{\prime} \mathrm{W}$ meridian. The use of the latter as a time meridian is prompted by the fact that this meridian crosses the main entrance of the Gulf of Maine and also the entrance of the Bay of Fundy. Note in Table 6 that the percentage of $S_{2} / M_{2}$ is close to the theoretical value of $46 \%$ near Newfoundland, but slightly less in the eastern North Atlantic. The relative strength of the $\mathrm{N}_{2}$ constituents remains close to $22 \%$, while the already weak diurnal $\mathrm{K}_{1}$ and $\mathrm{O}_{1}$ constituents are even weaker in mid-ocean. One might expect that the tidal wave would follow the apparent westerly movements of agents that account for the existence of the various constituents. However the phase lags indicate that the co-tidal lines move from west to east, in the opposite direction of the imaginary heavenly bodies.

Table 7 shows the same type of data for ports along the eastern seaboard of North America, with additional data from some stations offshore. Indications are that the time of High Water is virtually the same for all stations over a distance of $2200 \mathrm{~km}$ between Banquereau Bank, south of the Cabot Strait, and Charleston, South Carolina. The strength of the Sun's influence is much less than the theoretical $46 \%$ of the Moon's influence, dropping from $24 \%$ at the Banquereau Bank to $17 \%$ at Charleston. Again there is little change in the relative strength of the $\mathrm{N}_{2}$ constituent. Thus, variations in the tidal strength caused by the variable distance between Earth and Moon gain in significance over variations in the influence of the Sun's gravitation. Stated otherwise, the perigean tides become more important than the spring tides.

The influence of the Sun is far more noticeable along the coast of Newfoundland and Labrador. The percentage of $\mathrm{S}_{2}$ with respect to $\mathrm{M}_{2}$ ranges from $36 \%$ on the south coast of the Avalon Peninsula, north of the Cabot Strait, to 68\% near Fogo Island at the northeast corner of Newfoundland. It drops again to $50 \%$ near the northern tip of the island, and to $36 \%$ along the Labrador coast. Evidently tides near Newfoundland have characteristics in common with those in the mid and eastern North Atlantic whereas tides south of the Cabot Strait have a different pattern.

Table 5. Tides predicted for 5 September, 1975, along the west coast of North Africa and Europe

\begin{tabular}{lcccccccc}
\hline & \multicolumn{2}{c}{ Low Water } & \multicolumn{2}{c}{ High Water } & \multicolumn{2}{c}{ Low Water } & \multicolumn{2}{c}{ High Water } \\
& AST & $\mathrm{m}+\mathrm{CD}$ & AST & $\mathrm{m}+\mathrm{CD}$ & AST & m+CD & AST & m+CD \\
\hline Dakar, Senegal & 2156 & 0.55 & 0416 & 1.74 & 1031 & 0.34 & 1641 & 1.74 \\
Casablanca, Moroc. & 0322 & 0.64 & 0939 & 3.90 & 1551 & 0.49 & 2204 & 3.81 \\
Gibraltar & 0311 & 0.03 & 0948 & 1.11 & 1533 & 0.03 & 2205 & 1.10 \\
Lisbon, Portugal & 0405 & 0.37 & 1045 & 4.18 & 1633 & 0.21 & 2310 & 4.05 \\
Point de Grave, Fr. & 0432 & 1.16 & 1056 & 5.24 & 1657 & 0.94 & 2400 & 5.60 \\
Brest, France & 0532 & 1.16 & 1135 & 7.80 & 1754 & 0.85 & 2357 & 7.80 \\
Queenstown, Eire & 0733 & -0.12 & 1259 & 3.84 & 1928 & -0.18 & 2518 & 3.90 \\
Reykjavik, Iceland & 0752 & 0.00 & 1358 & 4.24 & 2017 & -0.12 & 2625 & 4.05 \\
\hline
\end{tabular}

Notes. Times are given in Atlantic Standard Time $(z+4)$. All heights are measured in metres from the Chart Datum at each port. Data from U.S. Department of Commerce (1975.) 


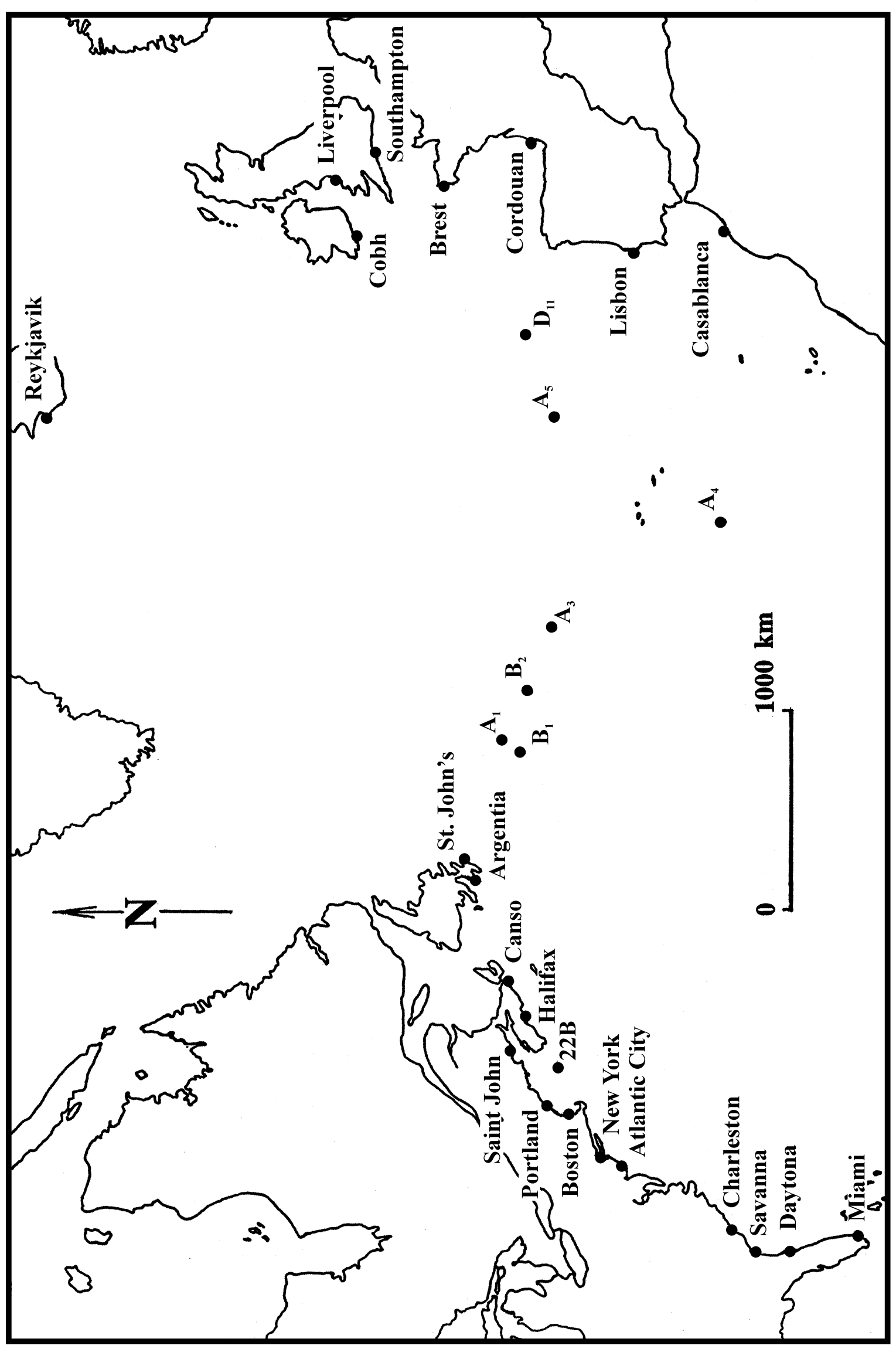


Table 6. Characteristics of the tides, measured at mid-Atlantic stations between St. John's Newfoundland, and Lisbon,

\begin{tabular}{|c|c|c|c|c|c|c|}
\hline $\begin{array}{l}\text { Station } \\
\text { Constituent }\end{array}$ & & $\mathrm{M}_{2}$ & $\mathrm{~N}_{2}$ & $\mathrm{~S}_{2}$ & $\mathrm{~K}_{1}$ & $\mathrm{O}_{1}$ \\
\hline \multicolumn{7}{|l|}{ St. John's } \\
\hline $1 .=46^{\circ} 34^{\prime}$ & $5 .=$ & 70 & 14 & 29 & 16 & 14 \\
\hline $2 .=52^{\circ} 42^{\prime}$ & $6 .=$ & 100 & 20 & 41 & 23 & 20 \\
\hline $3 .=$ & 7.= & 210 & 192 & 254 & 107 & 74 \\
\hline 4. $=$ & $8 .=$ & -5.98 & -6.63 & -4.46 & 6.19 & 4.63 \\
\hline \multicolumn{7}{|l|}{$\mathrm{A}_{1}$} \\
\hline $1 .=46^{\circ} 04^{\prime}$ & $5 .=$ & 30 & 6 & 14 & 12 & 8 \\
\hline $2 .=46^{\circ} 34^{\prime}$ & $6 .=$ & 100 & 21 & 46 & 41 & 27 \\
\hline $3 .=495$ & 7.= & 238 & 238 & 284 & 111 & 90 \\
\hline $4 .=515$ & $8 .=$ & -5.42 & -5.48 & -3.85 & 6.04 & 5.39 \\
\hline \multicolumn{7}{|l|}{$\mathrm{B}_{1}$} \\
\hline $1 .=45^{\circ} 59^{\prime}$ & $5 .=$ & 29 & 6 & 13 & 13 & 8 \\
\hline $2 .=46^{\circ} 27^{\prime}$ & $6 .=$ & 100 & 21 & 46 & 44 & 25 \\
\hline $3 .=507$ & 7.= & 249 & 239 & 285 & 110 & 90 \\
\hline $4 .=667$ & $8 .=$ & -5.05 & -5.42 & -3.82 & 5.94 & 5.35 \\
\hline \multicolumn{7}{|l|}{$\mathrm{B}_{2}$} \\
\hline $1 .=44^{\circ} 29^{\prime}$ & $5 .=$ & 30 & 7 & 13 & 10 & 4 \\
\hline $2 .=40^{\circ} 27^{\prime}$ & $6 .=$ & 100 & 23 & 44 & 34 & 14 \\
\hline $3 .=1001$ & $7 .=$ & 310 & 298 & 325 & 100 & 83 \\
\hline $4 .=2380$ & $8 .=$ & -3.36 & -3.76 & -2.9 & 4.88 & 4.43 \\
\hline \multicolumn{7}{|l|}{$\mathrm{A}_{3}$} \\
\hline $1 .=43^{\circ} 06^{\prime}$ & $5 .=$ & 49 & 11 & 18 & 9 & 2 \\
\hline $2 .=35^{\circ} 11^{\prime}$ & $6 .=$ & 100 & 23 & 36 & 18 & 4 \\
\hline $3 .=1451$ & $7 .=$ & 347 & 333 & 1 & 86 & 23 \\
\hline 4. $=3460$ & $8 .=$ & -2.47 & -2.92 & -2.06 & 3.64 & -0.23 \\
\hline \multicolumn{7}{|l|}{$\mathrm{A}_{4}$} \\
\hline $1 .=34^{\circ} 13^{\prime}$ & $5 .=$ & 79 & 17 & 32 & 7 & 5 \\
\hline $2 .=28^{\circ} 55^{\prime}$ & $6 .=$ & 100 & 21 & 40 & 10 & 6 \\
\hline $3 .=2473$ & 7.= & 348 & 337 & 4 & 44 & 271 \\
\hline 4. $=3525$ & $8=$ & -2.86 & -3.22 & -2.37 & 0.39 & -8.75 \\
\hline \multicolumn{7}{|l|}{$\mathrm{A}_{5}$} \\
\hline $1 .=43^{\circ} 02^{\prime}$ & $5 .=$ & 127 & 28 & 42 & 12 & 7 \\
\hline $2 .=21^{\circ} 52^{\prime}$ & $6 .=$ & 100 & 22 & 33 & 9 & 5 \\
\hline $3 .=2446$ & 7.= & 41 & 24 & 65 & 69 & 314 \\
\hline 4. $=2480$ & $8 .=$ & -1.52 & -2.05 & -0.82 & 1.59 & -6.12 \\
\hline \multicolumn{7}{|l|}{$\mathrm{D}_{11}$} \\
\hline $1 .=45^{\circ} 01^{\prime}$ & $5 .=$ & 175 & 37 & 59 & 14 & 11 \\
\hline $2 .=21^{\circ} 52^{\prime}$ & $6 .=$ & 100 & 21 & 33 & 8 & 6 \\
\hline $3 .=2850$ & 7.= & 66 & 44 & 90 & 74 & 320 \\
\hline $4 .=2830$ & $8 .=$ & -1.22 & -1.8 & -0.39 & 1.52 & -6.21 \\
\hline \multicolumn{7}{|l|}{ Lisbon } \\
\hline $1 .=38^{\circ} 41^{\prime}$ & $5 .=$ & 233 & 60 & 91 & 25 & 12 \\
\hline $2 .=9^{\circ} 06^{\prime}$ & $6 .=$ & 100 & 25 & 39 & 10 & 5 \\
\hline $3 .=3621$ & $7 .=$ & 59 & 41 & 83 & 39 & 309 \\
\hline 4.= & $8 .=$ & -1.77 & -2.35 & -1.06 & -1.24 & -7.44 \\
\hline
\end{tabular}

Notes. For each station are given: 1 , latitude-north; 2 , longitude-west; 3, distance $(\mathrm{km})$ from St. John's, Newfoundland; 4, depth $(\mathrm{m})$ at each station; 5, range $(\mathrm{cm})$ of the 5 major constituents; 6 , percentage of constituent's strength to $\mathrm{M}_{2}$ tide; 7, epoch (degrees); 8, phase lag (hours) from $66^{\circ} 30^{\prime}$ meridian.
Table7. Characteristics of the tides as measured along the edge of the continental shelf and at some ports along the east coast of North America

\begin{tabular}{|c|c|c|c|c|c|c|}
\hline \multicolumn{2}{|l|}{$\begin{array}{l}\text { Station } \\
\text { Constituent }\end{array}$} & \multirow[t]{2}{*}{$\mathrm{M}_{2}$} & \multirow[t]{2}{*}{$\mathrm{N}_{2}$} & \multirow[t]{2}{*}{$\mathrm{S}_{2}$} & \multirow[t]{2}{*}{$\mathrm{K}_{1}$} & $\mathrm{O}_{1}$ \\
\hline St. John's & & & & & & \\
\hline $1 .=46^{\circ} 34^{\prime}$ & $5 .=$ & 70 & 14 & 29 & 16 & 14 \\
\hline $2 .=52^{\circ} 42^{\prime}$ & $6 .=$ & 100 & 20 & 41 & 23 & 20 \\
\hline $3 .=1188$ & 7.= & 210 & 192 & 254 & 107 & 74 \\
\hline $4 .=$ & $8 .=$ & -5.98 & -6.63 & -4.46 & 6.19 & 4.63 \\
\hline \multicolumn{7}{|c|}{ St. Brides, Nfld } \\
\hline $1 .=46^{\circ} 55^{\prime}$ & $5 .=$ & 139 & 29 & 50 & 12 & 15 \\
\hline $2 .=54^{\circ} 11^{\prime}$ & $6 .=$ & 100 & 20 & 36 & 8 & 11 \\
\hline $3 .=1055$ & 7.= & 224 & 200 & 262 & 122 & 113 \\
\hline $4 .=$ & $8=$ & -5.38 & -6.24 & -4.1 & 7.13 & 7.53 \\
\hline \multicolumn{7}{|l|}{ Banquereau } \\
\hline $1 .=44^{\circ} 35^{\prime}$ & $5 .=$ & 88 & 20 & 21 & 11 & 9 \\
\hline $2 .=57^{\circ} 41^{\prime}$ & $6 .=$ & 100 & 22 & 24 & 12 & 11 \\
\hline $3 .=701$ & 7.= & 230 & 205 & 262 & 104 & 108 \\
\hline $4 .=64$ & $8 .=$ & -4.95 & -5.84 & -3.47 & 6.34 & 7.47 \\
\hline \multicolumn{7}{|l|}{ Sable Island } \\
\hline $1 .=43^{\circ} 35^{\prime}$ & $5 .=$ & 105 & 18 & 23 & 5 & 5 \\
\hline $2 .=58^{\circ} 46^{\prime}$ & $6=$ & 100 & 17 & 22 & 5 & 5 \\
\hline $3 .=519$ & 7.= & 232 & 213 & 269 & 102 & 151 \\
\hline $4 .=$ & $8 .=$ & -4.71 & -5.38 & -3.67 & 6.34 & 10.7 \\
\hline \multicolumn{7}{|l|}{ B1 } \\
\hline $1 .=42^{\circ} 48^{\prime}$ & $5 .=$ & 97 & 24 & 21 & 14 & 11 \\
\hline $2 .=63^{\circ} 12^{\prime}$ & $6 .=$ & 100 & 25 & 20 & 14 & 11 \\
\hline $3 .=216$ & 7.= & 224 & 200 & 257 & 109 & 113 \\
\hline $4 .=226$ & $8 .=$ & -4.78 & -5.63 & -3.67 & 7 & 8.26 \\
\hline \multicolumn{7}{|l|}{$22 B$} \\
\hline $1 .=42^{\circ} 03^{\prime}$ & $5 .=$ & 88 & 22 & 18 & 15 & 11 \\
\hline $2 .=65^{\circ} 38^{\prime}$ & $6 .=$ & 100 & 25 & 20 & 17 & 12 \\
\hline $3 .=0$ & 7.= & 210 & 219 & 263 & 110 & 116 \\
\hline $4 .=242$ & $8 .=$ & -4.12 & -4.84 & -3.37 & 7.2 & 8.51 \\
\hline \multicolumn{7}{|l|}{$\mathrm{T} 23$} \\
\hline $1 .=40^{\circ} 22^{\prime}$ & $5 .=$ & 81 & 21 & 17 & 15 & 12 \\
\hline $2 .=67^{\circ} 45^{\prime}$ & $6 .=$ & 100 & 24 & 21 & 19 & 15 \\
\hline $3 .=-257$ & 7.= & 221 & 201 & 245 & 112 & 112 \\
\hline 4. $=174$ & $8 .=$ & -4.57 & -5.28 & -3.77 & 7.1 & 8.48 \\
\hline \multicolumn{7}{|l|}{ Kelvin } \\
\hline $1 .=39^{\circ} 56^{\prime}$ & $5 .=$ & 87 & 21 & 18 & 17 & 14 \\
\hline $2 .=71^{\circ} 00^{\prime}$ & $6 .=$ & 100 & 24 & 21 & 20 & 16 \\
\hline $3 .=-511$ & 7.= & 206 & 190 & 235 & 107 & 110 \\
\hline 4.=? & $8 .=$ & -4.81 & -5.42 & -3.87 & 7.4 & 8.55 \\
\hline \multicolumn{7}{|l|}{ Sandy Hook } \\
\hline 1. $=40^{\circ} 27^{\prime}$ & $5 .=$ & 135 & 31 & 26 & 20 & 10 \\
\hline $2 .=74^{\circ} 10^{\prime}$ & $6 .=$ & 100 & 22 & 19 & 15 & 8 \\
\hline $3 .=-721$ & 7.= & 218 & 201 & 246 & 102 & 98 \\
\hline $4 .=$ & $8 .=$ & -4.23 & -4.82 & -3.3 & 7.27 & 7.9 \\
\hline \multicolumn{7}{|l|}{ Atlantic City } \\
\hline $1 .=39^{\circ} 21^{\prime}$ & $5 .=$ & 117 & 27 & 24 & 21 & 15 \\
\hline $2 .=74^{\circ} 26^{\prime}$ & $6=$ & 100 & 23 & 19 & 18 & 13 \\
\hline $3 .=-799$ & 7.= & 207 & 190 & 231 & 107 & 91 \\
\hline $4 .=$ & $8 .=$ & -4.58 & -5.18 & -3.77 & 7.63 & 7.43 \\
\hline \multicolumn{7}{|l|}{ Charleston } \\
\hline $1 .=32^{\circ} 46^{\prime}$ & $5 .=$ & 145 & 33 & 25 & 21 & 15 \\
\hline $2 .=79^{\circ} 56^{\prime}$ & $6 .=$ & 100 & 22 & 17 & 14 & 10 \\
\hline $3 .=-1495$ & 7.= & 210 & 200 & 246 & 126 & 126 \\
\hline $4 .=$ & $8 .=$ & -4.23 & -4.58 & -3.04 & 3.13 & 10.19 \\
\hline
\end{tabular}

Notes. Legend as for Table 6 except for item 3, distance $(\mathrm{km})$ from station 22B (Northeast Channel). 


\subsection{EQUINOCTIAL TIDES: EAST VERSUS WEST}

Other characteristics also indicate that tides between Newfoundland and Europe are of a different regime than those along the North American mainland. One of these characteristics concerns the stronger equinoctial tides. Plinys oft quoted statement probably accounts for the assumption by most oceanographers that the so-called equinoctial tides (March and September) reach higher levels than tides close to the solstices (June and December). Pliny may have been correct, for he was only aware of tides that can be observed on the east side of the Atlantic Ocean. Table 8 shows the highest predicted tides for each month in 1953 and 1975 for stations on the east side of the Atlantic. The semi-annual peaks are underlined. These data support Pliny's claim that the tides near the equinoxes are generally higher than those occurring during the remainder of the year. Even the fall tides are stronger than those in the spring, and the midwinter ones are stronger than

Table 8. Highest High Water predicted for each month for ports on the eastern side of the North Atlantic Ocean

\begin{tabular}{|c|c|c|c|c|c|c|c|c|c|c|c|c|}
\hline Year & $\mathrm{J}$ & $\mathrm{F}$ & M & A & M & $\mathrm{J}$ & $\mathrm{J}$ & A & $S$ & $\mathrm{O}$ & $\mathrm{N}$ & $\mathrm{D}$ \\
\hline \multicolumn{13}{|c|}{ Casablanca } \\
\hline 1953 & 12.5 & 12.8 & $\underline{12.8}$ & 12.5 & 12.1 & 12.1 & 12.5 & $\underline{12.8}$ & 12.8 & 12.5 & 12.1 & 12.1 \\
\hline 1975 & $\underline{13.0}$ & $\underline{13.0}$ & 12.5 & 11.8 & 11.5 & 11.6 & 12.3 & 13.0 & $\underline{13.1}$ & $\underline{13.1}$ & 12.6 & 12.3 \\
\hline \multicolumn{13}{|c|}{ Gibraltar } \\
\hline 1953 & 3.9 & 4.0 & 4.1 & 4.0 & 3.9 & 3.7 & 3.9 & 4.0 & 4.1 & 4.1 & 3.9 & 3.7 \\
\hline 1975 & $\underline{3.4}$ & 3.3 & 3.2 & 3.1 & 3.0 & 3.0 & 3.3 & 3.6 & $\underline{3.7}$ & $\underline{3.7}$ & 3.5 & 3.3 \\
\hline \multicolumn{13}{|c|}{ Lisbon } \\
\hline 1953 & 13.1 & 13.6 & 13.7 & 13.4 & 12.9 & 12.6 & 13.3 & 13.8 & 13.9 & 13.6 & 13.1 & 12.9 \\
\hline 1975 & 13.6 & $\underline{13.8}$ & 13.6 & 13.2 & 12.8 & 12.6 & 12.8 & 13.5 & 14.0 & $\underline{14.1}$ & 13.8 & 13.5 \\
\hline \multicolumn{13}{|c|}{ Cordouan } \\
\hline 1953 & 17.4 & $\underline{18.2}$ & $\underline{18.2}$ & 17.6 & 16.1 & 15.9 & 17.1 & 18.2 & $\underline{18.5}$ & 17.7 & 16.7 & 16.1 \\
\hline \multicolumn{13}{|c|}{ Pointe de Grave } \\
\hline 1975 & 19.2 & $\underline{19.5}$ & 19.2 & 18.2 & 17.4 & 17.1 & 18.0 & 19.0 & $\underline{19.5}$ & $\underline{19.5}$ & 18.9 & 18.0 \\
\hline \multicolumn{13}{|l|}{ Brest } \\
\hline 1953 & 25.8 & 26.4 & 26.7 & 25.9 & 24.3 & 24.0 & 25.4 & 26.7 & 26.9 & 26.2 & 25.1 & 24.3 \\
\hline 1975 & 26.4 & $\underline{26.8}$ & 26.4 & 25.4 & 24.3 & 24.0 & 25.1 & 26.2 & $\underline{26.9}$ & 26.7 & 25.9 & 23.8 \\
\hline \multicolumn{13}{|c|}{ Southampton } \\
\hline 1953 & 14.2 & 14.7 & $\underline{14.8}$ & 14.4 & 13.7 & 13.0 & 13.3 & 14.6 & 14.7 & 14.5 & 14.1 & 13.4 \\
\hline 1975 & 15.9 & $\underline{16.1}$ & 15.9 & 15.2 & 14.9 & 14.5 & 15.1 & 15.7 & 16.0 & $\underline{16.1}$ & 15.7 & 15.2 \\
\hline \multicolumn{13}{|c|}{ Liverpool } \\
\hline 1953 & 31.1 & $\underline{32.1}$ & 31.9 & 31.0 & 28.1 & 29.2 & 30.7 & $\underline{32.0}$ & 32.0 & 31.1 & 29.4 & 28.6 \\
\hline 1975 & 33.1 & $\underline{33.4}$ & 32.9 & 31.6 & 30.6 & 30.2 & 31.7 & 32.9 & $\underline{33.4}$ & 33.1 & 32.4 & 31.4 \\
\hline \multicolumn{13}{|c|}{ Queenstown } \\
\hline 1953 & 12.4 & 12.8 & 12.9 & 12.8 & 12.2 & 11.8 & 12.5 & 13.0 & 13.5 & 13.4 & 12.9 & 12.1 \\
\hline 1975 & 12.7 & $\underline{12.8}$ & $\underline{12.8}$ & 12.6 & 12.2 & 11.7 & 12.2 & 12.8 & 13.6 & $\underline{13.6}$ & 13.4 & 12.8 \\
\hline \multicolumn{13}{|c|}{ Reykjavik } \\
\hline 1953 & 14.2 & 14.6 & 14.5 & 14.1 & 13.6 & 13.5 & 14.3 & 14.6 & 14.5 & 14.2 & 13.8 & 13.5 \\
\hline 1975 & $\underline{14.6}$ & 14.2 & 13.4 & 13.1 & 12.9 & 13.1 & 13.7 & 14.2 & $\underline{14.4}$ & 14.2 & 14.3 & 14.2 \\
\hline \multicolumn{13}{|c|}{ Distribution of Peaks } \\
\hline & 2.5 & 9.0 & 6.5 & & & & & 2.0 & 11.5 & 4.5 & & \\
\hline \multicolumn{13}{|c|}{ Average Height } \\
\hline & 14.6 & 16.8 & 16.6 & 16.1 & 15.4 & 15.2 & 15.9 & 16.7 & 17.0 & 16.7 & 16.2 & 15.9 \\
\hline
\end{tabular}

Notes. Heights measured in feet from local Chart Datum. Semi-annual peak tides underlined. 
the midsummer ones. However, as shown below, Pliny's claim is not valid along the east coast of North America, or along the continent's west coast south of the Alaskan panhandle.

Data for 1953 and 1975 from stations on the west side of the Atlantic (Table 9) are rather less supportive of Pliny's case. However, in order to test for possible bias in the two sample years, Table 10 supplies a more complete set of data for Halifax. Note that the peak tides do not fall in the same months as they did on the other side of the ocean, and that they are spread over all seasons. The only month in which no peak occurs is September, one of the equinox months. Each successive year the peak appears to arrive somewhat later. This can be explained by the dominance of perigean tides on the west side of the ocean. The Spring Tide cycle has a period of 14.77 days, and the perigean cycle one of 27.56 days. After 205.89 days, these cycles overlap each other causing interference and extraordinary strong tides. Every second overlap occurs the following year, but 47 days later in the season. It is, therefore, incorrect to claim that on the western side of the ocean the equinoctial tides are the highest tides of the year. The highest tides of the year occur in the late fall and early winter season, because the mean water levels are higher in winter than in summer due to world-wide shifts in atmospheric pressures. Another phenomenon discernible in Table 10 (last column) is that every 4 to 5 years the tides reach another peak. This peak occurs because after 112 cycles of Moon declinations, their

Table 9. Highest High Water predicted for each month for ports on the western side of the North Atlantic Ocean

\begin{tabular}{|c|c|c|c|c|c|c|c|c|c|c|c|c|}
\hline Year & $\mathrm{J}$ & $\mathrm{F}$ & M & A & M & $\mathrm{J}$ & $\mathrm{J}$ & A & $S$ & $\mathrm{O}$ & $\mathrm{N}$ & D \\
\hline \multicolumn{13}{|c|}{ Argentia } \\
\hline 1953 & $\underline{6.6}$ & 6.4 & 6.1 & 6.2 & 5.9 & 5.7 & 5.9 & 6.0 & 6.4 & 6.7 & 6.7 & 6.4 \\
\hline 1975 & $\underline{8.3}$ & 8.1 & 7.8 & 7.9 & $\underline{8.0}$ & 7.9 & 8.2 & 8.4 & 8.5 & 8.5 & $\underline{8.6}$ & 8.4 \\
\hline \multicolumn{13}{|c|}{ Halifax } \\
\hline 1953 & 7.3 & 7.3 & 7.4 & 7.2 & 7.1 & 6.8 & 6.9 & 7.2 & 7.5 & 7.7 & 7.5 & 7.2 \\
\hline 1975 & $\underline{7.6}$ & $\underline{7.6}$ & 7.5 & 7.3 & 7.0 & 6.9 & 7.0 & 7.2 & 7.4 & $\underline{7.6}$ & $\underline{7.6}$ & 7.5 \\
\hline \multicolumn{13}{|c|}{ Newport } \\
\hline 1953 & 4.3 & 4.3 & 4.5 & 4.7 & 4.6 & 4.5 & 4.5 & 4.7 & $\underline{4.9}$ & $\underline{4.9}$ & 4.7 & 4.4 \\
\hline 1975 & 4.5 & 4.6 & 4.8 & $\overline{4.8}$ & 4.7 & 4.5 & 4.6 & 4.7 & $\overline{4.5}$ & $\overline{5.0}$ & 4.9 & 4.7 \\
\hline \multicolumn{13}{|c|}{ New York } \\
\hline 1953 & 5.3 & 5.3 & 5.5 & 5.7 & $\underline{5.8}$ & 5.6 & 5.7 & 5.8 & 5.9 & 6.0 & 5.7 & 5.3 \\
\hline 1975 & 5.5 & 5.4 & 5.7 & $\underline{5.9}$ & 5.8 & 5.6 & 5.7 & 5.9 & 5.9 & $\underline{6.1}$ & 6.0 & 5.7 \\
\hline \multicolumn{13}{|c|}{ Breakwater } \\
\hline 1953 & 5.4 & 5.3 & 5.3 & $\underline{5.5}$ & 5.4 & 5.1 & 5.2 & 5.2 & 5.0 & 5.6 & $\underline{5.6}$ & 5.3 \\
\hline 1975 & 5.2 & 5.0 & 5.3 & $\underline{5.4}$ & $\underline{5.4}$ & 5.2 & 5.3 & 5.4 & 5.4 & $\underline{5.7}$ & $\underline{5.7}$ & 5.4 \\
\hline \multicolumn{13}{|c|}{ Washington } \\
\hline 1953 & 3.0 & 3.2 & 3.2 & $\underline{3.7}$ & 3.6 & 3.5 & 3.6 & 3.3 & $\underline{3.9}$ & 3.7 & 3.4 & 3.0 \\
\hline 1975 & 3.1 & 3.1 & 3.3 & $\underline{3.6}$ & $\underline{3.6}$ & 3.5 & 3.5 & 3.6 & 3.6 & $\underline{3.8}$ & 3.6 & 3.2 \\
\hline \multicolumn{13}{|c|}{ Charleston } \\
\hline 1953 & 6.1 & 6.0 & 6.2 & $\underline{6.5}$ & 6.4 & 6.2 & 6.2 & 6.3 & 6.8 & $\underline{7.0}$ & 6.7 & 6.2 \\
\hline 1975 & 6.2 & 6.1 & 6.5 & $\underline{6.6}$ & 6.4 & 6.2 & 6.3 & 6.5 & 6.7 & $\underline{7.0}$ & $\underline{7.0}$ & 6.6 \\
\hline \multicolumn{13}{|l|}{ Miami } \\
\hline 1953 & 2.8 & 2.8 & 3.0 & $\underline{3.1}$ & 3.0 & 2.7 & 2.9 & 3.2 & 3.6 & $\underline{3.7}$ & 3.5 & 3.0 \\
\hline 1975 & 2.8 & 2.9 & $\underline{3.1}$ & $\underline{3.1}$ & 2.9 & 2.7 & 2.8 & 3.0 & 3.5 & $\underline{3.7}$ & $\underline{3.7}$ & 3.3 \\
\hline \multicolumn{13}{|c|}{ Distribution of Peaks } \\
\hline & 2.0 & 0.5 & 2.5 & 10.0 & 3.0 & & & & 1.5 & 10.0 & 3.5 & \\
\hline
\end{tabular}

Notes. Heights measured in feet from local Chart Datum. Semi-annual peak tides underlined. 
peaks occur again at almost the same time. The result is a 4.53 year cycle of extraordinary high tides.

As discussed earlier, the theoretical movements of water particles in the oceans, due to the direct gravitational effects of the Moon and Sun, generally result in diurnal loops. Only during either new or full moon close to the equinoxes do strictly semidiurnal movements occur near the Equator. During fall and winter the most westerly displacements are reached during the morning hours, and during spring and summer in the evening hours. The diurnal inequality of tides along the North American seaboard shows the same tendency. During the summer months the most easterly displacements are reached around 04:00 and 05:00 hours local time, and during the winter, around 16:00 and 17:00 hours. As shown in Table 11 the tidal observations along the eastern side of the ocean are not in step with these particle movements. Clearly, tidal characteristics on the eastern side of the Atlantic differ significantly from those on the western side. It seems likely that the North American ocean basin, with its Sohm, Hatteras, and Nares abyssal plains, enjoys its own tidal regime, distant from that of the basins between Newfoundland and Europe.

We turn now to the behaviour of tidal waters along the coast of northern New England where North Atlantic tides impinge on the Gulf of Maine and the Bay of Fundy.

Table 10. Highest High Water predicted for each month for the port of Halifax, Nova Scotia

\begin{tabular}{|c|c|c|c|c|c|c|c|c|c|c|c|c|c|}
\hline Year & $\mathrm{J}$ & $\mathrm{F}$ & M & A & M & $\mathrm{J}$ & $\mathrm{J}$ & A & $S$ & $\mathrm{O}$ & $\mathrm{N}$ & $\mathrm{D}$ & Maximum \\
\hline 1953 & 7.3 & 7.3 & 7.4 & 7.3 & 7.1 & 6.8 & 6.9 & 7.1 & 7.5 & (7.7) & 7.5 & 7.2 & 7.7 \\
\hline 1954 & 6.8 & 7.0 & 7.2 & 7.4 & 7.3 & 7.1 & 6.7 & 6.8 & 7.2 & 7.5 & (7.6) & 7.5 & 7.6 \\
\hline 1955 & 7.2 & 6.9 & 7.1 & $\underline{7.3}$ & $\underline{7.3}$ & 7.1 & 6.9 & 6.8 & 6.8 & 7.1 & (7.6) & 7.5 & 7.6 \\
\hline 1956 & 7.3 & 7.0 & 6.9 & 6.7 & 7.0 & 7.1 & 7.1 & 7.1 & 7.1 & 7.2 & 7.2 & (7.4) & 7.4 \\
\hline 1957 & 7.3 & 7.3 & 7.3 & 7.2 & 6.9 & 6.8 & 7.0 & 7.2 & 7.4 & $(7.5)$ & 7.3 & 7.0 & 7.5 \\
\hline 1958 & 7.1 & 7.2 & 7.4 & 7.4 & 7.3 & 7.1 & 6.7 & 6.9 & 7.3 & 7.6 & (7.7) & 7.5 & 7.7 \\
\hline 1959 & 7.1 & 7.0 & 7.2 & 7.4 & 7.3 & 7.2 & 6.9 & 6.7 & 6.8 & 7.2 & 7.6 & (7.7) & 7.7 \\
\hline 1960 & 7.3 & 6.9 & 6.8 & 6.7 & 7.2 & 7.2 & 7.2 & 7.1 & 7.0 & 7.1 & 7.4 & $(7.5)$ & 7.5 \\
\hline 1961 & 7.4 & 7.3 & 7.1 & 7.0 & 6.9 & 7.1 & 7.1 & 7.2 & 7.3 & $(7.4)$ & 7.2 & 7.1 & 7.4 \\
\hline 1962 & 7.2 & $\underline{7.3}$ & $\underline{7.3}$ & 7.3 & 7.2 & 7.0 & 6.8 & 7.0 & 7.3 & (7.6) & (7.6) & 7.4 & 7.6 \\
\hline 1963 & 7.0 & 7.1 & 7.2 & 7.4 & 7.4 & 7.1 & 6.8 & 6.6 & 6.9 & 7.3 & 7.6 & $(7.7)$ & 7.7 \\
\hline 1964 & 7.2 & 6.7 & 6.9 & 7.1 & $\underline{7.3}$ & 7.3 & 7.1 & 6.9 & 6.8 & 7.3 & $(7.5)$ & (7.5) & 7.5 \\
\hline 1965 & 7.3 & 7.1 & 6.8 & 6.8 & $\underline{7.0}$ & 7.0 & 6.9 & 7.0 & 7.1 & $(7.2)$ & 7.0 & (7.2) & 7.2 \\
\hline 1966 & $\underline{7.2}$ & 7.2 & $\underline{7.2}$ & 7.2 & 7.0 & 6.8 & 6.8 & 7.0 & 7.3 & 7.3 & $(7.4)$ & 7.2 & 7.4 \\
\hline 1967 & 7.4 & 7.5 & $\underline{7.6}$ & 7.4 & 7.1 & 6.8 & 6.7 & 7.0 & 7.4 & 7.7 & (7.8) & 7.7 & $\underline{7.8}$ \\
\hline 1968 & 7.3 & 7.3 & $\overline{7.4}$ & 7.4 & 7.2 & 7.0 & 6.9 & 6.9 & 7.3 & 7.6 & (7.7) & 7.6 & $\overline{7.7}$ \\
\hline 1969 & 7.6 & 7.4 & $\overline{7.2}$ & $\overline{7.1}$ & 7.3 & 7.3 & 7.1 & 7.1 & 7.2 & 7.3 & 7.4 & $(7.6)$ & 7.6 \\
\hline 1970 & 7.3 & $(7.5)$ & $(7.5)$ & 7.4 & 7.2 & 7.2 & 7.2 & 7.1 & 7.4 & $(7.5)$ & $(7.5)$ & 7.4 & 7.5 \\
\hline 1971 & 7.5 & 7.6 & (7.7) & 7.6 & 7.3 & 6.9 & 6.9 & 7.0 & 7.3 & 7.6 & (7.7) & $(7.7)$ & 7.7 \\
\hline 1972 & 7.4 & 7.2 & 7.3 & 7.4 & 7.4 & 7.3 & 7.1 & 6.9 & 7.4 & 7.7 & $(7.8)$ & (7.8) & 7.8 \\
\hline 1973 & 7.5 & 7.1 & 7.0 & $\overline{7.0}$ & $\overline{7.0}$ & 7.1 & 7.1 & 6.9 & 7.0 & 7.2 & 7.5 & (7.8) & $\overline{7.8}$ \\
\hline 1974 & $(7.8)$ & 7.5 & 7.3 & 6.9 & 6.8 & 7.1 & 7.2 & 7.2 & 7.3 & 7.4 & 7.4 & 7.7 & $\underline{7.8}$ \\
\hline 1975 & 7.6 & 7.6 & 7.5 & 7.3 & 7.0 & 6.9 & 7.0 & 7.2 & 7.4 & $(7.6)$ & $(7.6)$ & 7.5 & 7.6 \\
\hline 1976 & 6.8 & 7.2 & 7.5 & 7.7 & (7.8) & 7.6 & 7.7 & $(7.8)$ & 7.6 & 7.4 & 7.5 & 7.4 & 7.8 \\
\hline 1977 & 6.9 & 7.1 & 7.3 & 7.5 & 7.6 & 7.5 & 7.3 & 6.9 & 6.8 & 7.5 & $\overline{7.8}$ & (7.9) & 7.9 \\
\hline 1978 & $(7.6)$ & 7.4 & 7.0 & 7.3 & $\overline{7.4}$ & 7.4 & 7.2 & 7.1 & 7.0 & 7.1 & 7.5 & (7.6) & $\overline{7.6}$ \\
\hline 1979 & $(7.7)$ & 7.5 & 7.5 & 7.4 & 7.2 & 7.4 & 7.4 & 7.4 & 7.5 & $\underline{7.6}$ & $\underline{7.6}$ & 7.5 & 7.7 \\
\hline 1980 & 7.6 & 7.7 & $\underline{7.8}$ & 7.8 & 7.6 & 7.3 & 7.1 & 7.4 & 7.7 & $(\overline{7.9})$ & $(\overline{7.9})$ & 7.7 & $\underline{7.9}$ \\
\hline 1981 & 7.4 & 7.3 & 7.6 & 7.7 & 7.7 & 7.6 & 7.3 & 7.1 & 7.4 & 7.7 & 7.8 & (7.9) & 7.9 \\
\hline 1982 & 7.7 & 7.6 & 7.3 & $\overline{7.5}$ & $\overline{7.5}$ & 7.4 & 7.3 & 7.3 & 7.3 & 7.4 & 7.5 & (7.8) & 7.8 \\
\hline 1983 & $(7.8)$ & 7.7 & 7.5 & 7.2 & 7.2 & 7.2 & 7.3 & 7.4 & 7.5 & 7.7 & 7.6 & 7.5 & 7.8 \\
\hline 1984 & 7.3 & 7.6 & $\underline{7.8}$ & 7.7 & 7.5 & 7.1 & 7.2 & 7.4 & 7.8 & $(7.9)$ & 7.8 & 7.5 & 7.9 \\
\hline 1985 & 7.2 & 7.5 & 7.7 & 7.8 & 7.7 & 7.4 & 7.0 & 7.2 & 7.6 & 7.8 & $(7.9)$ & 7.7 & 7.9 \\
\hline
\end{tabular}

Notes. Heights measured in feet from local Chart Datum; values between brackets are the highest of the year. Values underlined are the higher of the other semiannual peak, and the pioridicity over the years (underlined) is shown in the last column. 
Table 11. Diurnal inequality during solstices in 1953 on both sides of the North Atlantic Ocean

\begin{tabular}{|c|c|c|c|c|c|c|c|c|c|}
\hline & \multirow{3}{*}{$\underset{\Xi}{\Xi}$ 芯 } & \multicolumn{4}{|c|}{ 21 June, 1953} & \multicolumn{4}{|c|}{20 December, 1953} \\
\hline & & Local & & Local & & Local & & Local & \\
\hline & & Time & $\mathrm{m}+\mathrm{CD}$ & Time & $\mathrm{m}+\mathrm{CD}$ & Time & $\mathrm{m}+\mathrm{CD}$ & Time & $\mathrm{m}+\mathrm{CD}$ \\
\hline St. John's & 3.5 & 0743 & 0.82 & 1942 & $\underline{1.19}$ & 0706 & 1.37 & 1937 & 1.19 \\
\hline Halifax & 4 & 0812 & 1.83 & 2008 & 2.01 & 0720 & 2.19 & 2008 & 2.01 \\
\hline New York & 5 & 0810 & 1.25 & 2029 & 1.68 & 0752 & 1.62 & 2021 & 1.22 \\
\hline Miami & 5 & 0747 & 0.73 & 2032 & 0.82 & 0750 & $\underline{0.91}$ & 1954 & 0.82 \\
\hline Dakar & 0 & 0841 & 1.58 & 2105 & 1.49 & 0822 & 1.49 & 2044 & 1.71 \\
\hline Casablanca & 0 & 0156 & 3.29 & 1415 & 3.60 & 0135 & 3.60 & 1402 & 3.51 \\
\hline Lisbon & 0 & 0316 & 3.41 & 1537 & 3.72 & 0245 & $\underline{3.81}$ & 1512 & 3.66 \\
\hline Brest & 0 & 0350 & 6.74 & 1612 & 7.04 & 0325 & 7.25 & 1549 & 7.16 \\
\hline
\end{tabular}

Note. Highest High Waters are underlined. 


\section{Tides of the Gulf of Maine}

\subsection{A DEGENERATE AMPHIDROMIC SYSTEM}

Like the rest of the continental shelf, the Gulf of Maine results from drowning of the coastline due to the postglacial rise in sea level. The tides which beset its shores are perhaps best described as a degenerate amphidromic system. The amphidromic point, if such existed, would lie southwest of Cape Cod. However, the waters are too deep in the Gulf, considering its area, for a full amphidromic system to develop. Thus the tides of the Gulf of Maine are generated by the tides of the North Atlantic Ocean rather than directly by the Sun and the Moon. According to Redfield (1980) "The coast of New England north of Cape Cod opens on the Gulf of Maine where the behavior of the tide determines the tide in the numerous passages along the coast." In effect, the Gulf of Maine and the Bay of Fundy should be viewed as a single tidal system.

As mentioned previously, fronting the Gulf of Maine, at the edge of the continental shelf, is a natural sill which separates ocean from Gulf. This sill consists of a sequence of shoals and banks running from Cape Sable at the southern tip of Nova Scotia to Chatham on Cape Cod. Water that fills the Gulf of Maine between Low Water and High Water must move over the sill or pass through three channels between the banks (Apollonio 1979). Figure 15 shows the location and length of the sill along a line that approximately follows its shallowest parts.

\subsection{SILLS, BANKS, AND CHANNELS}

The distance along the shallowest part of the sill fronting the Gulf of Maine is $589 \mathrm{~km}$, although the great circle distance between Cape Sable and Cape Cod is only $414 \mathrm{~km}$. The crest of the sill runs from Nova Scotia, over German and Browns Banks, continuing on the other side of the Northeast Channel over Georges Bank, the Georges, Cultivator and Little Georges Shoals, and the Nantucket Shoals to Nantucket Island and Monomoy Island near Cape Cod. In places such as Georges Shoals there is barely $4 \mathrm{~m}$ of water. Over much of its extent, Georges Bank, which forms the main part of the sill, is less than $60 \mathrm{~m}$ deep (see Fig. 15 and Table 12 for location of various features and place names).

Three channels through the sill provide the main connections between the Atlantic Ocean and the Gulf. They are:

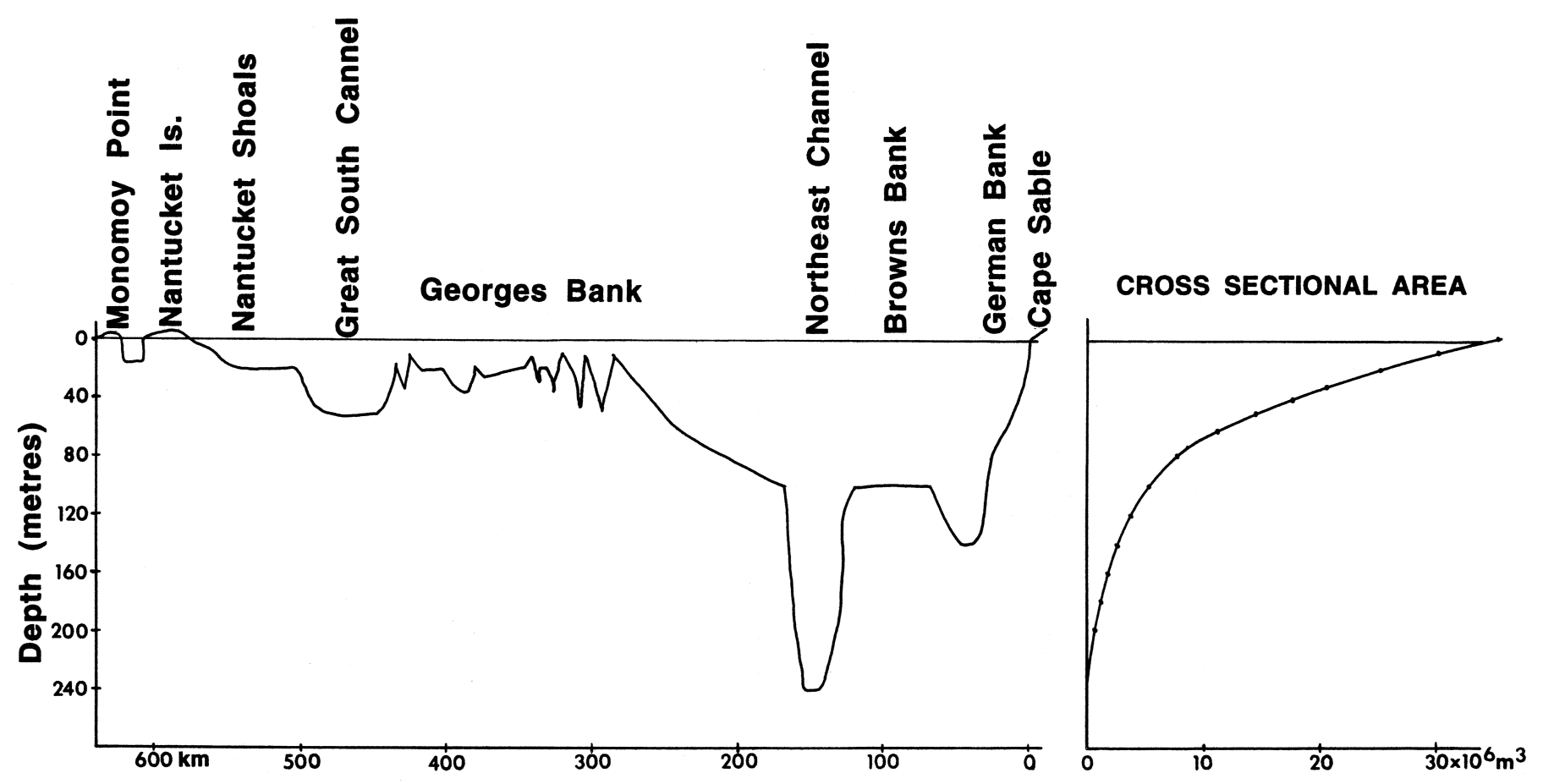

CROSS SECTION OF THE ENTRANCE TO THE GULF OF MAINE

Fig. 15 Profile of the sea floor from Monomoy Island, Cape Cod to Cape Sable (as read from left to right), N.S., along the sill separating the Gulf of Maine from the Atlantic Ocean. Area of cross-section and MSL shown at right. 
1. The Northeast Channel between Georges Bank and Browns Bank, which is over $230 \mathrm{~m}$ deep, $40 \mathrm{~km}$ wide and $70 \mathrm{~km}$ long.

2. A channel $120 \mathrm{~m}$ deep and $15 \mathrm{~km}$ wide between Browns Bank and German Bank off Cape Sable.

3. The Great South Channel between Georges Bank and Nantucket Shoals.

The shallowest parts of Browns Bank are small in area. The largest opening in the sill is between Georges Bank and German Bank; thus most of the water moving in and out of the Gulf of Maine flows through the section formed by the first two channels. Using bathymetric and hydrographic charts of the area, the width of the passage and its cross-sectional area at and below certain levels can be estimated. Because the Northeast Channel is the main passageway, these data are provided for the entire sill and for the Northeast Channel only (Table 13).

Approximately $80 \%$ of the available cross-sectional area is in the Northeast Channel section. Flow through this section has less friction to overcome than over the shoals, marked as they are in heavy weather by strong tidal currents and dangerously high seas. Thus an estimated flow of $80 \%$ through the Northeast Channel section is almost certainly a minimum.

The Gulf of Maine has a surface area of approximately $95000 \mathrm{~km}^{2}$, not including the $13000 \mathrm{~km}^{2}$ of the Bay of Fundy (Conkling 1995). Average depth of the Gulf is about $150 \mathrm{~m}$. Within the Gulf are 21 basins, of which Georges Basin (maximum depth 377 m), Jordan Basin (304 m), Crowell Basin (304 $\mathrm{m})$, and Wilkinson Basin $(280 \mathrm{~m})$ are the most prominent. These basins are separated by ridges and swells where the depth is between $150 \mathrm{~m}$ and $200 \mathrm{~m}$. Along the $1100 \mathrm{~km}$ shoreline is a shallow fringe with depths less than $80 \mathrm{~m}$. In detail, the shoreline is replete with numerous bays, islands, and tidal estuaries, its total length approaching $8000 \mathrm{~km}$ (Pilkey et al. 1989).

\subsection{TIDES PRE- AND POST-PLEISTOCENE}

In the millions of years before present that the Gulf of Maine was above sea level, subaerial erosion reshaped the exposed lowlands. Much of the sediment deposited during the early Cenozoic was removed, and valleys and deep stream beds were carved. The steep northern slope of Georges Bank may have been formed at this time. The main drainage outlet of the area was probably directed through what is now the Northeast Channel region.

Throughout the Pleistocene epoch, glaciers advanced and retreated several times on a global scale, deepening and widening valleys as well as causing sea-level fluctuations. Sea level dropped about $120 \mathrm{~m}$ as the last glacial advance removed water from the oceans, transferring it to continental glaciers. Advancing ice sheets were deflected eastward at the scarp-like northern edge of Georges Bank, and flowed as huge valley glaciers through what is now the Northeast Channel (Grant 1989; Keen and Piper 1990). On retreat, the ice left extensive
Table 12. Locations along a cross-section of the sill separating the Gulf of Maine from the North Atlantic ocean

\begin{tabular}{lcccc}
\hline & $\begin{array}{c}\text { Lat. } \\
\mathrm{N}\end{array}$ & $\begin{array}{c}\text { Long. } \\
\mathrm{W}\end{array}$ & $\begin{array}{c}\text { Length of } \\
\text { open water } \\
(\mathrm{km})\end{array}$ & $\begin{array}{c}\text { Accumulated } \\
\text { distance from Cape } \\
\text { Sable }(\mathrm{km})\end{array}$ \\
\hline Cape Sable & $43^{\circ} 24^{\prime}$ & $65^{\circ} 38^{\prime}$ & 0.0 & 0.0 \\
Northeast Channel & & & & \\
North side & $43^{\circ} 20^{\prime}$ & $65^{\circ} 38^{\prime}$ & 118.6 & 118.6 \\
$\begin{array}{l}\text { South side } \\
\text { Georges Bank }\end{array}$ & $42^{\circ} 00^{\prime}$ & $66^{\circ} 00^{\prime}$ & 47.8 & 166.4 \\
& $42^{\circ} 00^{\prime}$ & $67^{\circ} 20^{\prime}$ & 110.2 & 276.6 \\
Gr. S. Channel & $41^{\circ} 10^{\prime}$ & $68^{\circ} 00^{\prime}$ & 108.0 & 384.6 \\
Nantucket Island & $40^{\circ} 49^{\prime}$ & $69^{\circ} 00^{\prime}$ & 92.5 & 477.1 \\
Sankaty Point & & & & \\
Great Point & $41^{\circ} 17^{\prime}$ & $69^{\circ} 58^{\prime}$ & 26.5 & 573.3 \\
Monomoy Island & $41^{\circ} 24^{\prime}$ & $70^{\circ} 03^{\prime}$ & 0.0 & 573.3 \\
Monomoy Point & $41^{\circ} 32^{\prime}$ & $70^{\circ} 00^{\prime}$ & 15.4 & 588.7 \\
\hline
\end{tabular}

Table 13. Width and cross-sectional area of the water passage through the Northeast Channel, and over the sill separating the Gulf of Maine from the Atlantic Ocean

\begin{tabular}{ccccccc}
\hline & \multicolumn{3}{c}{ Total Sill } & & \multicolumn{3}{c}{ Northeast Channel Section } \\
Elevation & $\begin{array}{c}\text { Width } \\
\mathrm{km}\end{array}$ & $\begin{array}{c}\text { Area } \\
\mathrm{km}^{2}\end{array}$ & $\begin{array}{c}\text { Percent } \\
\%\end{array}$ & $\begin{array}{c}\text { Width } \\
\mathrm{km}\end{array}$ & $\begin{array}{c}\text { Area } \\
\mathrm{km}^{2}\end{array}$ & $\begin{array}{c}\text { Percent } \\
\%\end{array}$ \\
\hline 0 & 589 & 36.4 & 100 & 284 & 28.3 & 78 \\
10 & 570 & 30.6 & 84 & 276 & 25.4 & 70 \\
20 & 480 & 25.2 & 69 & 264 & 22.7 & 62 \\
30 & 360 & 21.3 & 58 & 259 & 20.0 & 55 \\
40 & 320 & 17.9 & 49 & 250 & 17.4 & 48 \\
50 & - & - & - & 240 & 14.8 & 41 \\
60 & - & - & - & 224 & 12.4 & 34 \\
80 & - & - & - & 179 & 8.3 & 23 \\
100 & - & - & - & 132 & 5.2 & 14 \\
200 & - & - & - & 28 & 0.9 & 2 \\
\hline
\end{tabular}

terminal moraines and large areas covered with glacial outwash. These and numerous other trademark glacial features have survived the drowning of this coastline by the postglacial rise in sea level.

Clearly, when the Gulf of Maine area was dry land, or covered with ice, the local tide action was of totally different character than it is now. At present, the amount of water exchanged during a tide of average strength within a 12.4 hour cycle, between the Atlantic and the Gulf, is about $300 \mathrm{~km}^{3}$. Of this total, about $100 \mathrm{~km}^{3}$ moves in and out of the Bay of Fundy. During the largest possible tides these amounts can be as much as 1.4 times average.

The watersheds of rivers flowing into the Gulf of Maine and the Bay of Fundy discharge about $95 \mathrm{~km}^{3}$ per year, or 0.135 $\mathrm{km}^{3}$ per tidal cycle. This is approximately $0.045 \%$ of the tidal prism of an average tide. Even during the spring when the river discharges can be ten times average, it is doubtful whether such a relatively small river flow can influence the circulation pattern in the Gulf.

During an average tidal cycle lasting 6.2 hours $(22357 \mathrm{sec}-$ 
onds), flow through the available cross-sectional area of $36 \mathrm{~km}^{2}$ needs on average to be only $0.37 \mathrm{~ms}^{-1}(0.73$ knots) to fill the Gulf with ocean water. Assuming a harmonic motion, represented by a sine curve, the maximum current speed is $0.59 \mathrm{~ms}^{-1}$ (1.14 knots). This speed can be generated if a mass is dropped $1.8 \mathrm{~cm}$ at the surface of the Earth. It can also be caused by a column of water $1.8 \mathrm{~cm}$ high. Thus, if the water in the ocean is $1.8 \mathrm{~cm}$ higher than in the Gulf, the maximum velocity into the Gulf can be generated. At the seashore the average amplitude of the tide is $0.45 \mathrm{~m}$. At mean sea level where the current is fastest, such a tide can rise $1.8 \mathrm{~cm}$ in 280 seconds (i.e., less than 5 minutes) (DeWolfe 1981). Therefore in order to receive all the water required to follow the ocean tide, the water surface in the Gulf has to follow the surface of the ocean by only $1.8 \mathrm{~cm}$ difference and less than 5 minutes in phase.

It has been argued that as the last glacial waned there was a time during which sea level was too low to allow tides of the present dimensions. The argument is that Georges Bank and other shallows were dry at the time, shortening the length of the opening. However, the remaining cross-sectional area in the Northeast Channel was still large enough to convey the water required to generate tides comparable to those today. The time lag would have been about 4 to 5 times larger than it is now but still small enough to prevent an appreciable change in the tidal regime.

Water entering the Gulf of Maine through the Northeast Channel moves as a wave through the channel, spreading quickly thereafter as a refracted wave throughout the Gulf. This wave travels $335 \mathrm{~km}$ to the coastline of Maine between Bar Harbor and Jonesport about 3 hours after entering the channel. Within half an hour, High Water will occur from Cape Cod Bay to the upper reaches of the Bay of Fundy except for Minas Basin, where there is a further delay of one hour.

According to Greenberg (1979) the average tidal range increases from $0.90 \mathrm{~m}$ at the entrance to the Northeast Channel to $3.10 \mathrm{~m}$ at Bar Harbor (Fig. 16). The ranges in the southern bight of the Gulf vary between 2.06 and $3.10 \mathrm{~m}$, with High Water occurring a bit later. Stations in the center of the Gulf show intermediate ranges and times of occurrence. It seems remarkable that tides in the Great South Channel off Nantucket range from $0.63 \mathrm{~m}$ to $0.50 \mathrm{~m}$, smaller than either ocean or Gulf.

Somewhere between Bar Harbor and Jonesport the tides assume a different character. Instead of having almost identi- cal ranges as in the southern bight, the tidal range increases steadily in an east-northeasterly direction, reaching a maximum in the Minas Basin, $320 \mathrm{~km}$ from Bar Harbor. Here the highest High Water levels are reached in the estuaries of the Salmon and Shubenacadie rivers near Truro, about $400 \mathrm{~km}$ from Bar Harbor.

Between Cape Sable and Tiverton at the end of Digby Neck, the average tidal range increases from 2.13 to $4.80 \mathrm{~m}$ over a distance of only $115 \mathrm{~km}$. Tides in this stretch of the Gulf shoreline of Nova Scotia adjust to the fact that the main thrust of the tidal wave is directed toward the Maine coast near Bar Harbor. The Gulf shore of Nova Scotia provides a short cut for the Fundy tides, resulting in a greater than usual increase in range per unit of distance along the shoreline.

A computer simulation developed by Greenberg (1979, 1987) of the behaviour of the $M_{2}$ constituent indicates that the amplitude of $\mathrm{M}_{2}$ over Georges Bank and the Nantucket Shoals is the least of all (Fig.16), decreasing to as little as $0.25(0.51 /-2)$. The close co-tidal lines between Georges Bank and Nova Scotia indicate the progressive wave character of the tide in that area, while the long distance in the southern bight and the Bay of Fundy indicates more of a prevailing standing wave (Greenberg 1987). High Water occurs last over the Nantucket Shoals and in the upper reaches of the Minas Basin (see Fig. 17). Standing waves in bays like Fundy, open-ended to the Gulf of Maine, behave much differently than standing waves in closed basins. From the edge of the continental shelf to the Minas Basin the tide takes from 3.3 to about 4 hours, an interval approaching a quarter of the oscillation period of the combined Gulf and Bay, accounting for the large tidal amplitude of the region.

The above considerations are of great importance in studies of tidal power generation because, among other things, construction of a tidal power dam in the Bay would lead to elevated tide levels. Controversy continues about the true resonant period of the Bay of Fundy, one problem in modelling being the determination of appropriate boundaries between Bay, Gulf, and ocean. Any major obstruction to tides in the Bay of Fundy would result in a change in the resonant period, which in turn could cause significant increase in the already extreme tidal amplification.

So much for the tides of a so-called "degenerate amphidromic system". Next we investigate the extent to which the Gulf of Maine and the Bay of Fundy act together as one tidal system resonating with the semidiurnal tides. 


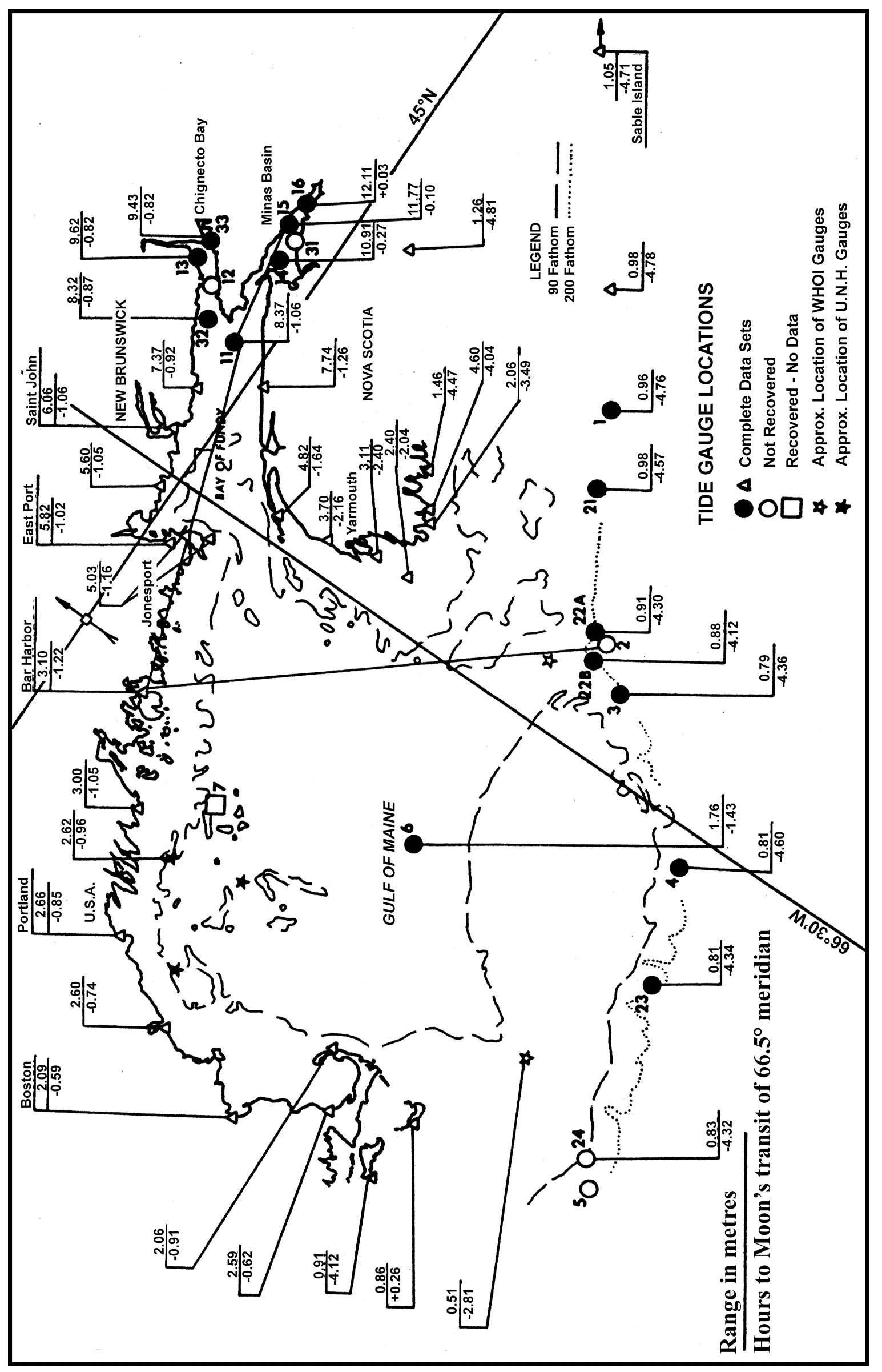

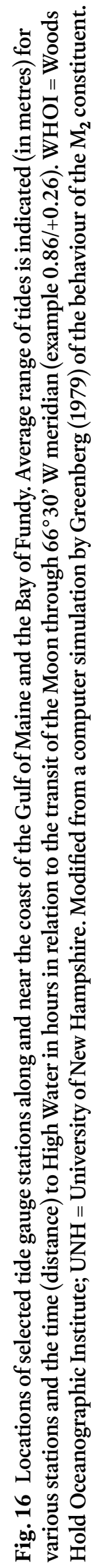




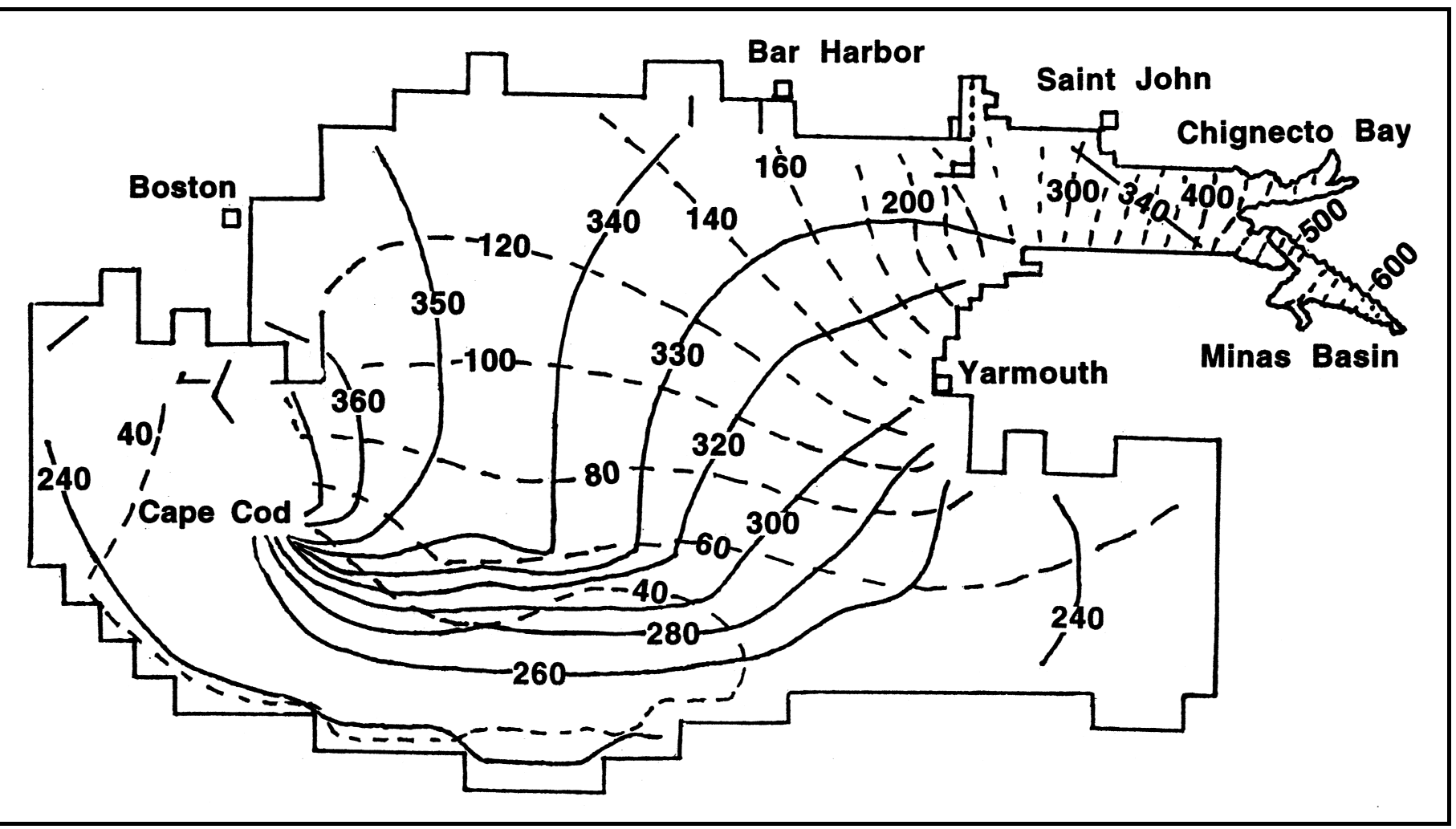

Fig. 17 Computer generated tidal regime of the Gulf of Maine - Bay of Fundy - Georges Bank system. Behaviour of the $\mathrm{M}_{2}$ constituent reflects the change in character from a progressive wave at the entrance to the Gulf to a standing wave in the Bay of Fundy. Solid lines indicate the tidal phase in degrees, i.e., the progress of the tide as it arrives at the edge of the continental shelf. Broken lines show the tidal amplitude in centimetres, i.e., the predicted height of the tide above MSL. Modified after Greenberg $(1979,1987)$. 


\section{Tides of the Bay of Fundy}

\subsection{INTRODUCTION}

Bay of Fundy Tidal predictions are published annually for the principal hydrographic station at the reference port of Saint John. A mathematical approach using harmonic analysis is employed to compute the actual tide as the combined effect of all the tide-generating variables. The result is a large number of cosine curves, so-called tidal constituents or "partial tides", each representing the influence or characteristic of the local tide. Local tidal characteristics along the eastern Canadian seaboard result from a combination of diurnal and semidiurnal tides. However, semidiurnal tides are prevalent in the North Atlantic, and Fundy tides amplified by resonance across Georges Bank and through the Gulf of Maine are an integral part of the system (Gehrels et al. 1995; Davis and Browne 1996).

Recent observations of environmental characteristics of the Bay of Fundy suggest modern change in the dynamics of the system. They include the changing grain size distributions on the tidal mud flats (Amos et al. 1991), anecdotal observations from the fishing community of increasing water depths in some areas, and changing benthic communities (Percy et al. 1996). There is a need to better understand the dynamics of the Bay of Fundy and to promote efforts by concerned groups for a more detailed knowledge of seabed, oceanographic and biological conditions. Could the changes observed apply to the entire tidal regime? Are the tides stable or are they increasing due to changes in water depth or resonance length of the Bay? What is the future of the tides and associated currents in the Bay? These questions are central to the evolution of the Bay of Fundy and the sustainable management of its resources. In the following overview of the geology and evolution of the tidal regime in the Bay of Fundy, we elaborate on the tides at Herring Cove in Fundy National Park, N.B., and then examine the geological significance of the tides.

\subsection{GEOLOGIC ORIGIN OF THE BAY OF FUNDY AND ITS TIDES}

In strict terms, the Bay of Fundy is underlain by a half-graben with key faults on the northwestern margin. These faults, of Paleozoic or older origin, were reactivated at the onset of the opening of the present day Atlantic Ocean due to plate tectonic movements in the early Mesozoic (Keppie 1982; Greenough 1995; Withjack et al. 1995; Wade et al. 1996). Sedimentary infilling of the half-graben, termed the Fundy Basin, commenced with continental sedimentation about $230 \mathrm{Ma}$, during the Mid Triassic (King and MacLean 1976; Stevens 1977; Olsen et al. 1989; Withjack et al. 1998). During a late rifting stage immediately following the Triassic-Jurassic transition, voluminous basaltic lava erupted upon Triassic strata and was followed by mainly clastic sediment deposition possibly into the earliest Mid Jurassic (Olsen et al. 1989; Wade et al. 1996; Mossman and Grantham 1996). The entire sequence was then folded, uplifted and tilted southwestward in a saucer-shaped structure (Withjack et al. 1995). Thus rock exposures along the Fundy graben mark the boundaries of a major synclinal structure, the axis of which is located toward the center of the Bay. Mesozoic strata underlie much of the Gulf of Maine and the Bay of Fundy. Cretaceous sedimentary deposits preserved in isolated pockets in lowlands adjacent to the Bay of Fundy rest unconformably, usually on Carboniferous rocks (Stea and Pullan 2001; Falcon-Lang et al. 2003), suggesting that the Bay of Fundy Basin may have been covered by Cretaceous (and possibly Tertiary) deposits and subsequently exhumed.

In addition to basalt, much of the $1400 \mathrm{~km}$ coastline of the Bay of Fundy consists of erosion-prone sandstone and conglomerate. Erosion rates can exceed $1 \mathrm{~m} / \mathrm{yr}$ (Amos 1978), giving rise to sandy estuaries in which fine-grained clastic material accumulates in sheltered embayments. Some coastal sections of mainly Paleozoic siltstone and shale, for example in Chignecto Bay (Amos et al. 1991; Amos 1995a), contribute materials that persist in suspension through wave action and tidal cycling. Elsewhere, sections such as the basalt along much of the Nova Scotia coast, and the more massive igneous and metamorphic rocks along the New Brunswick coast, are relatively erosion resistant.

Glaciation has exercised important controls on the geomorphology of the Bay of Fundy, as on its tidal regime. About 18000 to 20000 years BP, the Laurentide ice sheet blanketed most of Canada and extended far south of the Great Lakes. Crossing the Bay of Fundy and the Gulf of Maine, its approach to the edge of the continental shelf left blankets of glacial outwash and huge terminal moraines peripheral to the ice sheet, as well as extensive drumlin fields. These deposits now form many of the banks and shoals along the Maritime and New England coastlines. Associated valley glaciers, such as one believed to have occupied the Northeast Channel in the Gulf of Maine, were also significant (Grant 1985, 1989; Keen and Piper 1990). During the last glacial maximum they contributed to a global sea level lower by 100-130 $\mathrm{m}$ than at present. Overall then, there are two major phases to sea-level history in the Bay of Fundy: an early glacial emergence, and a present continuing submergence.

During the last 14000 years the depth of the Bay of Fundy has changed appreciably as the land surface rebounded and sea level rose as the last ice sheets receded. One of the main features of the postglacial evolution of the Bay was the depth of water over Georges Bank; inflow of tidal waters was evidently restricted at the lowest point of relative sea level (Scott and Greenberg 1983). With progressive submergence of Georges Bank, the Bay of Fundy became more directly subjected to 
tidal forces. Mathematical modelling of the Gulf of Maine tidal system indicates that 7000 years BP, tidal ranges will have been $20-50 \%$ of the present range (Greenberg 1979; 1987); by 4000 years BP they would have grown to $80 \%$, reaching present strength about 2500 years BP, when mean sea level was approximately $7 \mathrm{~m}$ lower than present. There is general agreement too, that increasing erosion of the sea bed, with localized bottom scour and deepening, signals an increase in the dynamic energy of the tides (Bleakney 1986; Godin 1992; Fader 1996). However, the timing of increased resonance is controversial, because evidence from detailed salt marsh records indicates that tidal range was relatively subdued about 4000 yr BP (Shaw and Ceman 1999), a point earlier inferred by Grant (1970).

\subsection{CHARACTERISTICS OF BAY OF FUNDY TIDES}

\subsubsection{Resonance and Range of Modern Fundy Tides}

Impelled by the oceanic tide through the Northeast Channel and across the Gulf of Maine (Fig. 10), an average single tidal flow into the Bay of Fundy matches the estimated total daily volume (about $104 \mathrm{~km}^{3}$ ) of all the world's river discharges into the oceans. Thus, during a lunar day ( 24 hours and 50 minutes), the water moving in and out of the Bay of Fundy is actually four times the combined discharge of all the world's rivers. During exceptionally high tides this volume may exceed $146 \mathrm{~km}^{3}$ every 6.2 hours.

In effect, the tidal energy channelled into the Bay creates a slow, large-scale oscillation, or seiche. Tremendous tidal amplification may occur through this near-resonant response. A comparison with the pendulum movement of a grandfather clock is instructive. In this instrument, the visible movements of a heavy pendulum are maintained by an imperceptible downward-moving weight, keeping the pendulum going through the escapement mechanism. By analogy, the oceanic tides maintain a co-oscillating seiche, and thus the tidal movements in the Fundy-Georges Bank-Gulf of Maine system.

The appropriate formula describing these conditions (for an open basin like the Bay of Fundy) is given by:

$$
\mathrm{T}=4 \mathrm{~L} /(\mathrm{g} \cdot \mathrm{d})^{0.5}
$$

where $\mathrm{T}$ is the resonant period in seconds, $\mathrm{L}$ the length of the basin in metres, the acceleration of the Earth's gravity $g=9.8$ $\mathrm{ms}^{-2}$, and d the depth in metres. Rao (1968) calculated the natural resonant period of the Bay of Fundy as approximately 9 hours. Garrett (1970) showed that the resonance of the Bay is combined with that of the Gulf of Maine to give a period of about 13.3 hours, a figure essentially in agreement with the estimate of Greenberg (1987). This is very near resonance with the semidiurnal Atlantic tide of 12.42 hours. Further complicating simple resonance calculations is tidal friction, which is believed to subtract considerable energy from the system (Greenberg et al. 1996). Thus, accurate determination of the degree to which true resonance is approached in the Bay of Fundy is not a simple matter.

Resonance in the Bay results in high tidal amplitude and a tidal range several times greater than the open ocean tide. Tides at Bar Harbor, with a mean range of $3.1 \mathrm{~m}$, result from the increase in the mean range in the oceanic tides of $0.9 \mathrm{~m}$, through the Northeast Channel and across the Gulf of Maine over a distance of $335 \mathrm{~km}$. At the mouth of the Bay of Fundy (Fig. 3) the average range of the tides is close to $5 \mathrm{~m}$, halfway into the Bay $7.3 \mathrm{~m}$ and at the head of Chignecto Bay near Belliveau Village, N.B., the average range is $12 \mathrm{~m}$ and can reach $15.2 \mathrm{~m}$.

At Burntcoat Head, N.S., in Minas Basin near the head of the Bay (Fig. 3), the maximum range between successive low and high tides of 53.43 feet $(16.29 \mathrm{~m})$ was observed on 16 July, 1916 by Dr. William Bell Dawson, Superintendent of Tidal Surveys: this remains a world record. Here the mean range of $12.1 \mathrm{~m}$ is amplified about 13.5 times in relation to the oceanic tides over a distance of $735 \mathrm{~km}$ (Dawson 1920). The difference between high and low tide in the upper reaches of the Bay of Fundy is shown in Fig. 18.

Just northeast of the Jordan Basin is a threshold or sill of rock, which at its deepest point is $160 \mathrm{~m}$ below the present Chart Datum. This sill runs southeast from Jonesport, Maine, over the Grand Manan Banks, to a submerged continuation of Digby Neck (Lurcher Shoal), $40 \mathrm{~km}$ southwest of Briar Island (Fig. 19). In the $55 \mathrm{~km}$ wide channel between Grand Manan Island and Brier Island the water depth in places exceeds 200 $\mathrm{m}$. Seventy-five kilometres farther into the Bay, on the line connecting Saint John, N.B. with Digby Gut, N.S., the depth is less than $100 \mathrm{~m}$, while off Cape Chignecto, another $85 \mathrm{~km}$ northeast, the depth is less than $40 \mathrm{~m}$. Here the Bay splits into two sections. In the narrowest section of the Minas Channel the depths may exceed $100 \mathrm{~m}$, although most of the Minas Basin has depths of less than $20 \mathrm{~m}$. Beyond Noel Head, $6.5 \mathrm{~km}$ east of Burntcoat Head, the Bay falls dry at low tides (see Fig. 3). However, tides reach even higher levels in the Salmon and Shubenacadie River estuaries, some $40 \mathrm{~km}$ east of Burntcoat Head.

\subsubsection{Exponential increase in tidal range and amplitude}

According to tide tables published by the United States Department of Commerce $(1953,1975)$, the Bay of Fundy tops the list of those places where the largest tides are observed. In these tables Mean Range is defined as the difference in height between mean High Water and mean Low Water. The Spring Range is the average diurnal range occurring semi-monthly when there is either a full moon or a new moon. For some Canadian areas, data provided by Canadian tide tables are also noted. However, in these tables, the mean range is defined by the difference in height between the Higher (diurnal) High Water and Lower (diurnal) Low Water. A large range implies the difference between Higher High Water and Lower Low 

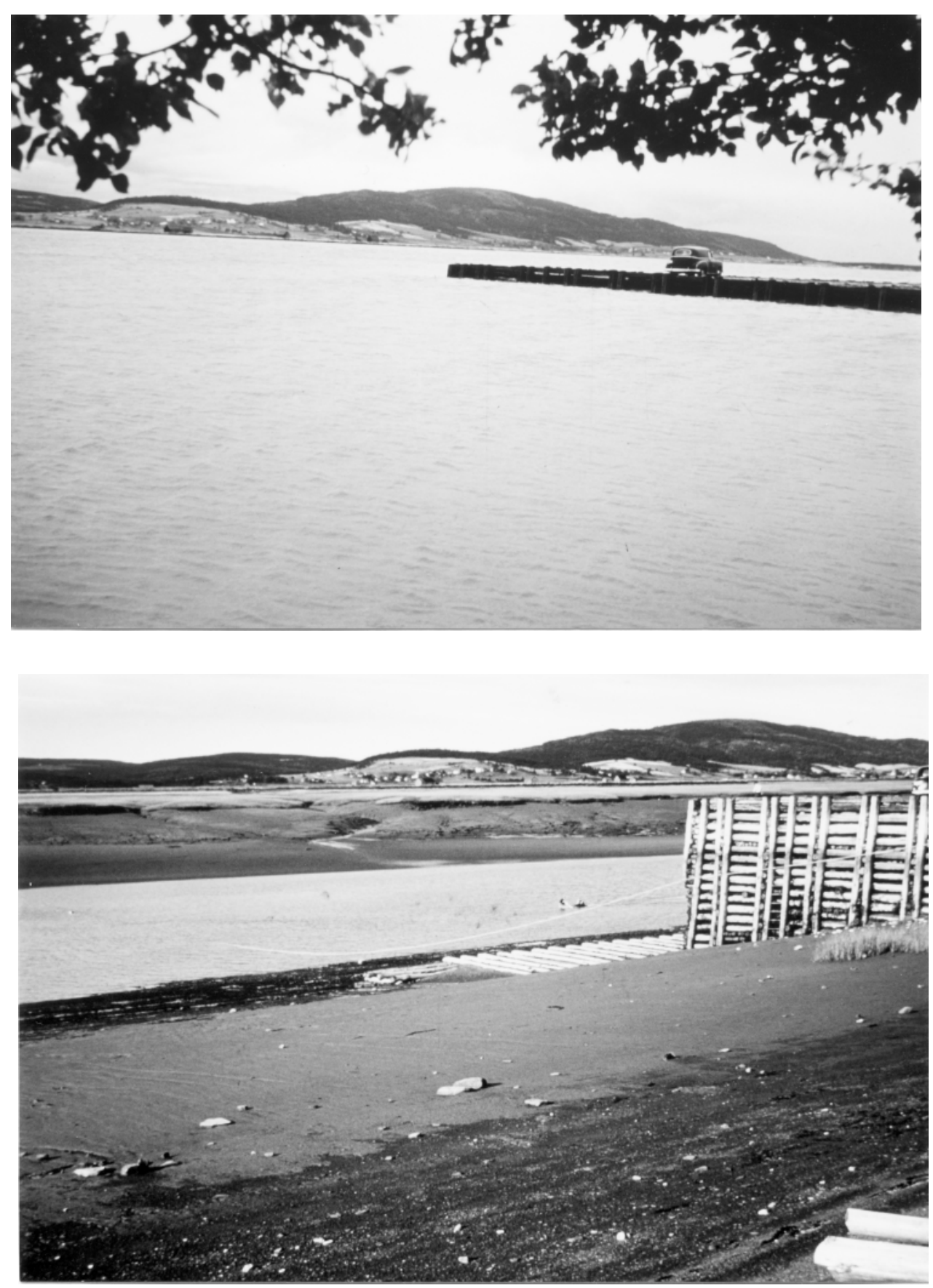

Fig. 18 Views six hours apart, of tidal conditions in the Shepody River estuary, summer 1954, two years before construction of Shepody River dam near Riverside, N.B. Photographs by Con Desplanque.

Water during exceptionally strong tides. Consequently, data in Canadian tide tables show greater mean and spring ranges than the U.S. tables.

In many estuaries and bays around the world the range of the tides increases exponentially with distance from any given reference point. This is the case in the Fundy-Georges Bank-Gulf of Maine system. Thus the range at a particular location $Y_{2}$ can be estimated if the distance $\mathrm{D}$ (positive in the direction of the head of the Bay) from a reference station $Y_{1}$ is known. If the percentage increase P per kilometre is known, the range $T$ at point $Y_{2}$ can be calculated with:

$$
\mathrm{Ty}_{2}=\mathrm{Ty}_{1} \cdot(1+\mathrm{P} / 100)^{\mathrm{D}}=\mathrm{Ty}_{1} \cdot \mathrm{F}^{\mathrm{D}}
$$

where factor $\mathrm{F}$ is $(1+\mathrm{P} / 100)$.

The importance of this relationship is illustrated for the Minas Basin. Note firstly (Table 3) that while the amplitudes of the semidiurnal tides increase toward Burntcoat Head at the 


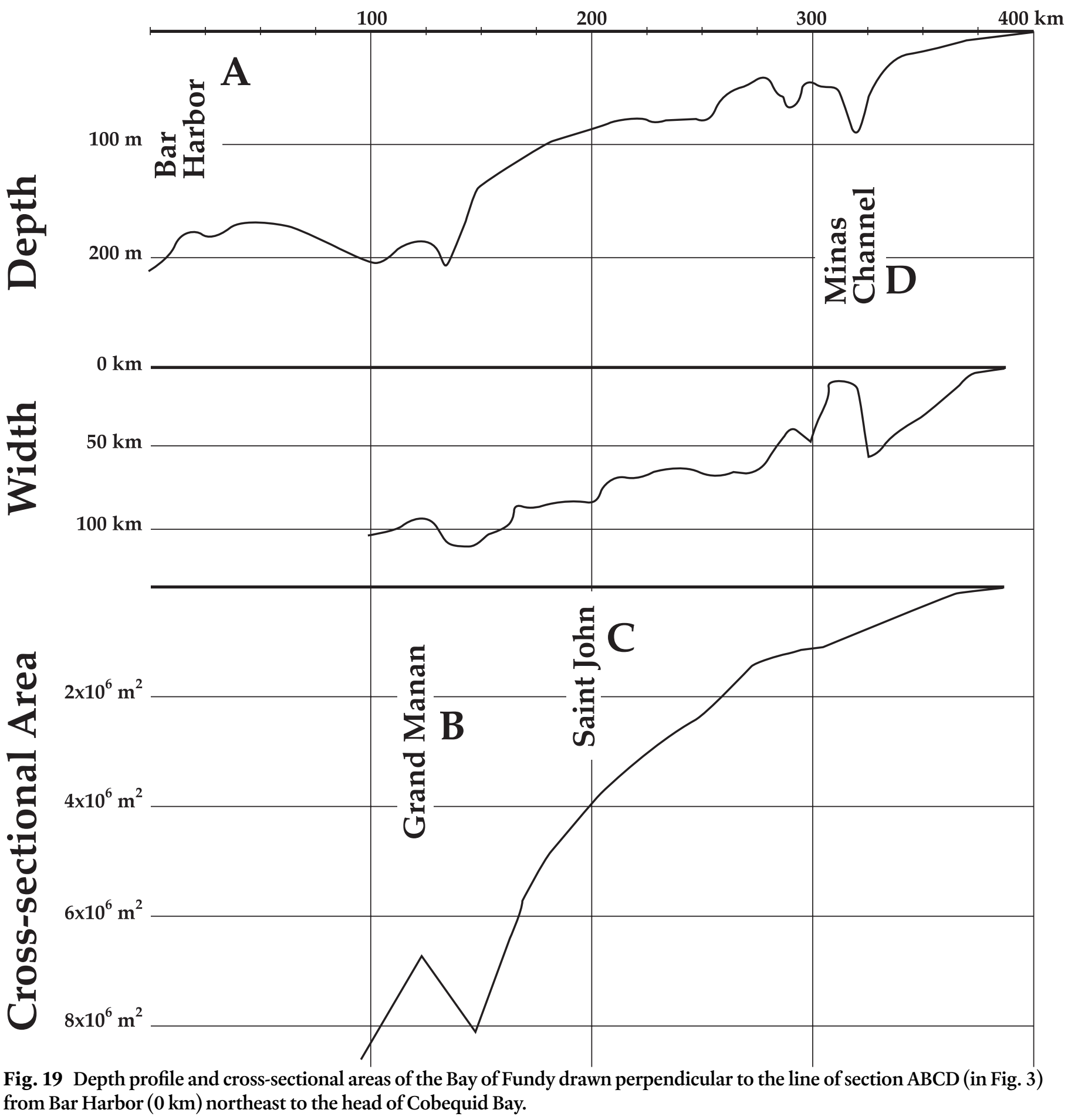

head of the Bay and Basin, the diurnal amplitudes (DL) remain virtually constant at about $0.2 \mathrm{~m}$. Nor is it likely that they will be altered when progressing into river estuaries. However, the semidiurnal tides are clearly a function of the distance from Saint John, where the principal tidal hydrographic station is located. This is shown in Table 14, where it is evident from the values of $\mathrm{F}$ (the exponential factor of the tidal increase over distance $D$ ) that the range of the semidiurnal tides increases as they advance into the Bay, at a rate $\mathrm{P}$, of approximately $0.35 \%$ per $\mathrm{km}$. This allows the local tidal range to be estimated rather accurately, with reference to the local Chart Datum, whence follow realistic estimates of Mean Water Level (MWL) and High Water level (HWL). Detailed examples of this procedure are documented in Gordon et al. (1985) and Desplanque and Mossman (1998a). The above relationship is relevant to issues as diverse as determining tidal boundaries (Desplanque and Mossman 1999a) and evaluating proposed tidal power generation schemes in the Bay of Fundy (Gordon and Dadswell 1984). 


\subsubsection{The importance of diurnal inequalities in the Bay}

As noted earlier, strength of tides is mainly modified by changing distances between Earth and Moon, and because the Sun and Moon act individually from varying directions. Diurnal inequalities are due to changing declinations of the Moon and Sun with respect to the plane of the Earth's equator. The strongest diurnal inequality is possible when spring tides occur during the solstices when both celestial bodies are near their maximum declination, and acting together. As seen from Earth, the Sun appears to move through the plane of the ecliptic, which makes an angle of $23.452^{\circ}$ with the Equator (see Fig. 6). The Sun is overhead at local midday at the Equator on 21 March and 23 September, and the length of the day and the night are the same everywhere on Earth. The Sun is said to have a north declination between the spring and fall equinoxes, and a south declination during the remainder of the year. It reaches its maximum north declination of $23.452^{\circ}$ at the summer solstice in June (Fig. 6). The Moon goes through a shorter declinational cycle lasting 27.322 days. Also, because the Moon's orbital plane is at an angle of $5.145^{\circ}$ to the ecliptic, its declination is more variable than that of the Sun. Thus the maximum

Table 14. Relationship between tidal magnitude and distance, the latter measured from Bar Harbor $\left(\mathrm{Y}_{1}\right)$, Maine

Exponential Growth of the Bay of Fundy Tides

Distance

(D) $(\mathrm{km})$

$(\mathrm{SD})\left(\mathrm{Y}_{2}\right) \mathrm{m} \quad \mathrm{R}=\mathrm{Y}_{2} / \mathrm{Y}_{1} \quad \mathrm{~F}=\mathrm{R}(1 / \mathrm{D})$

\begin{tabular}{lcccc}
\hline Atlantic Ocean & & & & \\
Station 22B & -333 & 0.45 & 0.285 & 1.00377 \\
Gulf of Maine & & & & \\
Portland & -175 & 1.38 & 0.873 & 1.00078 \\
Pulpit Harbor & -61 & 1.49 & 0.943 & 1.00096 \\
Bar Harbor (Y) & 0 & 1.58 & 1.000 & \\
Eastport & 120 & 2.67 & 1.690 & 1.00438 \\
Bay of Fundy & & & & \\
Saint John & 195 & 3.14 & 1.987 & 1.00353 \\
Partridge Island & 195 & 3.14 & 1.987 & 1.00353 \\
Cape Blomidon & 328 & 5.11 & 3.234 & 1.00358 \\
Parrsboro & 334 & 5.12 & 3.241 & 1.00353 \\
Five Islands & 353 & 5.51 & 3.487 & 1.00354 \\
Hantsport & 360 & 5.73 & 3.627 & 1.00359 \\
Burntcoat Head & 372 & 5.73 & 3.627 & 1.00347 \\
\hline
\end{tabular}

Notes. The range of the dominant semidiurnal tides in the Bay of Fundy increases exponentially at the rate of about $0.35 \%$ per kilometre from the edge of the continental shelf, via Bar Harbor, into the Bay. $\mathrm{R}$ is the ratio between the semidiurnal tides at the tidal stations, compared with those of Bar Harbor. F is the exponential factor of tidal increase over distance. Note that the two stations (Portland and Pulpit Harbor) west of Bar Harbor in the Gulf of Maine differ little in strength (F). declination of the Moon to the Earth's equatorial plane ranges from $28.597^{\circ} \mathrm{N}$ to $28.597^{\circ} \mathrm{S} 14$ days later. Halfway through its nodical cycle, 9.3 years later, the range of the Moon's declination is reduced from $18.307^{\circ} \mathrm{N}$ to $18.307^{\circ} \mathrm{S}$.

A sketch of the results of specific diurnal inequalities for locations in Maritime Canada serves to highlight details of the Fundy tides (Fig. 20). The combined effect of the semidiurnal constituents can be visualized as a wave, with nearly two cycles/ day moving through the area, whereas the combined diurnal constituents form a wave passing through a location once a day. If the High Water of the latter combines with one of the semidiurnal High Waters, the result will be an extra high tide (Schureman 1941). However the diurnal Low Water will then coincide with the next semidiurnal High Water, reducing it in strength. The two semidiurnal Low Waters will occur when the diurnal tide is at Mean Water Level, resulting in two Low Waters of equal height. This combination occurs in the Gulf of St. Lawrence, along the north shore of Prince Edward Island, and along the eastern shore of New Brunswick (Fig. 20, case 1). Here the two daily High Waters are unequal and the two Low Waters equal. When the Moon is close to the equatorial plane, High Waters are also equal for a day or so.

The reverse applies in the Northumberland Strait, where the High Waters are equal and the Low Waters unequal (Fig. 20, case 2). Here, one of the semidiurnal Low Waters coincides with the diurnal Low Water. In fact at times in sections of this area the semidiurnal tide is so weak that the amplitude of the diurnal wave is more than twice that of the semidiurnal amplitude. For example, in the western section of Northumberland Strait near Shediac Bay and Escuminac only one High Water and one Low Water may occur during the lunar day.

The situation concerning diurnal inequalities in the Bay of Fundy is detailed in Fig. 20, case 3. This illustrates a situation in which the midpoint of the falling diurnal wave coincides with one of the midpoints of a rising semidiurnal wave. The result is that a Lower High Water (LHW) is followed respectively by a Higher Low Water (HLW), a Higher High Water (HHW) and a Lower Low Water (LLW). Thus in the Bay of Fundy the sequence over a lunar day is typically HHW - LLW - LHW - HLW - HHW. The characteristic behaviour of the Fundy tides over the course of a month is shown in Fig. 21 for Herring Cove in Fundy National Park, N.B. Compared with marigrams from other localities in the Maritime Provinces, the diurnal inequalities of the Bay of Fundy are relatively modest.

Due to inertia in a frictionless system, the tides lag behind the forcing function by about 12 hours. For example, assume that at noon, 21 June, there is a solar (or lunar) eclipse (see Figs. $22 \mathrm{~A}$ and 22B) over the Greenwich Meridian. At this time, in theory, the center of one "bulge" would be at, say $23.5^{\circ} \mathrm{N}, 0^{\circ}$ longitude, the other at $23.5^{\circ} \mathrm{S}$ on the $180^{\circ}$ meridian. In theory, the bulge should be over the Fundy area $\left(65^{\circ} \mathrm{W}\right)$ around 16:00 hours GMT (i.e. about noon local time). However, observations in the Bay of Fundy will show that Higher High Water (HHW) on that day will occur at midnight (24:00 hours), and Higher Low Water (HLW) around 18:00 hours. The peak of diurnal inequality will occur around 21:00 hours, or about 9 


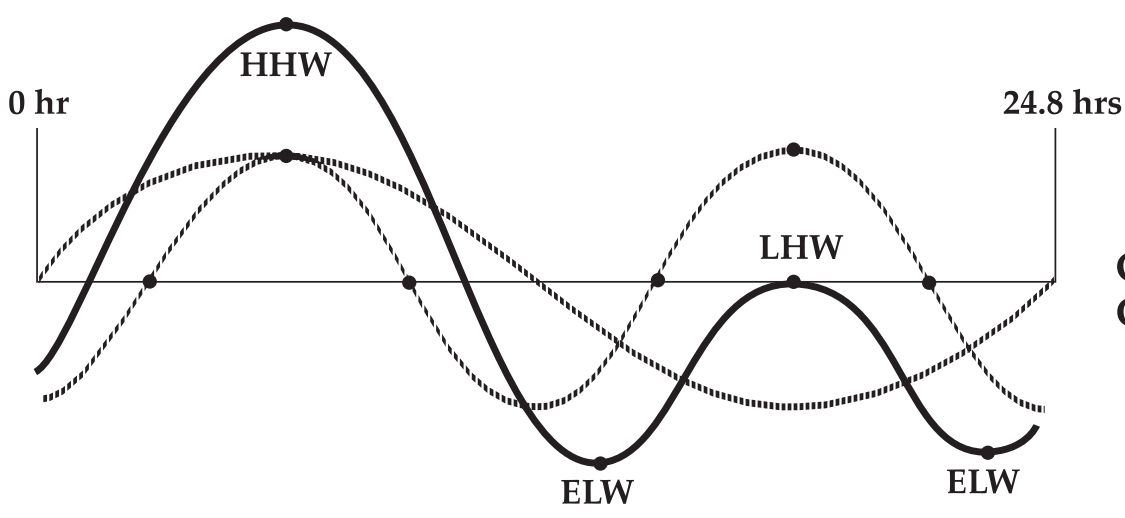

Case 1

Gulf of St. Lawrence

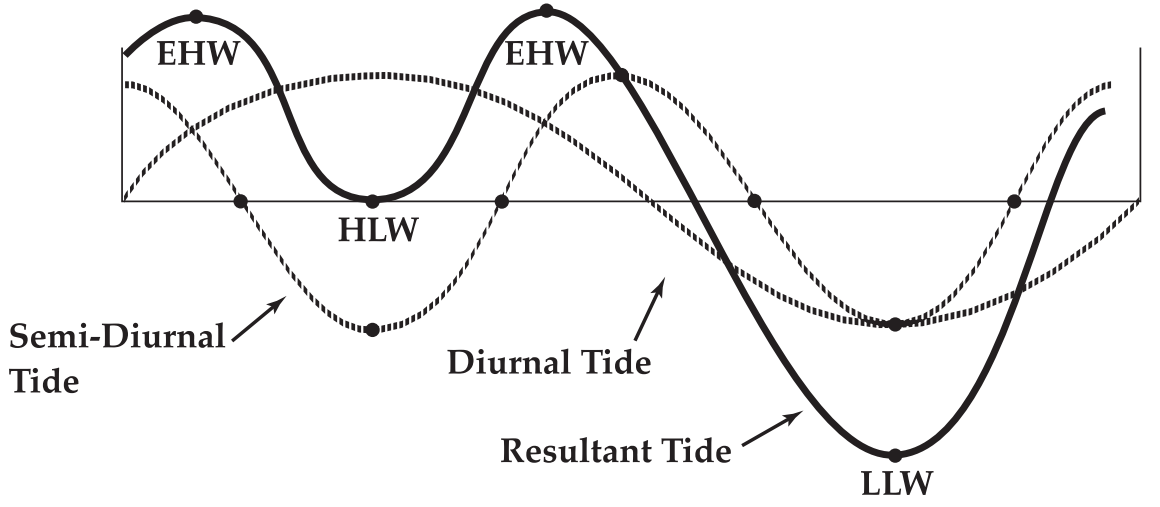

Case 2

Northumberland Strait

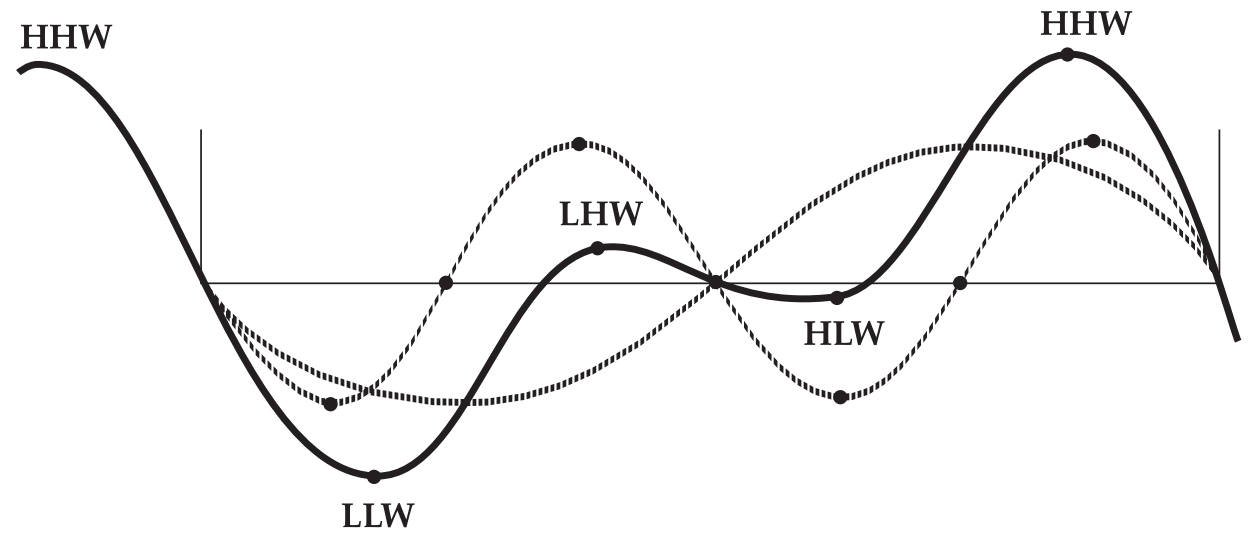

Case 3

Bay of Fundy

Fig. 20 Sketch showing the combined effects of diurnal and semidiurnal tides for: Case 1 - Gulf of St. Lawrence, north of Prince Edward Island, and eastern shore of New Brunswick; Case 2 - Northumberland Strait; Case 3 - Bay of Fundy.

Abbreviations: $\mathrm{HHW}=$ Higher High Water; ELW = Equal Low Water; LLW = Lower Low Water, etc.

hours later than the theoretical time (see also Desplanque and Mossman 2001b).

In contrast, during a solar (or lunar) eclipse on 23 December (Figs. 22c and 22d) a "bulge" would occur around midnight north of the Equator on the dark side of Earth. However, the peak of the diurnal tide would be around 9:00 hours, with HLW about 6:00 hours and HHW around noon. Thus in the Bay of Fundy, the HHW in spring and summer (i.e., between the equi- noxes) occurs during the night time ( $6 \mathrm{pm}$. to $6 \mathrm{am}$.) and during the fall and winter (September to March) during the daytime. For the same reason Lower Low Water (LLW) occurs in spring and summer between midnight and noon (morning) and during fall and winter between noon and midnight (afternoon and evening). This situation results in a close coupling between tidal forces and biomass behaviour and production (Gordon et al. 1985) especially in the macrotidal conditions in the upper part 
of the Bay. It also plays an important role in determining sea surface temperatures (cf. Cabilio et al. 1997) and winter ice conditions in the Bay (Gordon and Desplanque 1983).

\subsubsection{Tidal cycling at Herring Cove (Fundy National Park)}

Tidal variations in the Bay of Fundy throughout the year are well illustrated by a typical annual record of tide levels at Herring Cove in Fundy National Park, N.B. The port of Saint John, $89 \mathrm{~km}$ more seaward, serves as reference port because the tides throughout the Bay of Fundy all show virtually the same features, except for the ranges of the local tides. The tide levels can be estimated from the tidal predictions for Saint John, N.B. $\left(\mathrm{T}_{\mathrm{SJ}}\right)$, as given in the Tide and Current Tables published annually by the Canadian Hydrographic Service (Canadian Tide and Current Tables 2004). The following equation is used to convert the given predicted levels of $\mathrm{T}_{\mathrm{SJ}}$, measured in feet from the local Chart Datum (i.e. the lowest normal tide) to levels $\mathrm{T}_{\mathrm{HC}}$ measured in metres from Mean Water Level at Herring Cove.

$$
\mathrm{T}_{\mathrm{HC}}=\left(\mathrm{T}_{\mathrm{SJ}}-14.5\right) \cdot(1.0035)^{89} \cdot 0.3048 \mathrm{~m}
$$

where 14.5 feet is the height of local mean water level above chart datum at Saint John.

In the Bay of Fundy there is a close correspondence between the high tides predicted on the basis of astronomical conditions and those observed. The cyclic behaviour of the tides at Saint John, N.B. over a twenty year interval is shown in Fig. 23. The 206 day perigee/spring tide cycle is clearly evident, as are its matching cycles at 14 month, $4.5 \mathrm{yr}$ and $18 \mathrm{yr}$ intervals.

It is instructive also to examine more closely the variations in tidal cycles over the course of one year at Herring Cove. For example, in 1988 (Fig. 24) there were 706 tidal cycles; on most days there are two High Waters and two Low Waters, being the highest and lowest levels predicted. The levels are measured from the Mean Water Level (MWL) that the water surface would assume if no tide-producing gravitational influences of Moon and Sun were present. Of course, if the combined gravitational influences of Moon and Sun remained constant, tidal fluctuations would also remain constant. However, influences of the Moon and Sun do not remain constant, neither in strength nor direction.

Since the angle of maximum declination of the Moon changes over a 18.6 year cycle, the situation depicted for Herring Cove in Fig. 24 will not be duplicated until 2005 A.D. In 1987, the Moon's declination reached its maximum value. On 6 December, 1987 the full moon was as high above the horizon as it could be. When the Moon is exactly above the Equator, as happens every 13.6 days, there will be no difference in strength of the two daily tides (no diurnal inequality). But the inequality soon reappears and will be strongest seven days later, when the Moon is either in its most northerly or southerly declination. At Herring Cove, this inequality results in differ- ences in level reached by the daily tides of as much as $0.86 \mathrm{~m}$ for High Waters and $0.78 \mathrm{~m}$ for Low Waters. This occurred in January, July and December, 1988 (see Fig. 24); however, these differences disappear every two weeks as indicated where the HHW and LHW curves intersect, as do the LLW and HLW curves.

Because the new moon is never more than $5^{\circ}$ different from the Sun's declination, there is a close relationship between the Sun's declination, the phase of new moon and its declination. Therefore the maximum diurnal inequality is centred around spring tides in June and December, and the weakest inequality during neap tides in March and September. When the perigean and spring tides coincide in June and December, the diurnal inequality causes one of the daily tides to be especially strong. This phenomenon, when combined with storm conditions, presents grave risks of destruction for property owners and settlements along the coastal zone (Taylor et al. 1996; Desplanque and Mossman 1999b).

One can expect stronger than usual tides a few days later than full and new moon, and weaker tides near the quarter phases of the moon. There is a certain inertia in the development of the tides analogous to the fact that, in the Northern Hemisphere, the months of July and August are on average warmer than June, when days are longer and the Sun is higher. Doubtless, friction is also an important constraint. For these reasons the highest tides occur a few days after the astronomical configurations that induce them.

Thus, as detailed in Fig. 24, perigean tides at Herring Cove in 1998 coincided with one of the month's set of spring tides around 19 February. Perigee occurred on 17 February at 11:00 AST, while the new moon occurred on the same day. One of the highest tides of the year (5.53 m+MWL) was expected with a delay of 48 hours shortly after noon on 19 February. On the same day the water was predicted to drop to its lowest level (5.87 $\mathrm{m}-\mathrm{MWL}$ ). On 25 April, when apogee coincided with a quarter phase of the moon, the water dropped shortly after midnight to $2.79 \mathrm{~m}$ below Mean Water Level. One might expect the lowest High Water levels near the days that apogee coincided with one of the quarter phases, as on 23 May or 1 December, when the water was expected to reach levels of $3.20 \mathrm{~m}+\mathrm{MWL}$. This is considerably higher than the predicted level of $2.70 \mathrm{~m}+\mathrm{MWL}$ on 12 February, 12 March or 22 August, 1988. The explanation is that the first two dates were close to zero declination with nearly equal High Waters, while the latter three were close to maximum declination with $0.7 \mathrm{~m}$ diurnal inequality.

Note that two weeks before or after 19 February, the spring tides coinciding with full moon were not much higher than average tides. This is because the Moon was at apogee. This situation is repeated after about 6 and 7 months when, in September and October, the full moon occurs close to perigee. The 206-day cycle of perigean tides coincident with spring tides occurs all over the world, but it is far more pronounced (and far more important) in the Bay of Fundy because of the great tidal range. Two of these cycles last 412 days, meaning that each year the date that perigean tides are close to full moon is 47 days or 


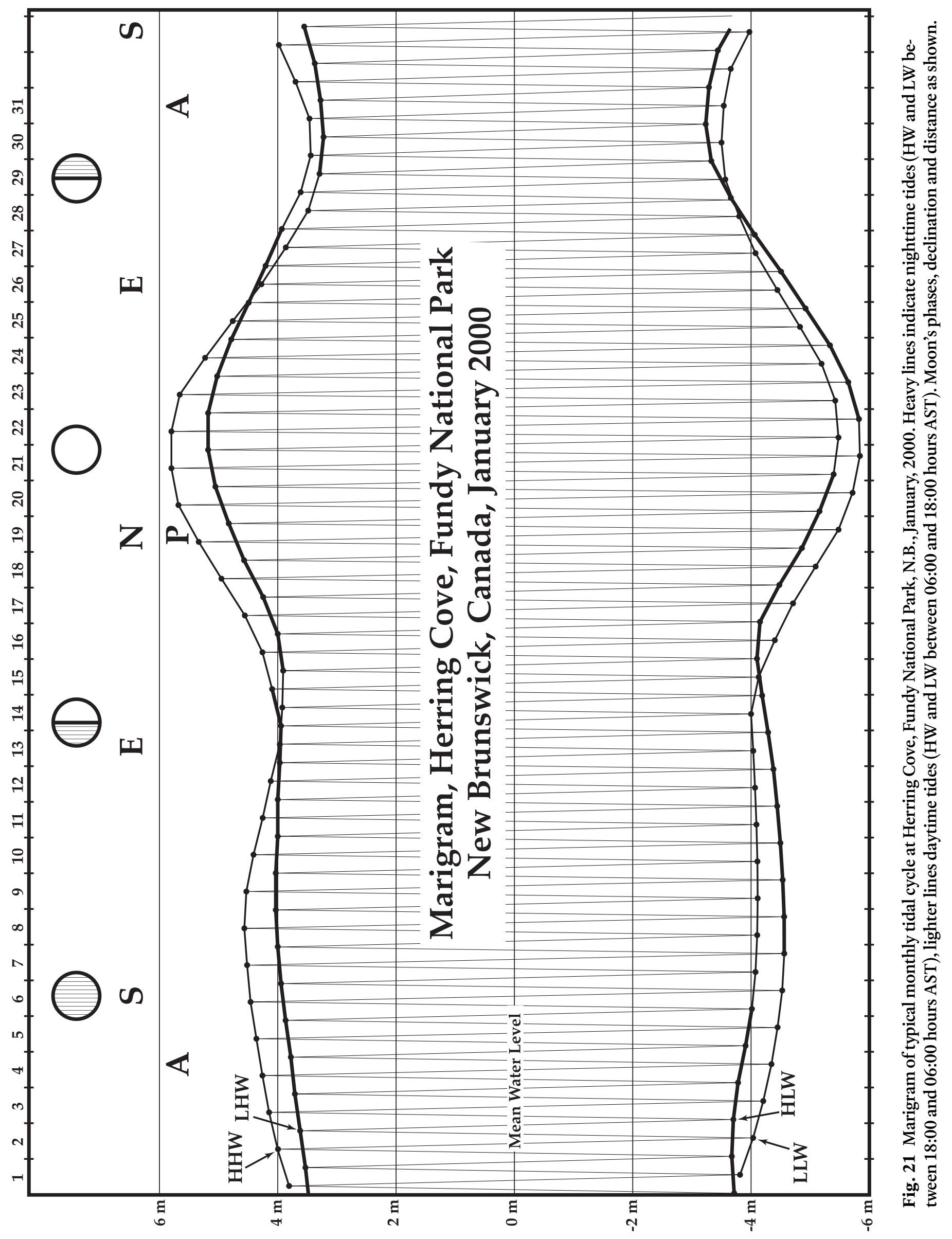



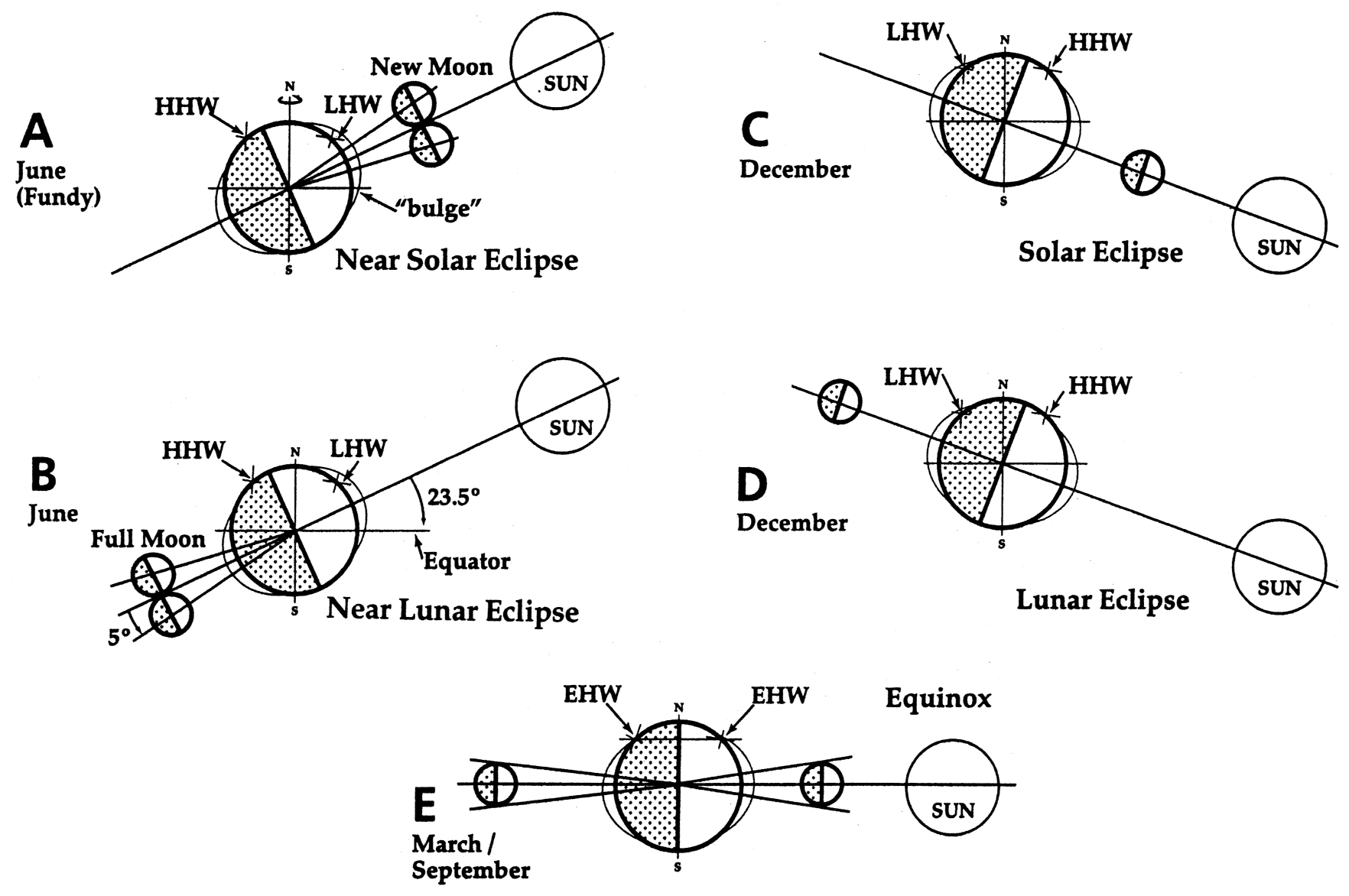

Fig. 22 Contrasts in diurnal inequalities developed in Bay of Fundy tides are greatest when spring tides occur during the solstices when Sun and Moon are near maximum declination and acting together (A to D); HHW = Higher High Water; LHW = Lower High Water. During the equinoxes there is little diurnal inequality and therefore Equal High Water (EHW) occurs day and night (E). Note: the declination of the Moon in June and December will not be exactly $23.5^{\circ}$, but anywhere between $18.5^{\circ}$ and $28.5^{\circ}$.

about 1.5 months later on the calendar. This shift means that especially strong tides in the Bay of Fundy can occur during all seasons, depending on the year of observation.

\subsection{IMPACTS OF FUNDY TIDES}

\subsubsection{Erosion}

The geological significance of the Bay of Fundy tides is most evident when linked to processes of erosion and sedimentation. A case in point is the effect of waves along some sections of the Fundy shore. Consider for example the shape of the curved erosional indentations in New Brunswick's rocky shoreline. Recall that throughout the Bay of Fundy the tidal range in absolute figures is high and that wave energy is concentrated near the surface of the water. One can also assume that the zone of the shoreline near the water surface will be most heavily subjected to wave action. Furthermore, during high water the foreshore is covered by a significant depth of water, and a much larger percentage of wave energy reaches the shoreline than when the tide is at low water.

Measurements of tidal levels conducted at Saint John, N.B. over an arbitrary 18 year interval are instructive (Figs. 25, 26, 27,28). Note that the percentage of time (Fig. 28) that the tide water surface is in the upper or lower $\mathrm{x} \%$ of the tidal range can be calculated for any tidal cycle, given that the amplitude ranges from 0 to 1 or, stated otherwise, from $0^{\circ}$ to $90^{\circ}$. In the case of, say, the upper or lower $10 \%$ of the range, the amount of time is: $[(\arcsin 1-\arcsin 0.9) / 90 \cdot 100]=28.7 \%$. This figure contrasts with the percentage of time that the water surface spends in passing through the central $10 \%$ of the range. This later figure calculated as $(\arcsin 0.05-\arcsin 0.0) / 90) \cdot 100 \cdot 2)$, amounts to only $6.4 \%$ of the cycle. Fig. 28 (solid curve) shows clearly the focus of erosion exercised by tidal processes at Saint John upon a vertical profile of the shoreline over 18 years (Desplanque and Mossman 2001b).

A specific example is provided by "The Rocks", a tourist attraction at Hopewell Cape, N.B., just east of Fundy National Park (see Fig. 29). Here the continually sculpted erosion profile 


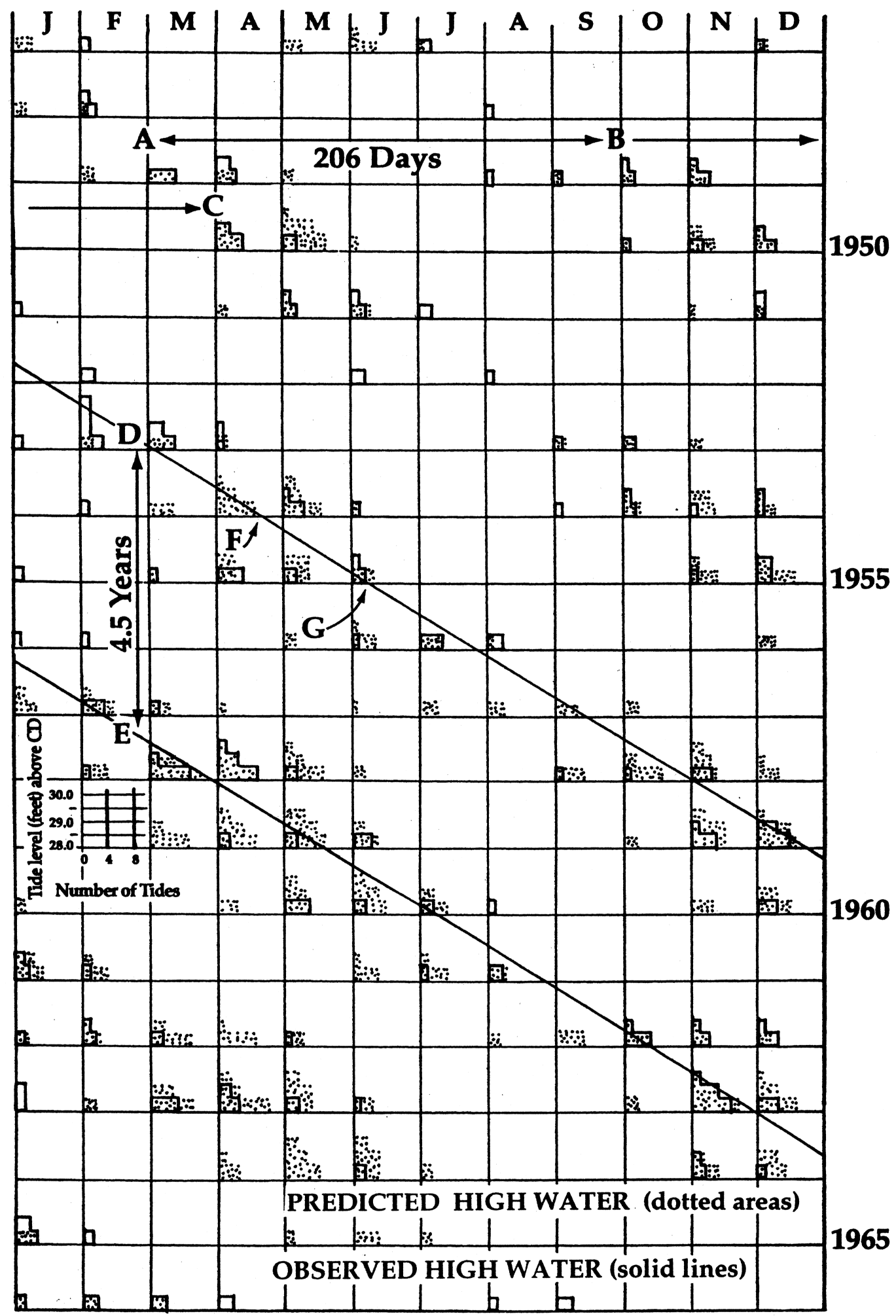

Fig. 23 Number of predicted (dotted areas) versus observed (areas enclosed by solid block) extreme High Waters per month at Saint John, N.B., for the interval 1947 to 1966. Cyclic behaviour of the tides is indicated by the 206 day perigee-spring tide cycles at 7 month (A to B), 14 month (A to B to C), 4.5 years (D to E, vertically), and 18 year intervals. Also shown is the number of tides that reached 28.0 feet $(8.5 \mathrm{~m})$ and higher, above Chart Datum. Note how the peaks shift 48 days ( $\mathrm{F}$ to $\mathrm{G}$ - where the sloping lines cross the horizontal axis) to a later date each year. 


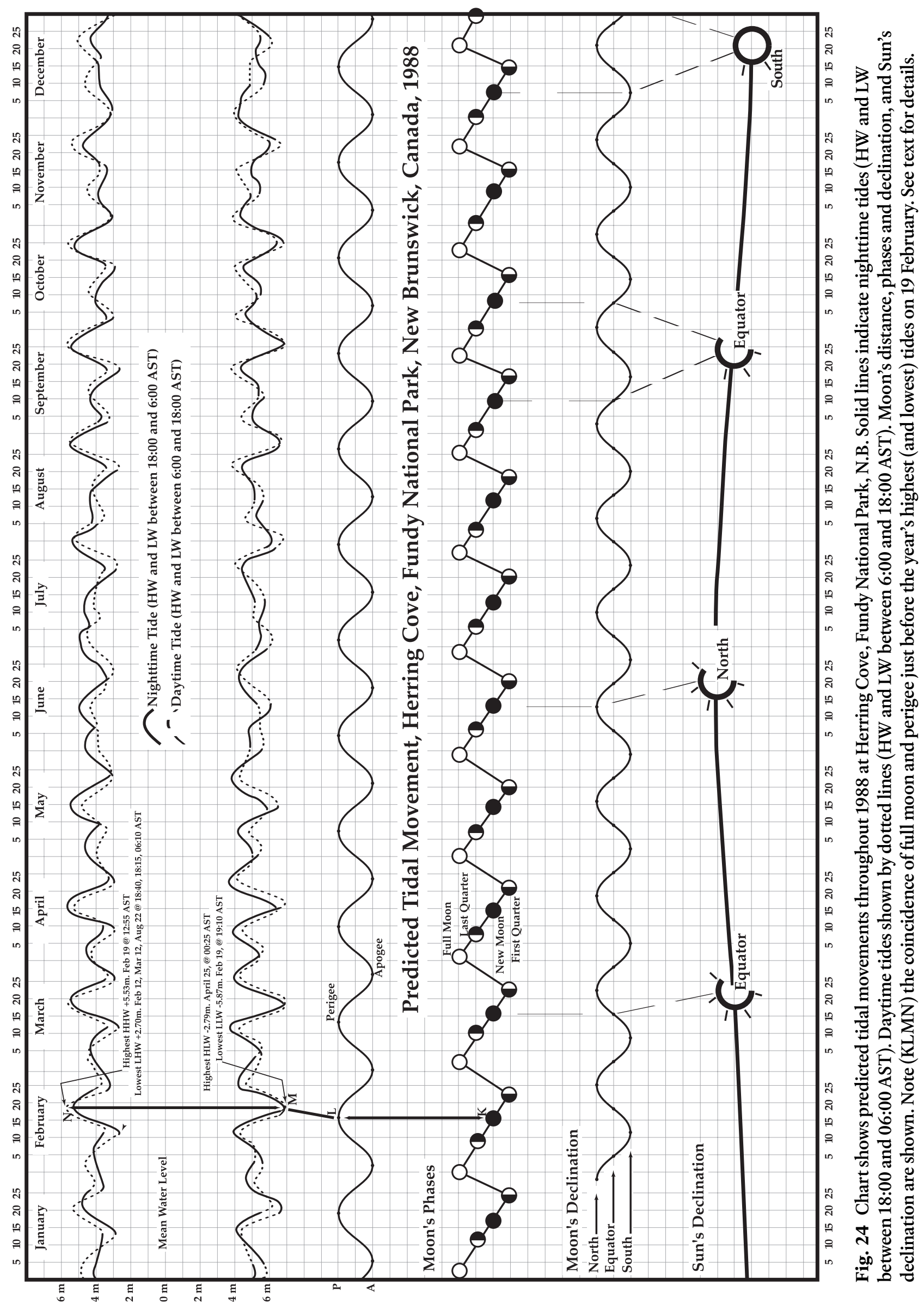




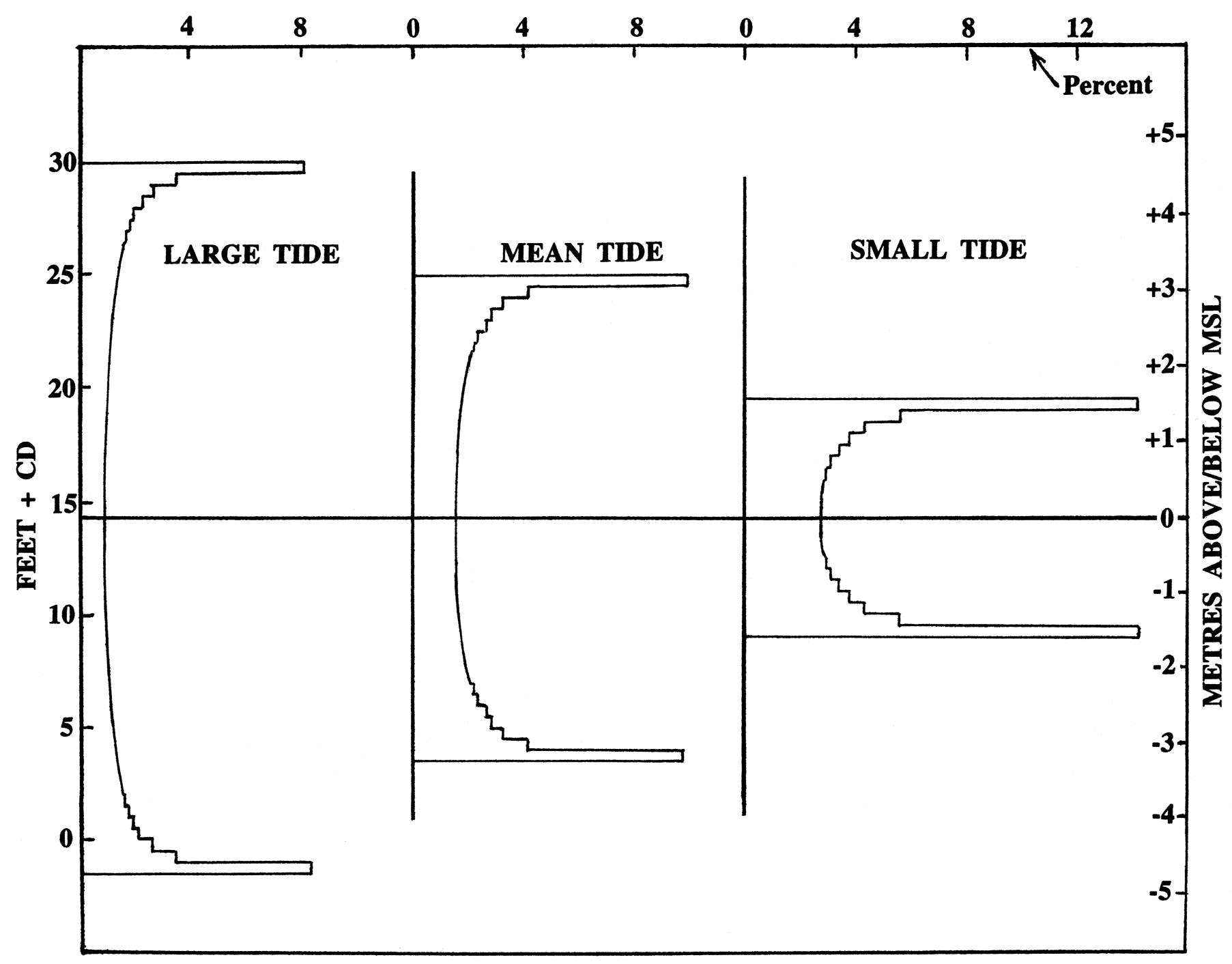

Fig. 25 Profiles across the range of average: large tides, mean tides, and small tides, as recorded at Saint John, N.B., (1947-1964) give the percentage of time that the water surface is located at a particular elevation during different tides $(\mathrm{MSL}=14.36$ feet + CD). Compare with Figs. 26 and 27.

exactly reflects the total time that the water surface is situated at certain levels throughout all tide cycles (Desplanque and Mossman 1998a; c.f. Trenhaile et al. 1998). The profile corresponds of course only with the upper half of the "\% Delta t" line indicated in Fig. 28, because the bottom half of the profile could not be formed due to the collected debris protecting the lower rocks from wave action.

Due to high tidal range, wave energy is thus expended over a considerable range of elevations, the highest being those in certain estuaries leading into the Bay. Using marigrams of various Bay of Fundy estuaries, we have documented the progressive reshaping of the tidal wave over its course and how its sediment-carrying and erosional capacities vary as a consequence of changing water surface gradients; likewise, how intertidal ice conditions contribute additional variations to an already complex tidal regime (Desplanque and Mossman 1998b). Clearly, Bay of Fundy tides play significant roles in a range of important geological processes centered on erosion and sedimentation and bearing directly on coastal construction/installations, dredging, dam and causeway construction, fishing etc. (Daborn and Dadswell 1988; Thurston 1990; Percy et al. 1996).

\subsubsection{Sedimentation and related processes}

Current regimes are critical to sediment dynamics and have significant scientific and economic applications, especially in the area of environmental marine geology. The results of the pioneering work of Pelletier (1974) in the Bay of Fundy suggest that major pulses of hydrodynamic energy are reflected in the coarse-grained sedimentary material concentrates as transverse bands across the central portion of the Bay and at the extreme eastern and western approaches. Pelletier (1974, p. 92) considered it likely that tidal velocities dominate over residual current velocities, and that interaction with the sea floor would produce 


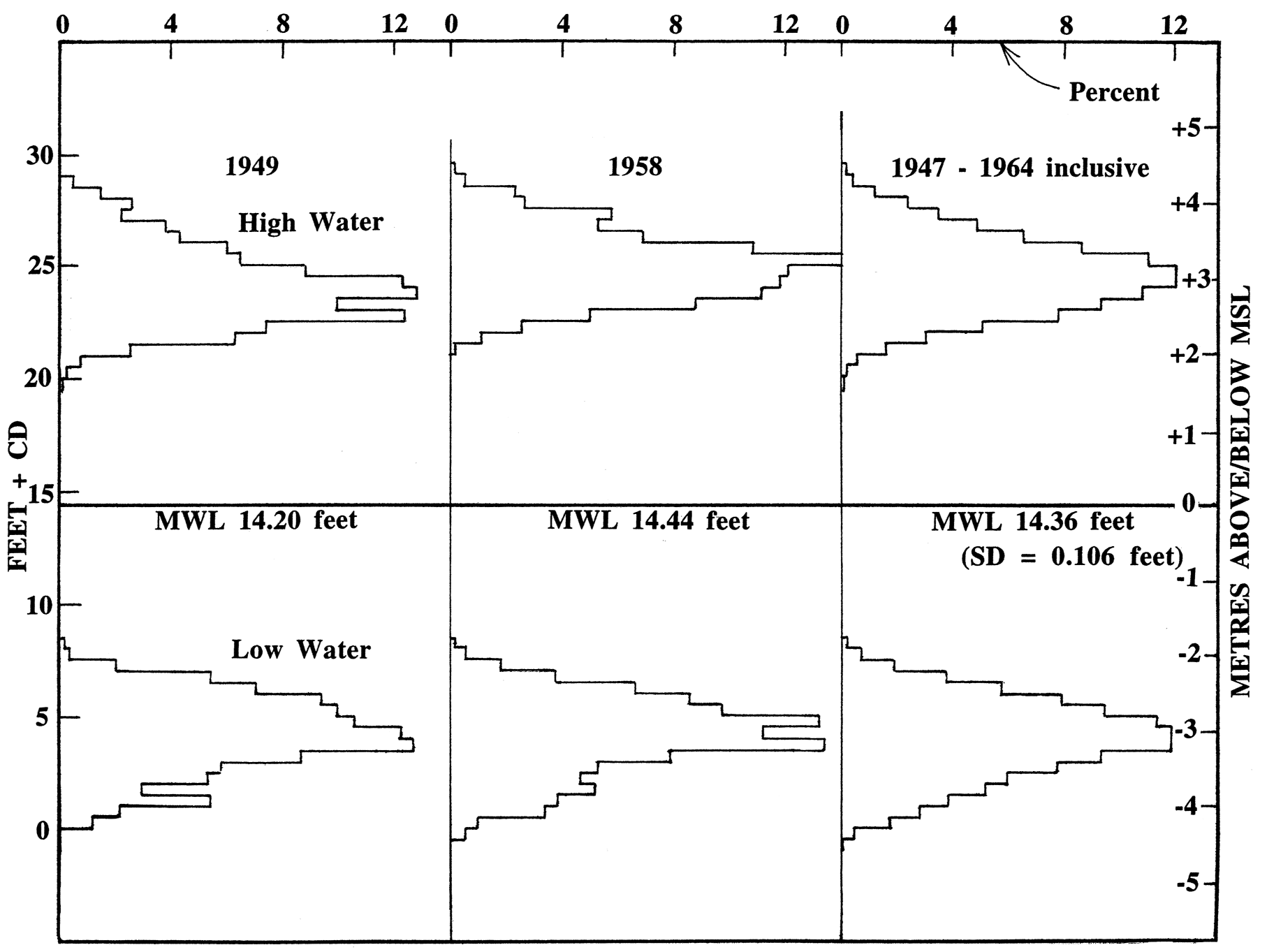

Fig. 26 Histograms show percentage of occurrence, at High Water, and at Low Water, of the water surface at particular elevations (with respect to MSL and CD) during observed tides at Saint John, N.B. for High Water and Low Water. Data apply to: 1949, 1958, and the average for the period 1947-1964 (note the symmetrical average for this interval). Relatively weak tides occurred in 1949 , compared with 1950, a year of strong tides. There is a slight variation in MSL record during these times.

a "wash-board" pattern of sediment distribution. His conclusions are elegantly complemented by the results of recent work by Fader (1996), who assessed surficial sediment stratigraphy, aggregate resources, and seabed dynamics of the inner Bay of Fundy using a new multibeam bathymetric mapping system. Fader (1996) shows the presence of extensive areas of thin gravel lag overlying thick glaciomarine sediments. Overlying the gravel are large transverse fields of active sand bedforms, likely formed by winnowing processes initiated by increases in tidal range about 8000 years BP. The numerous symmetrical sand waves range in length from 0.3 to $0.8 \mathrm{~km}$ and are oriented normal to the length of the Bay.

Fader's interpretation of the bedforms and related processes suggests that the large sand waves are presently inducing scour of the adjacent seabed by virtue of their presence, size and redirection of flow. This localized scour has coalesced in some areas, resulting in major erosion and deepening of the seabed of up to $10 \mathrm{~m}$. The result is the release of large quantities of glacial mud to the water column, leaving behind residual sand deposits (cf. Amos and Joice 1977). Input of this subsea glacial age mud was not previously accounted for in the determination of sediment budgets. It could explain recent increasing mud content and textural alterations on mud flats in the upper Bay of Fundy, which has important implications for the survivability of migratory bird populations (e.g., Shepherd et al. 1995). Indeed, scour of the seabed with localized over-deepening could also explain observations by the fishing community of changing bathymetry. Perhaps more importantly, the apparently active and increasing erosion of the seabed could signal that the Bay of Fundy is experiencing a level of dynamics never before observed. At present, models of resonance length are too coarse to validate these observations, but there seem to be important connections between tides, currents, sedimentation, erosion, and the biological community. Implications of these findings have yet to be applied to seabed fishery management practices. 


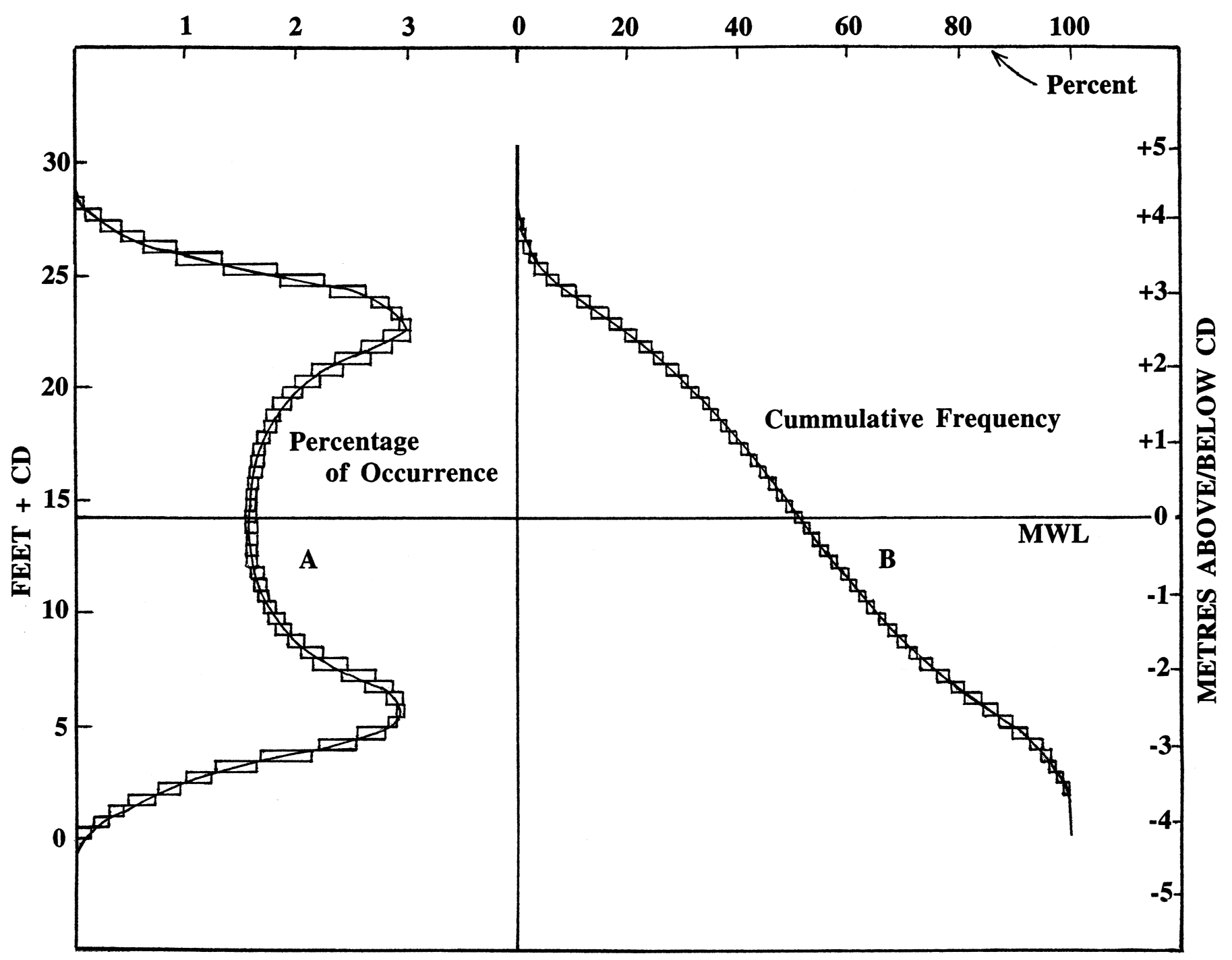

Fig. 27 (A) Profile shows the percentage of time that the water surface is situated in the indicated incremental (0.5 foot) intervals at various elevations with respect to CD. Included here are data for all large, mean, and small tides, as recorded at Saint John, N.B., from 1947 to 1964. (B) Cumulative frequency curve for the level of the water surface during all large, mean, and small tides at Saint John, N.B., from 1947 to 1964. Elevations are given in feet above CD (left hand side), and in metres above MSL (right hand side). See text for details. 


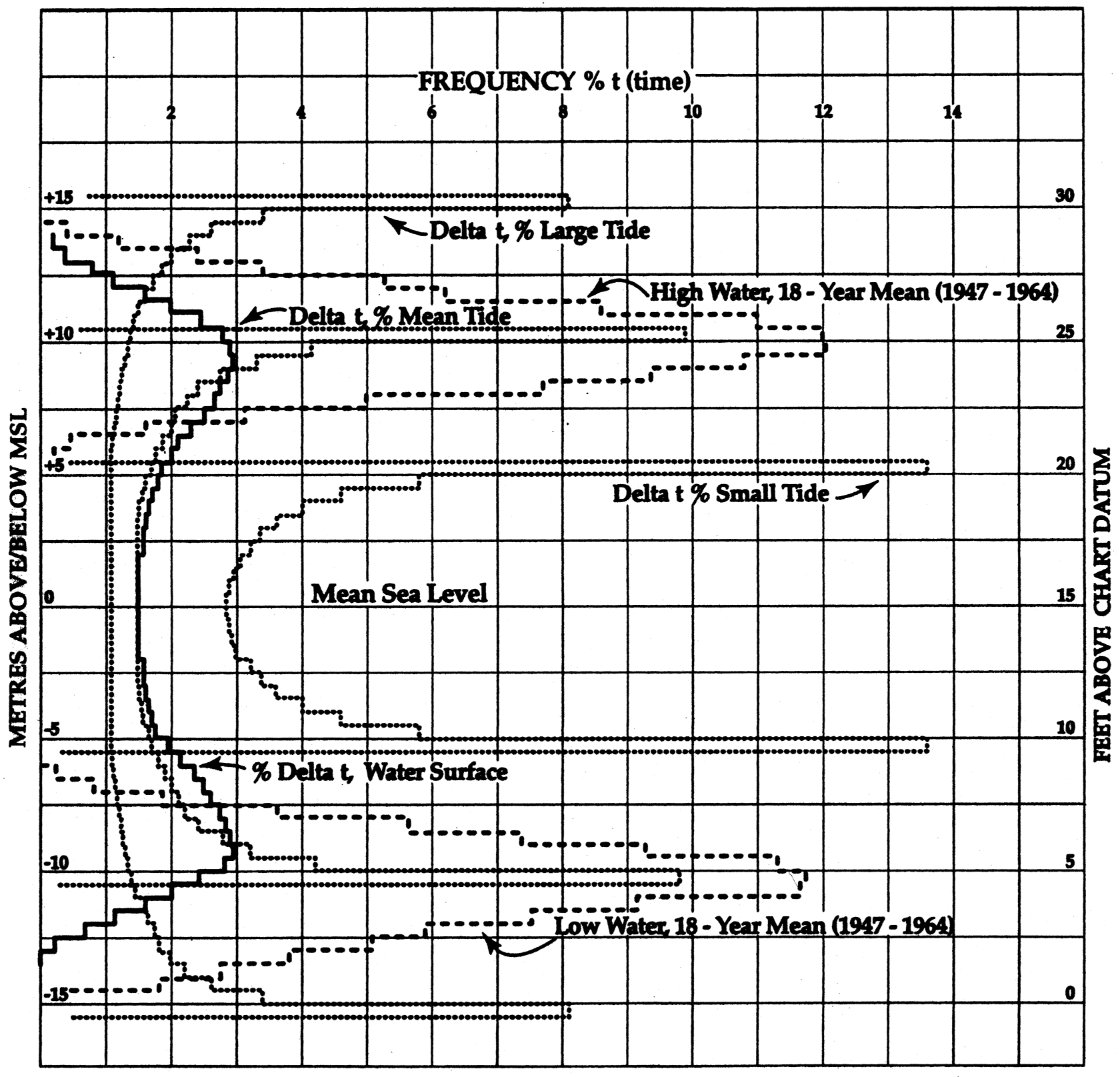

Fig. 28 An 18-year record at Saint John, N.B. (1947-1964). Three histograms (dotted lines) show profiles across the average range of: large tides, mean tides, and small tides, giving the percentage of time that the water surface is located at a particular elevation during different tides [Mean Sea Level $(\mathrm{MSL})=14.36$ feet + Chart Datum $(\mathrm{CD})$ ]. The histograms also show the percentage of occurrence at high water and at low water of the water surface at particular elevations (with respect to MSL and CD) during observed tides. Data apply to 1949, 1958 and the average for the period 1947-1964. There is a slight variation in the MSL record during this time. The two curves (broken lines) show the 18-year mean frequency (Delta $t$ ) of (LW and HW) tides with respect to MSL. The area beneath the "\% Delta $t$, water surface" curve (solid line) gives the percentage of time that the water surface occupied the indicated elevations. 


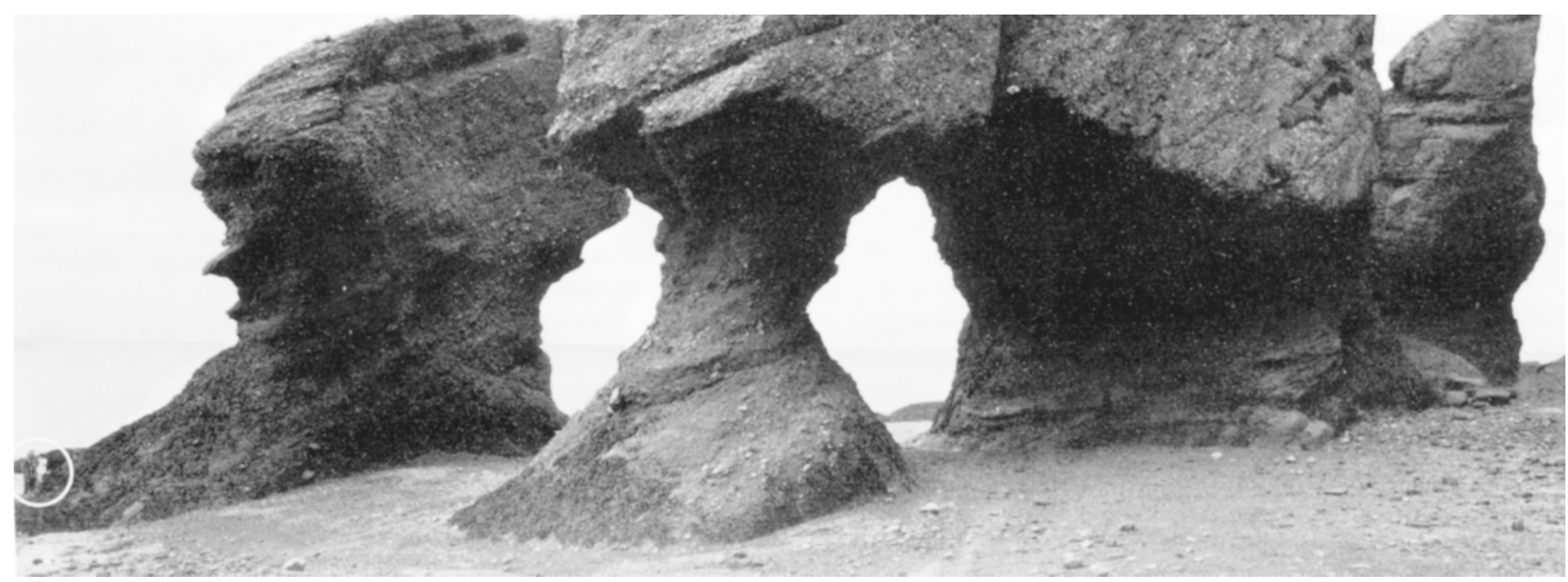

Fig. 29 Shoreline at “The Rocks," Hopewell Cape, N.B., at low tide, 3 p.m., Thursday, 29 June 2000, shows the vertical profile eroded by tidal processes in sub-horizontal Pennsylvanian clastic sedimentary rocks. Individuals circled at lower left provide scale. Photograph by Thaddeus Holownia - with permission. 


\section{Tidal Bores in Estuaries}

\subsection{TIDAL VOLUMES, TIDAL PRISMS}

Tidal waves, as recorded on marigrams, are typically symmetrical, the shape of the falling limb being the mirror image of the rising limb. However a process of translation takes place as a tidal wave enters a shallow estuary. The wave becomes distorted (see equation 7 ), the rising limb being compacted within a shorter period, whereas the period of the falling tidal wave increases (Carter 1998). Friction is often given as the cause, although this is not necessarily so. This is because the rising tide is a function of the predetermined tidal wave, whereas the return is a matter of hydraulics peculiar to that particular channel. We define a tidal river as that stretch of a freshwater river where the dominating factor in shaping the river channel is the freshwater regime. A tidal estuary is the mouth of a tidal river where the tidal flow regime shapes the channel bed. Because tidal range and freshwater flow are variables, the tidal river and the tidal estuary are separated by a transitional section where the dominance of tidal regime and freshwater regime alternate.

The volume of an estuary upstream of an arbitrarily chosen cross-section can be conveniently divided into two parts. The tidal prism is the top part of the estuary between the Low Water and the High Water levels. More simply it is the volume of water flowing in and out of the estuary with the rise and fall of the tide. The tidal volume is that portion below Low Water Level. Because tides are variable in strength, the tidal prism and the tidal volume are variable, as is the wet cross-sectional area through which the water that fills the tidal prism must flow. In general, where a moderate tidal range prevails in combination with deep waters and a limited surface area, only small currents are required in the estuary to have its tide follow the outside tide in terms of vertical movement. An increase in the current speed can only happen when the water surface drops in the direction of flow. In outside tidal waters, the current speed is generally so small that it can be neglected. During Low Water, the upper parts of an estuary may become virtually empty. Water levels in the estuary are only able to match the rising tide if enough water flows through the available cross-sectional area to fill the tidal prism to the level reached by the tide. Except for the extremely critical conditions of tidal bore development, the maximum current speed possible in a cross-sectional area is limited, being proportional to the square root of the water depth. Rectangular cross-sectional areas are able to discharge much more water than either parabolic or triangular cross-sectional areas. Sediment transport is of course associated with the tidal cycle, and at any given location velocity changes in tidal currents bring about periodic changes during flood and ebb portions of the cycle.

The vertical movement $\mathrm{Y}$ of the tide in seas and deep bays can be roughly expressed as:

$$
\mathrm{Y}=\mathrm{A} \cdot \cos (\mathrm{n} \cdot \mathrm{t})
$$

where $\mathrm{A}=$ the amplitude of the tide, $\mathrm{t}=$ the time expired since the occurrence of the High Water selected at the time of origin, $\mathrm{n}=$ the speed number, or the change in angle during a unit of time.

An appropriate speed number ( $\mathrm{n}$ ) for describing average semidiurnal tidal conditions in the Bay is $28.984^{\circ}$ per hour or $1.405 \cdot 10^{-4}$ radians per second. The reciprocal $v$, of the last value is 7116.5 . When seconds are used as time units, (22) can be replaced by:

$$
\mathrm{Y}=\mathrm{A} \cdot \cos (\mathrm{t} / \mathrm{v})
$$

The rate of rise or fall $Y^{\prime}$ per second, of the tide in front of the mouth of the estuary at any value of $t$ or $Y$ can be expressed as:

$$
\begin{aligned}
& Y^{\prime}=-A \cdot \sin (n \cdot t) / v \\
& =( \pm)\left(A^{2}-Y^{2}\right)^{0.5} / v
\end{aligned}
$$

These equations indicate that the rate of rise and fall is strongest when $Y=0$, i.e., when the tide is at Mean Water Level. In the upper reaches of the Bay of Fundy, the mean tidal amplitudes are $6 \mathrm{~m}$. Here, the tide will rise at a rate $\mathrm{Y}^{\prime}$ of $6 / 7116.5=8.4 \cdot 10^{-4}$ $\mathrm{ms}^{-1}$ or over $3.0 \mathrm{~m}$ per hour. To fill a relatively large estuary at this rate requires large amounts of water. The momentary rate of rise $\mathrm{p}_{\mathrm{t}} \mathrm{i}$ in the tidal prism can be expressed as:

$$
\mathrm{p}_{\mathrm{t}}{ }^{\prime}=\mathrm{V}_{\mathrm{mt}} \cdot\left(\mathrm{A}_{\mathrm{t}} / \mathrm{S}_{\mathrm{t}}\right)
$$

where $\mathrm{V}_{\mathrm{m}}=$ the maximum possible flow velocity in cross-section $\mathrm{A}$, and $\mathrm{S}=$ the surface area of the tidal volume at a certain time t.

However, there are conditions in which the rate p' cannot equal $Y^{\prime}$, either because the values of $V_{m}$ and $A$ are relatively small compared to $S$, or because the value $V_{m}$ depends on the depth of the flowing water. In order for the incoming tide to gain speed, the water level of the tidal volume must be below the level of the outside water. If the wet cross-sectional area is $\mathrm{A}$, the required velocity $\mathrm{V}$ through the gap must be at least $\mathrm{Y}^{\prime} \cdot(\mathrm{S} / \mathrm{A}) \mathrm{ms}^{-1}$, because eddies and local currents prevent the total area being available for the discharge. These relationships are explored in greater detail in section 6.3.

\subsection{WAVES OF TRANSLATION - TIDAL BORES}

Basically, a tidal bore is a wave of translation, a hydraulic shock wave formed by a rolling wall of water. Analogous to 
a sonic boom (Lynch 1982), it develops when the rising tide forces water to move up a river channel faster than it otherwise could propagate in a given depth of water. Ideally the tidal range should be high, the river shallow, and the channel gradient slight. In reality a tidal bore is a single wave or a group of symmetrical sine waves that travel upstream signalling the turn of the tide at Low Water. In deep water these waves move at different speeds and separate from each other. However, in shallow water the component waves of the bore are translated into a single wall of water.

An estuary generates a bore when the level of the water surface is unable to keep up with the rising tide. Too small a cross-sectional area is available in the river channel. Thus at the mouth of the estuary more water enters than can be moved along at the front of the bore. The developing wave travels more quickly in deep water than in the shallow water of the estuary. Upstream, cross-sectional area and depth decrease. Consequently, possible current speeds are smaller in front of the advancing wave and the volume of the flow is decreased. As excess water overtakes the bore its height increases. Bore height continues to rise until the rate of rise in the tide becomes insignificant. The bore terminates when the tide reaches its most upstream point in the estuary. Under favourable geographical and astronomical conditions, a bore may be a metres-high wall of water moving up an estuary with a roar heard tens of kilometres distant; under other conditions, it is a leisurely moving ripple.

Waves of translation are surprisingly common. For example, during a heavy rainfall a sheet of water may be seen flowing down a steeply-sloping asphalt street. Here at regular intervals, waves form which move faster the higher they become. Another example occurs with the last uprush of water upon a sandy beach, pushing bits of shell, seaweed and other light materials to the line of its farthest reach. Here it is momentum that carries the water up the beach and over a slope upon which water from the previous wave has mostly been drained. The steep front of the breaking wave is, in effect, the crest of a miniature bore. These waves also occur in canals used for inland navigation when water is suddenly discharged from a reservoir or lock into the canal. Wave height here depends on the amount discharged and the dimensions of the canal. However, this is a negative wave of translation that results in a distinct drop in the level of water moving down a canal. Likewise, a negative bore also may occur when a lock is filled at an appreciable rate. The following theory outlines the conditions governing maximum flow.

\subsection{LIMITING CONDITIONS FOR BORE DEVELOPMENT}

Elementary physics provides the following equations for free fall near the surface of the Earth.

$\mathrm{g}=$ the acceleration $\left(9.806 \mathrm{~ms}^{-2}\right)$ due to the gravitation of the Earth near its surface.

$\mathrm{h}=0.5 \mathrm{~g} \cdot \mathrm{t}^{2}$ $h=$ vertical drop in free fall

$\mathrm{v}=\mathrm{g} \cdot \mathrm{t}$, the speed attained after at the end of a vertical drop

$\mathrm{t}=$ time

Thus:

$$
\mathrm{t}=(2 \mathrm{~h} / \mathrm{g})^{0.5} \text {, and } \mathrm{v}=(2 \mathrm{~g} \cdot \mathrm{h})^{0.5}
$$

Note that this relationship between drop and velocity holds whether the resulting movement is vertical or not. Pressure due to differences in surface elevations will cause the same speeds. Also,

$\mathrm{Q}=\mathrm{c} \cdot \mathrm{v} \cdot \mathrm{A}$, where $\mathrm{Q}=$ volume of water passing through the channel in $1 \mathrm{~s}$ and

$c=$ coefficient of loss in average speed due to eddying and heat production,

$\mathrm{v}=$ theoretical speed $=(2 \mathrm{~g} \cdot \mathrm{h})^{0.5}$

$\mathrm{A}=$ wetted cross-sectional area of channel, and

$\mathrm{D}=$ water depth.

Assume that water is moving from a deep reservoir under the conditions illustrated in Fig. 30. In order to attain a speed $\mathrm{v}$, the surface of the water near the entrance has to drop $h$ metres, causing a pressure on the water in the cross-sectional area equal to the weight of the water in the column $\mathrm{h}$ metres high. In a rectangular channel $\mathrm{B}$ metres wide (Fig. 30) and the water $\mathrm{D}$ metres $(\mathrm{H}-\mathrm{h})$ deep.

$$
\mathrm{Q}=\mathrm{c} \cdot \mathrm{v} \cdot \mathrm{A}=\mathrm{c} \cdot(2 \mathrm{~g} \cdot \mathrm{h})^{0.5} \cdot(\mathrm{H}-\mathrm{h}) \cdot \mathrm{B}
$$

If $\mathrm{h}$ becomes larger, $\mathrm{A}=(\mathrm{H}-\mathrm{h}) \cdot \mathrm{B}$ becomes smaller.

$\mathrm{Q}$ will be zero if $\mathrm{h}=0$ (No speed)

$\mathrm{Q}$ will be zero if $\mathrm{h}=\mathrm{H}=0$ (No area)

$\mathrm{Q}$ will be maximum when $\mathrm{dQ}=0$

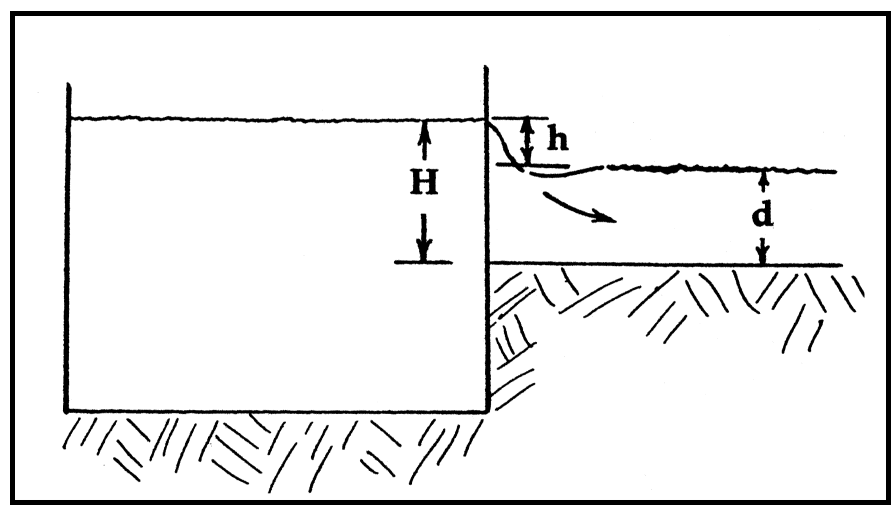

Fig. 30 Sketch illustrates the condition of maximum flow in a rectangular channel caused by a decrease in head $(h)$ of water in a reservoir feeding into a channel $\mathrm{H} \mathrm{m}$ below surface of the water reservoir. The limits for the ratio $\mathrm{d} / \mathrm{H}$ for rectangular, triangular, and parabolic channels respectively, are $0.667,0.80$ and 0.75. For trapezoidal receiving channels, the limit is variable, but somewhere between these limits. 


$$
\begin{gathered}
\mathrm{dQ}=\mathrm{d}(\mathrm{c} \cdot \mathrm{v} \cdot \mathrm{A})=\mathrm{c} \cdot \mathrm{v} \cdot \mathrm{dA}+\mathrm{c} \cdot \mathrm{A} \cdot \mathrm{dv}=\mathrm{c} \cdot \mathrm{d}\left[(2 \mathrm{~g} \cdot \mathrm{h})^{0.5} \cdot \mathrm{A}\right] \\
\mathrm{dQ} /\left[\mathrm{c} \cdot(2 \mathrm{~g})^{0.5}\right]=\mathrm{d}\left(\mathrm{h}^{0.5} \cdot \mathrm{A}\right)=0 \\
0=\mathrm{h}^{0.5} \cdot \mathrm{dA}+\mathrm{A} \cdot \mathrm{dh}^{0.5}
\end{gathered}
$$

When $\mathrm{dA}$ is positive, $\mathrm{dh}$ will be negative, and since $\mathrm{dA}=\mathrm{B} \cdot \mathrm{dh}$, where $B$ is the surface width of the flowing water:

$$
h^{0.5} \cdot \mathrm{B} \cdot \mathrm{dh}=\mathrm{A} \cdot \mathrm{dh} /\left(2 \cdot \mathrm{h}^{0.5}\right), \text { or } \mathrm{h}=\mathrm{A} /(2 \mathrm{~B})
$$

Note that the condition of maximum flow is caused by the drop (or head) h metres, which is equal to the wet cross-sectional area A prevailing in that condition, divided by twice its surface width. This is valid for all shapes of channels. For rectangular (r) or very wide channels $\mathrm{A}=\mathrm{B} \cdot \mathrm{D}$ and:

$$
\mathrm{h}_{\mathrm{r}}=\mathrm{D} / 2=\mathrm{H} / 3 \text {, and } \mathrm{D}_{\mathrm{r}}=2 \mathrm{H} / 3
$$

For triangular $(\mathrm{t})$ channels $\mathrm{A}=\mathrm{B} \cdot \mathrm{D} / 2$ and:

$$
\mathrm{h}_{\mathrm{t}}=\mathrm{D} / 4=\mathrm{H} / 5 \text {, and } \mathrm{D}_{\mathrm{t}}=4 \mathrm{H} / 5
$$

For parabolic-shaped $(\mathrm{p})$ channels $\mathrm{A}=2 \mathrm{~B} \cdot \mathrm{D} / 3$, where $(\mathrm{B}=$ $\mathrm{K} \cdot \mathrm{D}^{0.5}$ ), and:

$$
h_{p}=D / 3=H / 4 \text {, and } D_{p}=3 H / 4
$$

Thus the speed of the water flowing into the channel will be highest when the channel has a flat bottom. The maximum flow $\mathrm{Q}_{\mathrm{r}}$ in a rectangular or flat-bottomed channel will be:

$$
\mathrm{Q}_{\mathrm{r}}=\mathrm{c} \cdot(2 \mathrm{~g} \cdot \mathrm{H} / 3)^{0.5} \cdot \mathrm{B} \cdot 2 \mathrm{H} / 3=1.705 \mathrm{c} \cdot \mathrm{B} \cdot \mathrm{H}^{1.5} \mathrm{~m}^{3} \mathrm{~s}^{-1}
$$

The maximum flow $\mathrm{Q}_{\mathrm{t}}$ in a triangular channel, where $\mathrm{B}=\mathrm{kD}, \mathrm{k}$ $=$ the relationship between surface width and maximum depth of water, and $\mathrm{A}=0.32 \mathrm{k} \cdot \mathrm{H}^{2}$, will be:

$$
\mathrm{Q}_{\mathrm{t}}=0.32 \mathrm{c} \cdot \mathrm{k}(2 \mathrm{~g} \cdot \mathrm{H} / 5)^{0.5} \cdot \mathrm{H}^{2}=0.634 \mathrm{c} \cdot \mathrm{k} \cdot \mathrm{H}^{2.5} \mathrm{~m}^{3} \mathrm{~s}^{-1}
$$

The maximum flow $\mathrm{Q}_{\mathrm{p}}$ in a parabolic channel, where $\mathrm{B}=\mathrm{k} \cdot \mathrm{D}^{0.5}$ and $\mathrm{A}=0.433 \mathrm{k} \cdot \mathrm{H}^{1.5}$ will be:

$$
\mathrm{Q}_{\mathrm{p}}=0.433 \mathrm{c} \cdot \mathrm{k}(2 \mathrm{~g} \cdot \mathrm{H} / 4)^{0.5} \cdot \mathrm{H}^{1.5}=0.959 \mathrm{c} \cdot \mathrm{k} \cdot \mathrm{H}^{2} \mathrm{~m}^{3} \mathrm{~s}^{-1}
$$

Thus, the maximum discharge in a receiving channel depends on the height $(\mathrm{H})$ between the bottom of the channel and the surface elevation of the body supplying the water.

In a sinusoidal tidal movement the height of the tide can be expressed as:

$$
T=-A_{t} \cdot \cos (2 \pi \cdot t / 44714)=-A_{t} \cdot \cos \left(1.405 \cdot 10^{-4} \cdot t\right)
$$

where $A_{t}=$ tidal amplitude (half range), and $t=$ is time from Low Water, in seconds. The rate of rise and fall of the tide can be expressed with the derivative of the above equation:

$$
\begin{gathered}
\mathrm{dT} / \mathrm{dt}=1.405 \cdot 10^{-4} \cdot \mathrm{A}_{\mathrm{t}} \cdot \sin \left(1.405 \cdot 10^{-4} \cdot \mathrm{t}\right)= \\
1.405 \cdot 10^{-4} \cdot\left(\mathrm{A}_{\mathrm{t}}^{2}-\mathrm{T}^{2}\right)^{0.5}
\end{gathered}
$$

If the bottom of the tidal channel is at elevation $\mathrm{F}$, and a velocity head $h$ is required to move water at a certain speed $v$, over the flat, then the depth $\mathrm{D}$, in the channel is:

$$
\mathrm{D}=\mathrm{T}-\mathrm{h}-\mathrm{F} \text { and its derivative is }
$$$$
\mathrm{d}(\mathrm{D})=\mathrm{dT}-\mathrm{d}(\mathrm{h})
$$

In order to establish the dimensions of discharge sluices in major Bay of Fundy estuaries, it was necessary for the MMRA to determine the volume $\mathrm{P}$ of the tidal prism upstream of the construction sites. Following surveys it was found that there was a rather constant relationship between the tidal crosssection $\mathrm{A}$ and the volumes $\mathrm{P}$ of the tidal prisms upstream of them. A general relationship for estuaries or tidal basins has been proposed by Jarrett (1976) and by Van de Kreeke (1998). Regional characteristics determine the constant and the power of A. This relationship can be empirically expressed as:

$$
\mathrm{P}=113.27 \mathrm{~A}^{1.54} \mathrm{~m}^{3}
$$

Tidal estuaries where bores occur are flat bottomed and the width is large compared with the possible water depth. Thus the cross-section is close to rectangular in shape. The following discussion assumes a rectangular cross-section. Thus $\mathrm{A}=\mathrm{B} \cdot \mathrm{D}$.

Taking $\mathrm{d}(\mathrm{h})$ as zero, so that the volume of a rectangular tidal prism to be filled in 1 second becomes:

$$
\begin{gathered}
\mathrm{dP}_{\mathrm{t}}=1.54 \cdot 113.27 \cdot \mathrm{B}^{1.54} \cdot \mathrm{D}^{0.54} \cdot \mathrm{d}(\mathrm{D}) \\
\mathrm{dP}_{\mathrm{t}}=174.44 \cdot \mathrm{B}^{1.54} \cdot \mathrm{D}^{0.54} \cdot \mathrm{d}(\mathrm{D})
\end{gathered}
$$

and

$$
\mathrm{dP}_{\mathrm{t}} / \mathrm{dt}=174.44 \cdot \mathrm{B}^{1.54} \cdot \mathrm{D}^{0.54} \cdot 1.405 \cdot 10^{-4} \cdot\left(\mathrm{A}_{\mathrm{t}}{ }^{2}-\mathrm{T}^{2}\right)^{0.5}
$$

whence

$$
\mathrm{Q}=\mathrm{dP}_{\mathrm{t}} / \mathrm{dt}=0.0245 \cdot \mathrm{B}^{1.54} \cdot \mathrm{D}^{0.54} \cdot\left(\mathrm{A}_{\mathrm{t}}^{2}-\mathrm{T}^{2}\right)^{0.5}
$$

To calculate the velocity $\mathrm{v}$ of the water, this discharge $\mathrm{Q}$ is divided by the area $\mathrm{A}=\mathrm{B} \cdot \mathrm{D}$

$$
\mathrm{v}=0.0245 \cdot \mathrm{B}^{0.54} \cdot\left(\mathrm{A}_{\mathrm{t}}{ }^{2}-\mathrm{T}^{2}\right)^{0.5} / \mathrm{D}^{0.46}
$$

From elementary physics the required velocity head $h$ to generate this speed is $\mathrm{v}^{2} /(2 \mathrm{~g})$, whence

$$
\mathrm{h}=3.063 \cdot 10^{-5} \cdot \mathrm{B}^{1.08} \cdot\left(\mathrm{A}_{\mathrm{t}}{ }^{2}-\mathrm{T}^{2}\right) / \mathrm{D}^{0.92}
$$

The maximum flow discharge is reached when this velocity head $\mathrm{h}=\mathrm{D} / 2$. Whence

$$
\mathrm{D}=\left[6.125 \cdot 10^{-5} \cdot \mathrm{B}^{1.08} \cdot\left(\mathrm{A}_{\mathrm{t}}^{2}-\mathrm{T}^{2}\right)\right]^{(1 / 1.92)}
$$

Thus, maximum flow will be reached when the bottom $\mathrm{F}$, of the channel, is at elevation $\mathrm{T}-1.5 \mathrm{D}$. If the channel bottom is 
higher, the inflow of water will be insufficient to fill the estuary at almost the same rate as the tide is rising. The level in the estuary has to lag behind because of the velocity head required to generate the discharge into the estuary. This velocity head is, of course, also changing with time. The examples given in Table 15 illustrate specific conditions that favour bore formation.

Note that the critical depth does not change much when the tide is near mean sea level. Thus the simplification of neglecting $\mathrm{d}(\mathrm{h}) / \mathrm{dt}$ has no serious effects. Note too that the critical bottom elevation is at lower elevations when the channel is wider. Therefore the bore can start as soon as these conditions are met.

As not enough water can enter to raise the water levels at the same rate as the tidal waters, the water that is able to enter the estuary will flow at the maximum speed, depending on the depth of the water. The first water to enter flows considerably slower than that which follows, as depth increases. In fact the later water will overtake the earlier water, with the result that the wave entering the estuary will do so as a bore of increased height. The water in the bore front is thus a mixture of volumes of water that had different initial speeds and momentum. For this reason the speed $V_{b}$ of the bore is likely to be somewhat less than maximum flow speed indicated by the height $\mathrm{H}$ of the bore. Thus:

$$
\mathrm{V}_{\mathrm{b}} \approx(\mathrm{g} \cdot \mathrm{H})^{0.5} \mathrm{~ms} \text {, or } 3.6(\mathrm{~g} \cdot \mathrm{H})^{0.5} \mathrm{~km} / \text { hour }
$$

Note that the maximum flow condition is actually unstable, although depths can deviate slightly from the critical depth without changing the discharge very much. This could explain the presence of "whelps" behind the bore front. Whelps are waves that are very conspicuous after the passage of the bore. But even if maximum flow conditions are not reached, the water surface elevation in the estuary will always be lower than the rising water in the tidal sea. This is because of the required velocity heads. Thus water near the head of the estuary will be flowing on a slope with decreasing cross-sectional area. Consequently the sinusoidal wave is distorted and becomes less and less symmetrical. This can be illustrated by plotting the centre line in marigrams, obtained at different locations along the estuary (see section 7.2).

A bore will be formed if the frontal part of the distorted tidal wave becomes vertical. It will grow in size when it flows over horizontal bottom plain(s). However, if the elevation of the estuary bottom is rising steeply, there is less chance of a large bore due to inadequate distance and time. When a tidal bore flows over a dry tidal flat, or shallow water, its progress is unrestricted. But as soon as the original water depth is $2 / 3$ or more of the water depth of the bore, maximum flow conditions no longer prevail and progress becomes restricted. This figure approaches the 1.4 ratio, evidently the dividing condition between breaking and non-breaking bores. Note that in parabolic-shaped channels the original water depth would interfere when $3 / 4$ of the bore depth, a figure corresponding with a ratio of 1.33 .

With the exception of the Bay of Fundy, tides along the coastlines of North America are not particularly strong and
Table 15. Data for two hypothetical river channels illustrate conditions favouring tidal bore formation

\begin{tabular}{|c|c|c|c|}
\hline $\begin{array}{c}\text { Tidal } \\
\text { elevation } \\
\mathrm{m}+\mathrm{MSL}\end{array}$ & $\begin{array}{c}\text { Depth }(\mathrm{d}) \\
\mathrm{m}\end{array}$ & $\begin{array}{c}\text { Velocity } \\
\text { head (h) } \\
\mathrm{m} / \mathrm{s}\end{array}$ & $\begin{array}{l}\text { Critical bottom } \\
\text { elev }(\mathrm{T}-\mathrm{h}-\mathrm{d}) \\
\mathrm{m}+\mathrm{MSL}\end{array}$ \\
\hline
\end{tabular}

Case 1: Tidal amplitude $=6 \mathrm{~m}$; Width of tidal channel $=500 \mathrm{~m}$

$\begin{array}{llll}-5 & 0.735 & 0.367 & -6.102 \\ -4 & 1.003 & 0.501 & -5.505 \\ -3 & 1.173 & 0.586 & -4.760 \\ -2 & 1.282 & 0.641 & -3.923 \\ -1 & 1.343 & 0.671 & -3.014 \\ 0 & 1.363 & 0.681 & -2.044 \\ 1 & 1.343 & 0.671 & -1.015 \\ 2 & 1.282 & 0.641 & 0.076 \\ 3 & 1.173 & 0.586 & 1.239 \\ 4 & 1.003 & 0.501 & 2.294 \\ 5 & 0.735 & 0.367 & 3.697 \\ 6 & 0.000 & 0.000 & 6.000\end{array}$

Case 2: Tidal amplitude $=6 \mathrm{~m}$; Width of tidal channel $=1500 \mathrm{~m}$

$\begin{array}{llll}-5 & 1.363 & 0.681 & -7.045 \\ -3 & 2.176 & 1.088 & -6.265 \\ -1 & 2.492 & 1.246 & -4.738 \\ 1 & 2.492 & 1.246 & -2.738 \\ 3 & 2.176 & 1.088 & -0.265 \\ 5 & 1.363 & 0.681 & 2.954\end{array}$

thus not conducive to the formation of tidal bores. However, the bottom gradients of the Bay of Fundy are too steep to permit a large bore to develop. Thus, a tide with an amplitude of $5 \mathrm{~m}$ can only develop a bore $0.6 \mathrm{~m}$ high after travelling 6.2 $\mathrm{km}$ over a horizontal plane. With a tide of $2.6 \mathrm{~m}$ amplitude it requires a distance of $12 \mathrm{~km}$, and with an amplitude of 1.5 $\mathrm{m}$, a distance of $21 \mathrm{~km}$ is needed in order to develop a $0.6 \mathrm{~m}$ high bore. No bore will form with a tide of $5 \mathrm{~m}$ amplitude if the estuary gradient is steeper than 0.000193 . A tide of $2.6 \mathrm{~m}$ amplitude cannot form a bore in a channel with a gradient more than 0.0001. In short, channels of certain dimensions can discharge quantities of water up to a certain limit, at which point maximum flow conditions prevail.

\subsection{TIDAL BORES IN THE BAY OF FUNDY}

The global catalogue of tidal bores (Bartsch-Winkler and Lynch 1989) includes five of the main bores from the Maritime Provinces, all in the Bay of Fundy area. These are in the Hebert, Maccan, Salmon and Shubenacadie rivers (Nova Scotia) and in the Petitcodiac River (N.B.). Each constitutes an important tourist attraction at several localities. The rivers Hebert and Maccan empty into Cumberland Basin upstream from Fort Beausejour. Like all Fundy examples, the height of bores developed in these two rivers is variable, being dependent upon 
predictable astronomical conditions. The chief controlling factor is the rate of rise of water in Cumberland Basin, which of course peaks during either the new moon or the full moon phase, whichever is closest to perigee. Compared to predicted arrival times of tides using Saint John tidal data, the arrival time of the bores in these two rivers is generally earlier at spring tides than at neap tides. The same is true of the Shubenacadie and Salmon River bores near the head of the Minas Basin.

In contrast to the Hebert, Maccan, and Salmon rivers, the (observed) arrival times of the bore in the Petitcodiac River at Moncton is delayed more at spring tides than at neap tides. A check on the difference between predicted and observed tides at Saint John, and the prevalent weather conditions at the time, rules out weather as a cause of the delay. The explanation may lie in the fact that the Petitcodiac River bottom is below mean sea level, whereas at the other localities, river bottoms are well above mean sea level.

Unfortunately, a causeway built in 1968 upstream from Moncton shortened the estuary by about $21 \mathrm{~km}$ and decreased its tidal prism by about $20 \cdot 10^{6} \mathrm{~m}^{3}$. A similar story applies to numerous estuaries: when estuary equilibrium is disturbed, channel readjustment follows. In the Petitcodiac, the decreased outgoing tidal flow was no longer able to remove as much silt as previously (Thurston 1990). Consequently the channel lost $450 \mathrm{~m}$ of its width and the bottom gradient became steeper because of a tremendously increased rate of silt accumulation. For example, between 1968 and 1971, an estimated $10 \cdot 10^{6} \mathrm{~m}^{3}$ of sediment accumulated in the estuary.

Change in shape of the channel has greatly affected the size of the bore (Figs. 31, 32), which now must follow a steeper, more tortuous channel. As a result the bore falls far short of the $1.2 \mathrm{~m}$ height that it had prior to causeway construction. Further, the arrival time of this tidal bore has also changed during the last several decades. In 1920 Dr. W. Bell Dawson determined that the Petitcodiac bore occurred 2 hours and 22 minutes before High Water (spring tide) in Saint John. The present daytime difference between the arrival of the bore and Saint John High Water of 1 hour and 38 minutes indicates that the causeway and resultant change in the shape of the Petitcodiac River estuary has retarded the arrival of the bore by almost one hour since 1920. (The Bell Dawson difference was used and mentioned as a footnote in the tide tables between 1922 and 1983 inclusive. In the 1984 tables a shift was made to the new difference of 1 hour and 38 minutes).

\subsection{QUIANTANG RIVER BORE, CHINA}

The decline of the Petitcodiac bore disappoints local tourists and tourism promoters alike. In curious contrast, in China there is an ambitious program to suppress the bore in the Quiantang River. This bore and those of the Amazon delta (McIntyre 1972) are among of the most spectacular in the world. In the case of the Quiantang River, the drainage area is about $50000 \mathrm{~km}^{2}$ (roughly equivalent to the watershed of the Saint John River, N.B.). Its tidal section starts at Fuyang, which is occasionally reached by a bore. However, the estuarine portion commences $18 \mathrm{~km}$ downstream of Fuyang, at Wenjiayan, and continues $101 \mathrm{~km}$ further downstream to Ganpu (Fig. 33). The main tidal channel shifts frequently, sometimes $245 \mathrm{~m}$ a day. Near Hanghzou the width of the estuary is about $1 \mathrm{~km}$, and $20 \mathrm{~km}$ at Ganpu. Beside the tidal channels are vast tidal flats raised to about $1.2 \mathrm{~m}$ below the highest tide levels. During low tide the channel is shallow, many sections having a depth of 1 to $2 \mathrm{~m}$, but even here where flow is rapid, ships of 100 tonnes or less can navigate.

Beyond Ganpu is the flaring Hangzou Bay, which runs 100 $\mathrm{km}$ to its $95 \mathrm{~km}$ wide mouth, open to the East China Sea. The

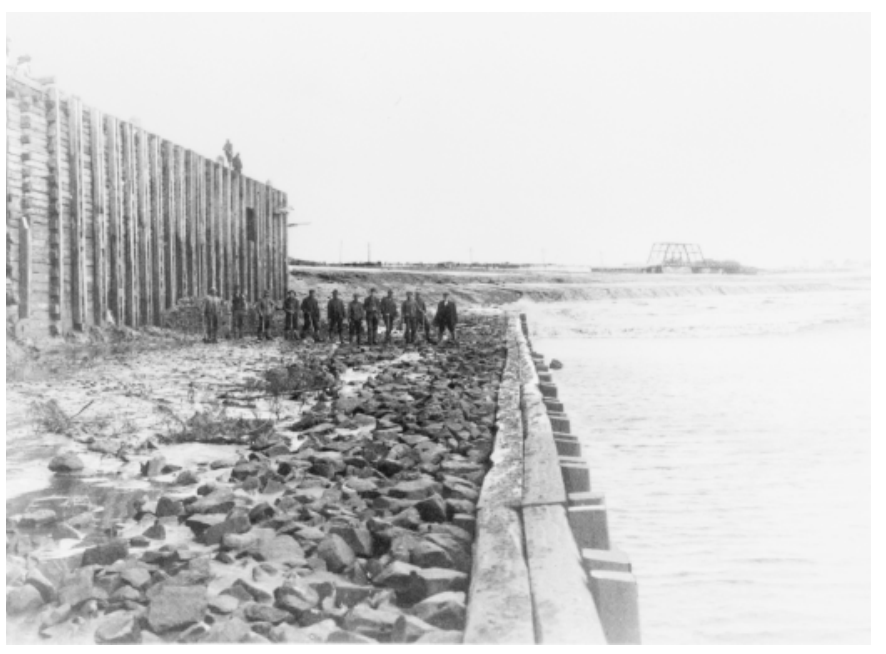

Fig. 31 Tidal bore on the Petitcodiac River, viewed (ca. 1964) from the old Irving Oil dock in Dieppe, N.B. This bore started to develop at Stony Creek near Dover, $10 \mathrm{~km}$ downstream from Moncton/Dieppe, and $17.5 \mathrm{~km}$ upstream from Dorchester Cape. Photograph New Brunswick Provincial Archives. Photograph by David Coon, Conservation Council of New Brunswick - with permission.

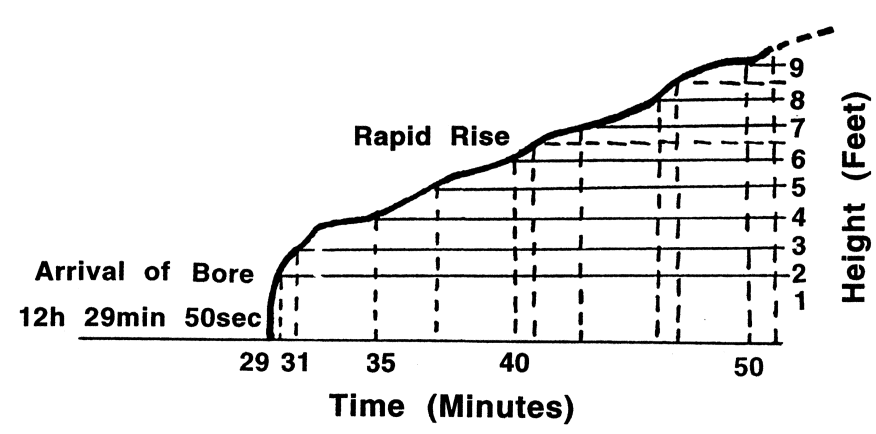

Fig. 32 Cross-section of the Petitcodiac tidal bore at Moncton, N.B. determined by measurement of water height with passage of time. Note the 2 -foot $(0.61 \mathrm{~m})$ high steep front of the bore, the relatively rapid rise to 3 -feet $(0.91 \mathrm{~m})$ and the further 6-foot $(1.83 \mathrm{~m})$ rise during the next 20 minutes. Modified after Clancy (1969, p. 120). 
tidal range in Hangzhou Bay doubles over this distance of $100 \mathrm{~km}$ to a maximum range of $8.93 \mathrm{~m}$ at Ganpu. This rate of increase is $0.7 \%$ per kilometre, twice the rate of the Bay of Fundy. Upstream from Ganpu, the river bed rises abruptly and the channel becomes shallow. According to Dai Zeheng (1982), the bore begins to form near Jianshan $19 \mathrm{~km}$ upstream from Ganpu, and reaches its maximum height in the vicinity of Baboa $(33 \mathrm{~km})$ and Haining $(40 \mathrm{~km})$ (see Figs. 34 and 35 ). The height of the bore is normally 1 to $2 \mathrm{~m}$, but reaches a maximum height of $3 \mathrm{~m}$. It usually travels $5-7 \mathrm{~ms}^{-1}(18-25$ $\mathrm{km} / \mathrm{hr}$ ) but has been recorded at $12 \mathrm{~ms}^{-1}(43 \mathrm{~km} / \mathrm{hr}$ ) (van der Oord 1951). Stretched across the 3 to $10 \mathrm{~km}$ wide channel, it moves upriver like a silver curtain with a roar that can be heard over a distance of $20 \mathrm{~km}$.

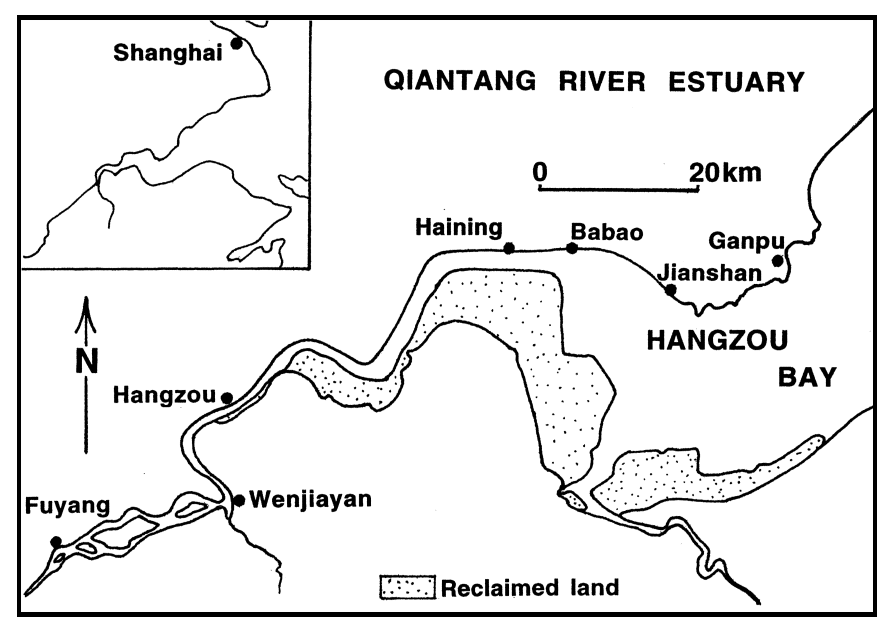

Fig. 33 Map of Qiantang River estuary near Hangzhou, China. After Dai Zeheng (1982, p. 2).
Although there are few accounts of the Qiantang bore in western literature (see Darwin 1898), the bore must have been present in the river for at least the last 1000 years. Long standing doubts of its existence probably arose because Marco Polo never mentioned the bore in his detailed account of the city of Hangzhou (which he called Kinsai). According to Masefield (1926), Marco Polo probably left this tale untold lest he lose all credibility. Unfortunately the original manuscript is lost, and the oldest written account of his story dates from 1559 . The tale of a metres-high wall of water entering the river at regular intervals was probably demanding too much from his audience.

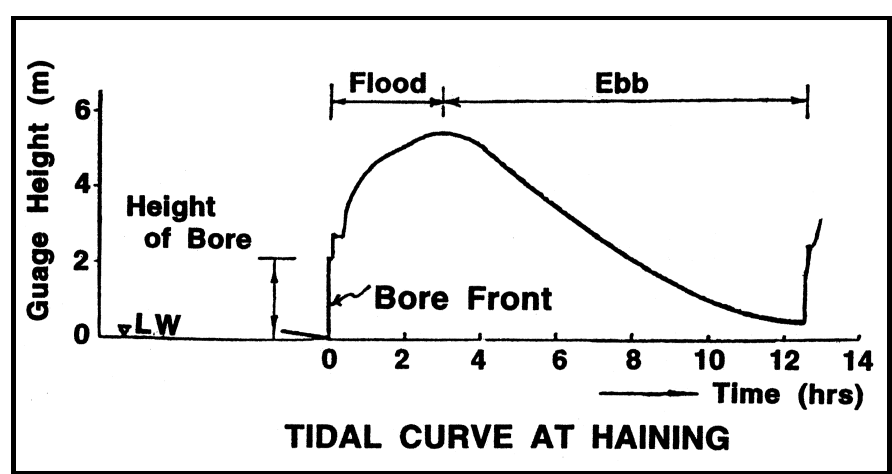

Fig. 35 The tidal curve of the "crossing bore", also known as the "rolling thunder" and the "wet wild beast". $\mathrm{LW}=$ low water. From Dai Zeheng (1982, p. 3), with permission.

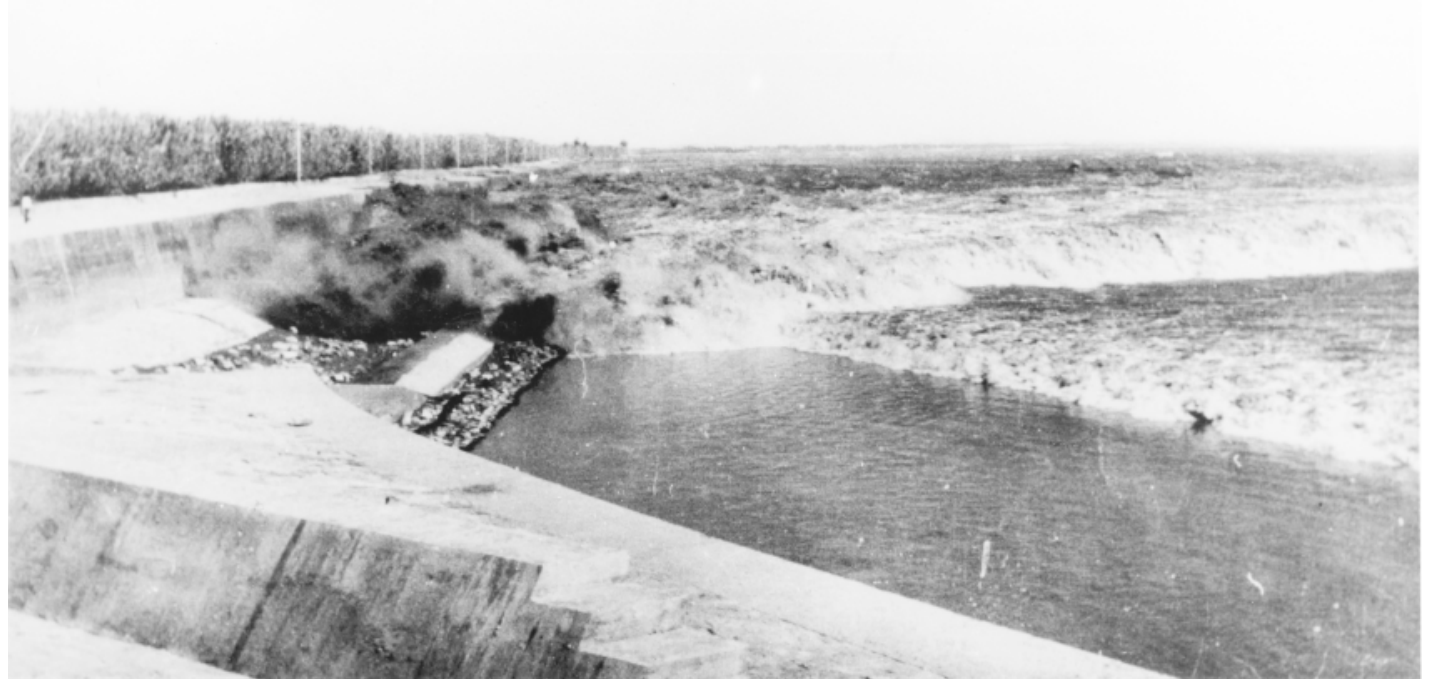

Fig. 34 The "crossing bore" at Babao, Haining, China, 1975. For scale, note the person standing on the wall (left side of photo). Photograph by Dai Zeheng - with permission. 


\section{Ebb and Flow in Estuaries}

\subsection{INTRODUCTION}

Because tides are variable in strength, the tidal prism and tidal volume in an estuary are also variable as is the wet crosssectional area, which is that part of the total cross-sectional area filled with water. As discussed in section 6.3 , it is through this wet area that the water which fills the tidal prism must flow. The upper parts of an estuary may become virtually empty during Low Water. Water levels in the estuary are only able to match the rising tide if enough water flows through the available crosssectional area to fill the tidal prism to the level reached by the tide (Lauff 1967; Carter 1998). In many cases this is physically impossible as the maximum current speed possible in a crosssectional area is limited, being proportional to the square root of the water depth (Kjerfve 1988). Rectangular cross-sectional areas are able to discharge much more water than either parabolic or triangular cross-sectional areas because the larger cross-sections allow higher current velocities.

In channels that empty, or nearly empty, during Low Water, the first water to return after the turn of the tide is very much restricted moving into the estuary. This is so even discounting friction, because the water depth and cross-sectional area are very small or zero. However the following water finds a partly filled channel and can thus move faster and at a greater discharge rate. As long as the discharge is inadequate to fill the tidal prism at the same rate of rise of water surface as the outside water, the result is that the seaward gradient of the incoming water will initially have a strong upward curvature. This curvature may become so strong that a bore will form at the bottom of the incoming wave.

What happens when, at a certain location in the estuary, the water reaches its highest level? Certainly the more upstream parts of the estuary remain unfilled with water. Seaward of this point the water level is already falling. Thus water continues moving landward on its own inertia when the high tide level is reached at that point. As a result, the water surface has already dropped before the direction of flow reverses. Thus the time of peak elevation and zero velocity are not coincident. When the water ceases its advance into the estuary it has already a considerable downward slope seaward. Soon a sizable seaward current develops, occupying a smaller cross-sectional area than when it moved into the estuary on the rising tide. The falling water level may at first follow the outside tide rather well because of the large cross-sectional areas, but progressively the reduced depth restricts water outflow. Consequently the seaward gradient of the water surface during ebb flow now has a downward curvature.

In terms of sediment transport this means that while the incoming tide is at high levels and gradually reducing in speed, its sediment carrying capacity is reduced (Amos and Tee 1989; Amos 1995a). Much of the released sediment is spread over the full height of the channel banks, and during very high tides, over the salt marshes also (Postma 1967). However the outgoing tide is concentrated toward the bottom of the channel, having at times higher speeds than the incoming tide. This situation promotes erosion through undercutting of the channel banks. Excess material high on the banks will slide down, resulting in unstable soil conditions. In testimony, the banks of tidal creeks and rivers in the Bay of Fundy region are characteristically bare of any vegetation except perhaps for some being transported downslope by undercutting (Scott 1980). Only where currents are slight is vegetation able to take root. Overall the intertidal flats of estuaries may vary seasonally, storing clays and silts during summers and removing them during heavy freshwater run-offs.

\subsection{RESHAPING THE TIDAL WAVE THROUGH TIME}

\subsubsection{The Shubenacadie estuary}

When the tidal wave enters a shallow estuary its sinusoidal symmetry becomes distorted. The rising limb of the curve becomes compacted within a shorter period, whereas the period of the falling tidal wave increases. The manner in which a tidal wave may be reshaped as it moves into an estuary is well illustrated by conditions in the Shubenacadie and Cornwallis river estuaries in Nova Scotia (for locations see Figs 3 and 43). At the mouth of the Shubenacadie estuary the rising tide is retarded by the shallow waters of Cobequid Bay (see Fig. 36). However, the centreline $\left(\mathrm{CL}_{1}\right)$, being the locus halfway between rising and falling tide levels at Black Rock at the mouth of the river, is almost straight and vertical in the uppermost part of the marigram. This means that there is little distortion in the symmetrical shape of the local tide wave. The near-vertical rise of the tide at the bottom of the incoming tide wave (K) indicates that a bore may possibly develop.

The curvature (asymmetry) of the centre lines at locations further upstream indicates that the tidal wave is becoming increasingly distorted with much steeper rises of the tide, and slower rates of drop. Meanwhile, the thalweg (the median line of the channel) of the estuary is rising at some distance beneath points $\mathrm{K}, \mathrm{L}, \mathrm{M}, \mathrm{N}$, and $\mathrm{O}$ (which indicate the water level in the river before the tide wave arrives), thus increasingly limiting the inflow of tidal water. The High Water levels rise for about the first $8.3 \mathrm{~km}$ (A to B in Fig. 36) before gradually dropping (B to $\mathrm{E}$ ). This situation is reflected by the asymmetry of the marigrams, as indicated by the increasing curvatures of their centrelines $\left(\mathrm{CL}_{1}\right.$ to $\left.\mathrm{CL}_{5}\right)$ with distance from the river mouth. Eventually, the water levels in the river will fall back to $\mathrm{K}, \mathrm{L}$, 


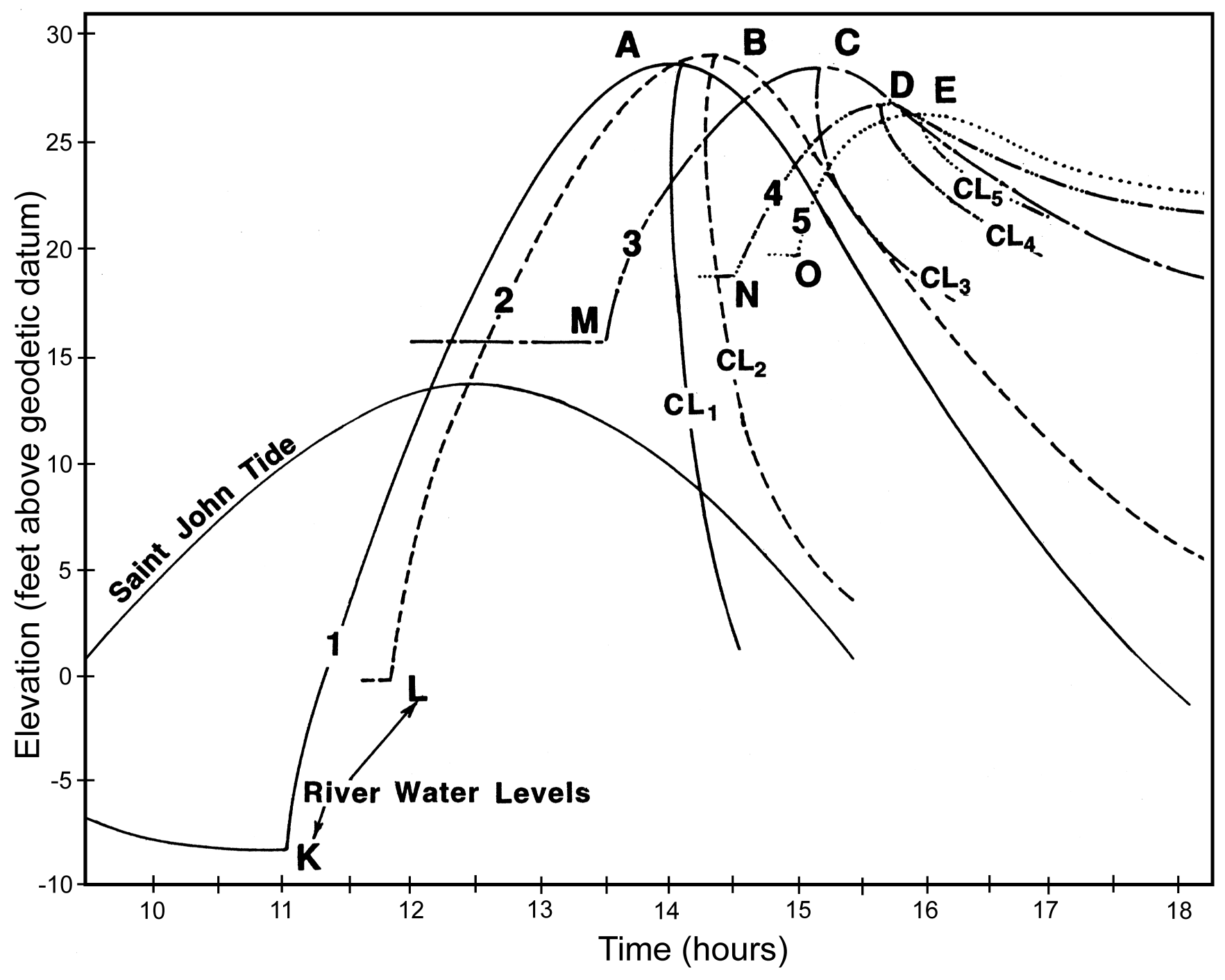

Fig. 36 Curves 1 through 5 indicate modifications to the shape of the tidal wave based on measurements of the whole marigram, at various cross-sections of the Shubenacadie River, near Truro, N.S., on 15 October, 1970: 1) Black Rock, at mouth of the river, 0 $\mathrm{mi}(0 \mathrm{~km}) ; 2)$ D.A.R. (Dominion Atlantic Railway, precursor to the Canadian Pacific Railway) bridge, $5.3 \mathrm{mi}(8.53 \mathrm{~km}) \mathrm{upstream}$; 3) Fort Ellis - Stewiacke River, $14.7 \mathrm{mi}(23.65 \mathrm{~km})$ upstream; 4) Shubenacadie high water bridge, $20 \mathrm{mi}(32.18 \mathrm{~km})$ upstream; and 5) mouth of Gays River, $24 \mathrm{mi}(38.62 \mathrm{~km})$ from the Shubenacadie River's mouth. Saint John tide was $27.9 \mathrm{ft}(8.5 \mathrm{~m})$ plus Chart Datum at 11.30 AST. CL is the centreline of the tidal wave and the high water levels are A, B, C, D, and E. The points K, L, M, N, and $\mathrm{O}$ indicate the initial freshwater level at the location (e.g., $\mathrm{K}=$ Black Rock) at the time (in hours) indicated.

$\mathrm{M}, \mathrm{N}$ and $\mathrm{O}$, as the water exits the estuary prior to the next incoming tide.

\subsubsection{The Cornwallis River estuary}

Figure 37 shows the reshaping of the tidal curve in the uppermost $4 \mathrm{~m}$, near the peak of the tide, for a tidal wave in the Cornwallis River, N.S. The asymmetry of the marigrams, and the shape of the centrelines $\left(\mathrm{CL}_{1}\right.$, etc.,) show that the further the wave goes into the estuary (Site \#1 to Site \#5), the slower the rate of rise of tide near the peak (A, B, etc., on Fig. 37) and the faster the drop after the peak has passed. Initially, the curvature of the centrelines is reversed near the top of the wave (eg., A), but further upstream (eg., D) this reversal disappears.
Figure 38 shows the momentary gradients of the water surfaces at different times during the passage of the top of the Cornwallis River tidal wave. While the wave is moving upstream on its own inertia through this section (between 12:15 and 13:30 hours), the gradients of the water surface seaward of the wave top are negative and rather uniform. The moment its inertia is spent, the water starts moving backward toward the sea. The difference is that now, on the outflow, the gradients are not only reversed but are steeper because water levels have dropped considerably, forcing flow through small cross-sections at higher velocities. Note too that the water's surface is curved downward, concentrating the flow of outgoing water in the lower section of the channel.

The difference between tidal rivers and tidal creeks is that 


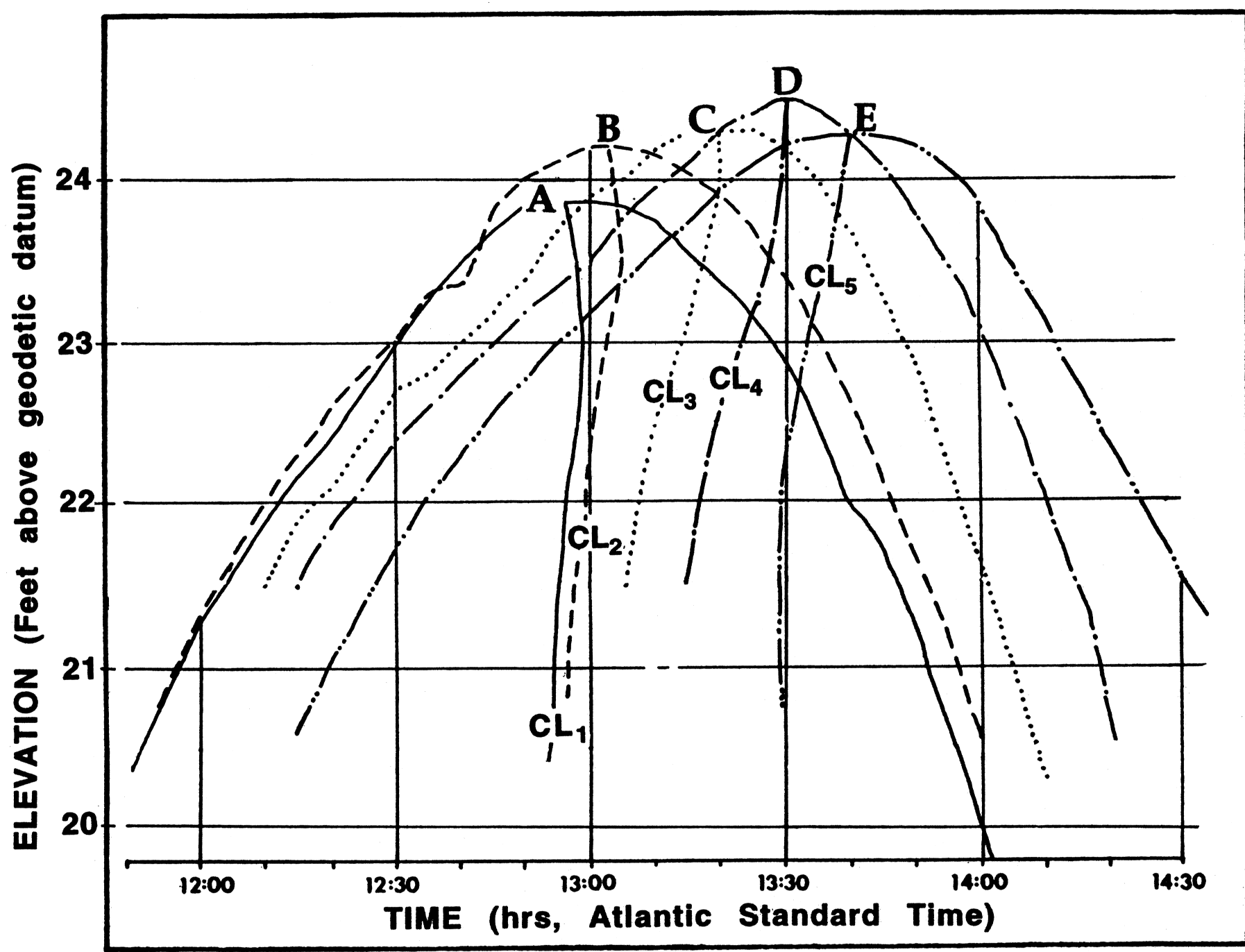

Fig. 37 Observed tidal curves at five stations, illustrating modifications to the shape of the top of the tidal wave in the Cornwallis River, near Kentville, N.S., on 5 September, 1956. Station 1, (Port Williams bridge), 0 km upstream; Station 2, $2 \mathrm{mi}$ (3.2 km) upstream; Station 3, $6 \mathrm{mi}(9.75 \mathrm{~km})$ upstream; Station 4, $8 \mathrm{mi}(13.1 \mathrm{~km})$ upstream; Station 5, $9 \mathrm{mi}(14.3 \mathrm{~km})$ upstream. High Water on the Saint John River at $27.4 \mathrm{ft}(8.4 \mathrm{~m})$ above CD at 11.43 AST. Data drawn from MMRA observations. The five axes indicate the "centreline" or loci halfway between the rising and falling tide levels; measurements apply here only to the uppermost $4 \mathrm{~m}$ of the tidal wave.

tidal rivers discharge fresh water from upland watersheds. In the upper reaches of the estuary, freshwater flow maintains a drainage channel, the size of which is related to the river discharges. In contrast, a tidal creek is formed by tidal water that moves onto a tidal marsh during Higher High Waters, discharging following the turn of the tide. The only fresh water moving in such creeks is rain water collected on the salt marsh itself. In effect, creek formation requires a certain area of marsh because the erosion process demands a minimum flow volume from the marsh in order to initiate channel cutting through vegetated soil. For this reason there always exists a margin of land not cut by tidal creeks on the seaward side of dykes built on reclaimed salt marshes. This feature is readily visible on aerial photographs of out-to-sea marshes.
Tidal channels reach a quasi-equilibrium condition ranging between certain limits. In spring, river discharges erode silt deposited during the summer and early fall when the river flows are greatly reduced; consequently, river bottoms may accrete or erode by as much as two metres (see Fig. 39). Before dyke construction the tidal marshes served as sinks for excess sediment in the system. However, the construction of dykes, causeways and tidal dams in estuaries further upsets the quasiequilibrium state of tidal channels.

Uplands, or freshwater bogs in the case of extensive salt marshes, form the landward limit of the high marsh. The latter situation can be explained by the fact that most of the sedimentation that occurs when sediment-charged tidal water floods the marsh, happens soon after it enters the marsh, form- 